\title{
Extended Hydrogen Bond Network for Effective Proton-Coupled Electron Transfer (PCET) Reactions: The Unexpected Role of Thio- phenol and its Acidic Channel in Photocatalytic Hydroamidations
}

Nele Berg, Sebastian Bergwinkl, Patrick Nuernberger, Dominik Horinek and Ruth M. Gschwind*

\section{Contents}

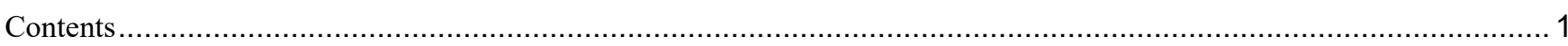

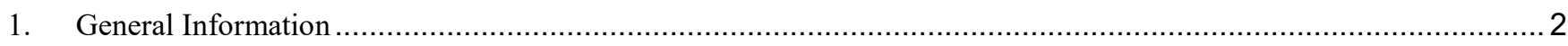

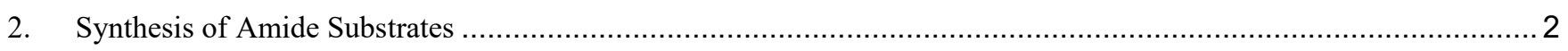

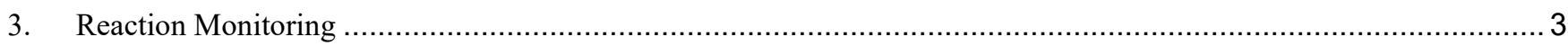

3.1 Photoredox catalytic hydroamidation of $N$-phenylpent-4-enamide with thiophenol ..................................... 4

3.2 Photoredox catalytic hydroamidation of ${ }^{15} \mathrm{~N}$-phenylpent-4-enamide with phenol ……..................................

3.3 Photoredox catalytic hydroamidation of 3,3-dimethyl- $N$-phenylpent-4-enamide with thiophenol ........................ 10

3.4 Photoredox catalytic hydroamidation of 3,3-dimethyl- $N$-phenylpent-4-enamide with phenol ............................. 13

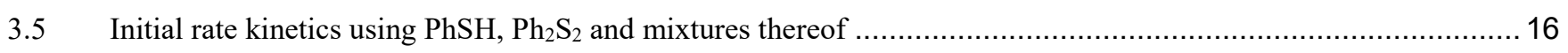

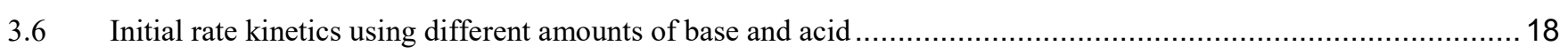

3.7 Initial rate kinetics using different amounts of base and acid in equiv. relevant for synthesis ............................ 19

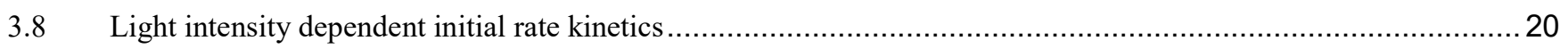

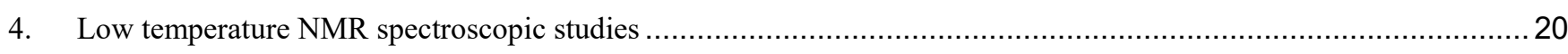

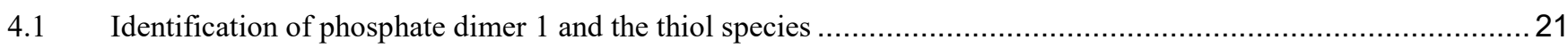

4.2 Identification of phosphate dimer 1 in the photocatalytic reaction mixture …............................................24

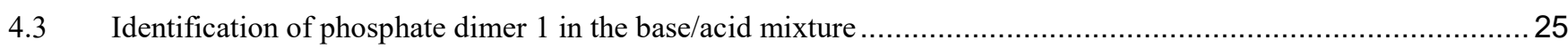

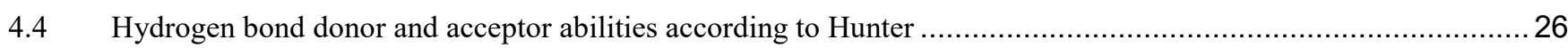

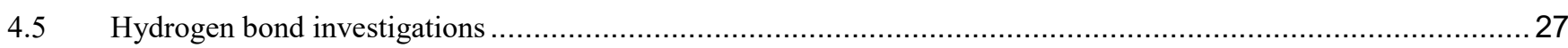

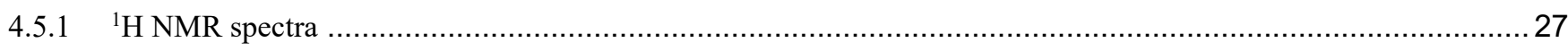

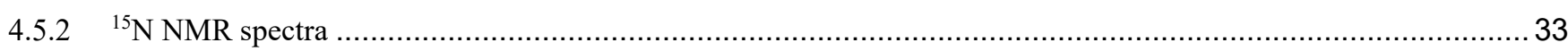

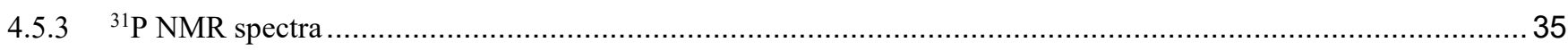

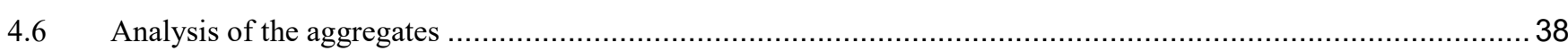

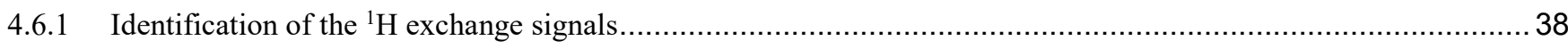

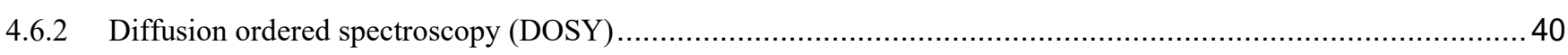

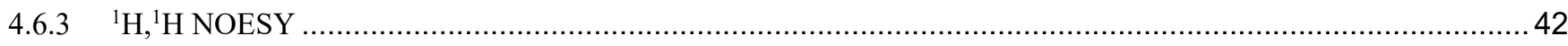

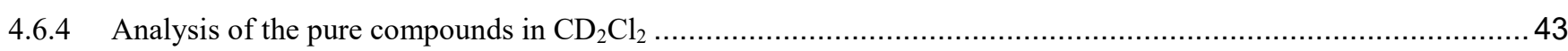

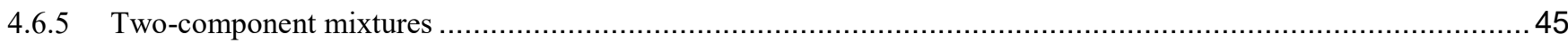

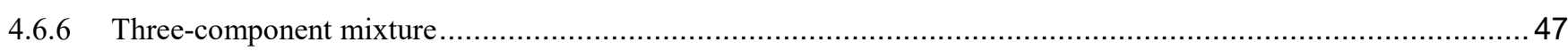

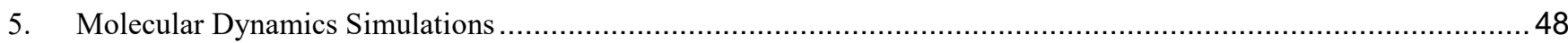

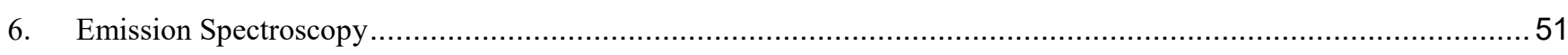

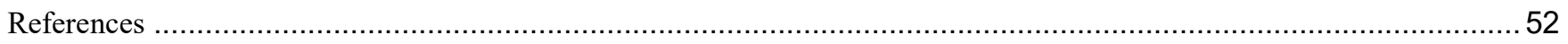




\section{General Information}

The standard NMR spectroscopic experiments, when not otherwise mentioned, were performed on a Bruker Avance III HD $400.13 \mathrm{MHz}$ (400.13 MHz for ${ }^{1} \mathrm{H}$ ) spectrometer with a $5 \mathrm{~mm}$ BBO BB-1H/D probe head with Z-gradients. Temperature was controlled by BVT 3000.

The advanced and low temperature NMR spectroscopic measurements were performed on a Bruker Avance III HD 600 (600.13 MHz) and a $5 \mathrm{~mm}$ TBI-F probe head with a z-gradient $(53.5 \mathrm{Gauss} / \mathrm{cm})$. The temperature of $180 \mathrm{~K}$ was controlled by a BVTE 3900.

If not otherwise noted, $5 \mathrm{~mm}$ NMR tubes were used and the spectra were referenced to the corresponding solvent. ${ }^{1}$ The spectra were processed and evaluated using TopSpin 3.2 (Bruker) and plotted with TopSpin Plot Editor and Corel Draw 2017. Molecular structures were pictured with Chem Draw Professional 17.0.

The solvents for NMR measurements, dichloromethane- $\mathrm{d}_{2}\left(\mathrm{CD}_{2} \mathrm{Cl}_{2}\right)$ and chloroform- $\mathrm{d}_{1}\left(\mathrm{CDCl}_{3}\right)$, were purchased from Sigma Aldrich/Merck or Deutero. When water free samples were needed, $\mathrm{CD}_{2} \mathrm{Cl}_{2}$ was freshly dried over $\mathrm{CaH}_{2}$ under Argon atmosphere. The $\operatorname{Ir}\left(\mathrm{dF}_{(} \mathrm{CF}_{3}\right)$ ppy)2(bpy) $\mathrm{PF}_{6}$ photocatalyst, thiophenol, phenol and diphenyldisulfide were purchased from Sigma Aldrich/Merck, tetrabutylammonium di-tert-butylphosphate from Activate Scientific and the amides were synthesized. The solvents for synthesis were purchased from Sigma Aldrich/Merck and the substrates from Fisher Scientific (Acros) and Sigma Aldrich/Merck.

\section{Synthesis of Amide Substrates}

\section{General Procedure for amide synthesis:}

The amides were synthesized according to literature procedures. ${ }^{23}$

A round bottom flask was dried and purged with argon prior to use. Under inert conditions, (1-(3-dimethylaminopropyl)-3-ethylcarbodiimide hydrochloride (EDC-HCl; 1.3 equiv.) and DMAP (1.4 equiv.) were added and solved in DCM before the flask was cooled to $0{ }^{\circ} \mathrm{C}$ using an ice bath. Next, 4-pentenoic acid (1.0 equiv.) was added and the reaction mixture stirred for 5 minutes. After adding ${ }^{15} \mathrm{~N}$ - or unlabeled aniline (1.2 equiv.) the mixture was then stirred at room temperature for at least 24 hours. Via TLC (PE/EE 1:1), the progress of the product formation was controlled and after full conversion, the mixture was quenched with $\mathrm{HCl}(1 \mathrm{M})$. The resulting organic and aqueous phases were separated and the aqueous extracted with DCM. The combined organic layers were dried over $\mathrm{Na}_{2} \mathrm{SO}_{4}$ before the solvent was removed and the crude mixture was obtained. The crude product was recrystallized (PE/EE $\left.4: 1 ; 80-130{ }^{\circ} \mathrm{C}\right)$ and the product generated in up to $94 \%$ yield.

The NMR spectroscopic data of the following amide species are in agreement with literature spectra. ${ }^{2}$<smiles>C=CCCC(=O)Nc1ccccc1</smiles>

${ }^{15} \mathrm{~N}$-Phenylpent-4-enamide

The labeled amide was synthesized according to the general procedure using 4-pentenoic acid (8.8 mmol), ${ }^{15} \mathrm{~N}$ - aniline (10.6 mmol), EDC$\mathrm{HCl}(11.5 \mathrm{mmol})$ and DMAP $(12.4 \mathrm{mmol})$ in DCM $(30 \mathrm{ml})$. After recrystallization of the white-orange crude product $1.02 \mathrm{~g}(65 \%)$ of white flakes were obtained.

${ }^{1} \mathrm{H}-\mathrm{NMR}\left(400 \mathrm{MHz}, \mathrm{CDCl}_{3}\right): \delta(\mathrm{ppm})=7.50(\mathrm{~d}, \mathrm{~J}=7.6 \mathrm{~Hz}, 2 \mathrm{H}), 7.32(\mathrm{t}, \mathrm{J}=7.8 \mathrm{~Hz}, 2 \mathrm{H}), 7.14\left(\mathrm{~d}, \mathrm{~J}=88.7 \mathrm{~Hz}, 1 \mathrm{H},{ }^{15} \mathrm{~N}-\mathrm{H}\right), 7.10(\mathrm{t}, \mathrm{J}=7.3$ $\mathrm{Hz}, 1 \mathrm{H}), 5.94-5.84(\mathrm{~m}, 1 \mathrm{H}), 5.13(\mathrm{~d}, \mathrm{~J}=16.8 \mathrm{~Hz}, 1 \mathrm{H}), 5.06(\mathrm{~d}, \mathrm{~J}=10.2 \mathrm{~Hz}, 1 \mathrm{H}), 2.53-2.44(\mathrm{~m}, 4 \mathrm{H})$.<smiles>C=CCCC(=O)Nc1ccccc1</smiles>

\section{$N$-Phenylpent-4-enamide}

The unlabeled amide was synthesized according to the general procedure using 4-pentenoic acid (20 mmol), aniline (24 mmol), EDC-HCl $(26 \mathrm{mmol})$ and DMAP $(28 \mathrm{mmol})$ in DCM $(60 \mathrm{ml})$. After recrystallization of the white-orange crude solid, $3.28 \mathrm{~g}(94 \%)$ of white flakes were obtained.

${ }^{1} \mathrm{H}-\mathrm{NMR}\left(400 \mathrm{MHz}, \mathrm{CDCl}_{3}\right): \delta(\mathrm{ppm})=7.50(\mathrm{~d}, \mathrm{~J}=7.9 \mathrm{~Hz}, 2 \mathrm{H}), 7.32(\mathrm{t}, \mathrm{J}=7.9 \mathrm{~Hz}, 2 \mathrm{H}), 7.10$ (t, J = 7.4 Hz, $\left.1 \mathrm{H}\right), 5.99-5.84(\mathrm{~m}, 1 \mathrm{H}), 5.13$ (d, J = 16.5 Hz, $1 \mathrm{H}), 5.06$ (d, J = 10.2 Hz, $1 \mathrm{H}), 2.53-2.44$ (m, $4 \mathrm{H})$. 


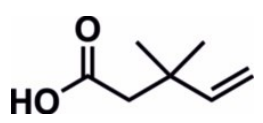

\section{3,3-Dimethylpent-4-enoic acid}

The synthesis was performed according to literature procedure. ${ }^{4}$ To a solution of $\mathrm{NaOH}\left(15 \mathrm{~g}\right.$ in $\left.38 \mathrm{ml} \mathrm{H} \mathrm{H}_{2} \mathrm{O}, 10 \mathrm{M}\right)$, methyl 3,3-dimethylpent4-enoate $(10 \mathrm{ml}, 64 \mathrm{mmol})$ was added and the mixture was stirred under reflux at $130{ }^{\circ} \mathrm{C}$ for $5.5 \mathrm{~h}$. The reaction was quenched with $\mathrm{HCl}$ until acidic conditions were reached prior to extraction with methyl tert-butyl ether. The combined organic layers were washed with brine and dried over $\mathrm{MgSO}_{4}$. The solvent was removed and $6.2 \mathrm{~g}(76 \%)$ of the liquid product were obtained.

${ }^{1} \mathrm{H}-\mathrm{NMR}\left(400 \mathrm{MHz}, \mathrm{CDCl}_{3}\right): \delta(\mathrm{ppm})=5.91(\mathrm{dd}, \mathrm{J}=17.4 \mathrm{~Hz}, 10.7 \mathrm{~Hz}, 1 \mathrm{H}), 5.89(\mathrm{td}, \mathrm{J}=17.2 \mathrm{~Hz}, 0.7 \mathrm{~Hz}, 2 \mathrm{H}), 2.34$ (s, $\left.2 \mathrm{H}\right), 1.7(\mathrm{~s}, 6 \mathrm{H})$.<smiles>C=CC(C)(C)CC(=O)Nc1ccccc1</smiles>

\section{3,3-Dimethyl- $N$-phenylpent-4-enamide}

The amide was synthesized according to the general procedure using the synthesized 3,3-dimethylpent-4-enoic acid (9 mmol), aniline (11 $\mathrm{mmol})$, EDC- $\mathrm{HCl}(12 \mathrm{mmol})$ and DMAP $(13 \mathrm{mmol})$ in DCM $(20 \mathrm{ml})$. After recrystallization of the orange crude solid, $0.4 \mathrm{~g}(23 \%)$ of white product were obtained.

${ }^{1} \mathrm{H}-\mathrm{NMR}\left(400 \mathrm{MHz}, \mathrm{CD}_{2} \mathrm{Cl}_{2}\right): \delta(\mathrm{ppm})=7.46(\mathrm{~d}, \mathrm{~J}=8.0 \mathrm{~Hz}, 2 \mathrm{H}), 7.30(\mathrm{t}, \mathrm{J}=7.8 \mathrm{~Hz}, 2 \mathrm{H}), 7.22(\mathrm{br} \mathrm{s}, 1 \mathrm{H}, \mathrm{NH}), 7.09(\mathrm{t}, \mathrm{J}=7.4 \mathrm{~Hz}, 1 \mathrm{H})$, $6.01(\mathrm{dd}, \mathrm{J}=17.4 \mathrm{~Hz}, 10.7 \mathrm{~Hz}, 1 \mathrm{H}), 5.07-5.12(\mathrm{~m}, \mathrm{~J}=10.2 \mathrm{~Hz}, 2 \mathrm{H}), 2.32$ (s, $2 \mathrm{H}), 1.18$ (s, $6 \mathrm{H})$.

\section{Reaction Monitoring}

The photoredox catalytic hydroamidation reactions were followed by ${ }^{1} \mathrm{H}$ NMR spectroscopy using $N$-phenylpent-4-enamide as well as 3,3dimethyl- $N$-phenylpent-4-enamide. The dimethyl substrate was chosen in order to exclude self-HAT. $N$-phenylpent-4-enamide was chosen as representative amide for the low temperature hydrogen bonding and aggregation analysis (see chapter 4 and 5).

\section{In-situ NMR illumination:}

For the measurements of the ${ }^{1} \mathrm{H}$ NMR spectra at room temperature a Bruker Avance III HD $600 \mathrm{MHz}\left(600.13 \mathrm{MHz}\right.$ for $\left.{ }^{1} \mathrm{H}\right)$ with a $5 \mathrm{~mm}$ TBI-F probe head and Z-gradients and a Bruker Avance $600 \mathrm{MHz}$ spectrometer with a Prodigy BBO probe head were used. The temperature was controlled by a BVT Unit or BCU II (298 or $300 \mathrm{~K})$. The data were processed and plotted with Brukers Topspin 3.2, the graphs were generated with Excel (Office 2016) and pictured using Corel Draw 2017. The photoredox catalytic reaction mixtures were prepared in $5 \mathrm{~mm}$ amberized NMR tubes of Spintec. $\mathrm{CD}_{2} \mathrm{Cl}_{2}$ was used as solvent, which was freshly destilled over $\mathrm{CaH}_{2}$ prior to use. For the in-situ illumination inside the NMR, the combined illumination setup described by Feldmeier et al. was applied. ${ }^{5}$ As light source, a $450 \mathrm{~nm}$ Lumitronix Cree XT-E-1 (royalblue; $452 \mathrm{~nm}$ peak wavelength measured in our group) LED was used.

The amounts (in \%) were obtained by integration of the corresponding amide and product signals. For accurate integration, the respective signal regions were baseline corrected. As no conversion was observed in the dark, the signal integral of the starting material was set to $100 \%$. According to this reference, the progression of the photoredox catalytic reaction was determined after starting the illumination. Due to the hygroscopic properties of the phosphate base, residual $\mathrm{H}_{2} \mathrm{O}$ is observable in the NMR spectra.

\section{General procedure of sample preparation:}

The samples were prepared according to the procedure applied by Knowles et al. ${ }^{2}$ For the corresponding proper amounts of reactants, see the detailed descriptions in the chapters 3.1-3.4.

A screw cap Schlenk tube was charged with amide starting material (1 equiv.), tetrabutylammonium di-tert-butylphosphate ( 0.2 equiv.) and $\operatorname{Ir}\left(\mathrm{dF}\left(\mathrm{CF}_{3}\right) \text { ppy }\right)_{2}(\mathrm{bpy}) \mathrm{PF}_{6}\left(0.02\right.$ equiv., $2 \mathrm{~mol} \%$ ) and flushed with argon. Dry $\mathrm{CD}_{2} \mathrm{Cl}_{2}$ (sample concentration of $\left.101 \mathrm{mM}\right)$ was added followed by thiophenol (0.1 equiv.). The mixture was degassed using freeze-pump-thaw technique and subsequently transferred into an amberized NMR tube under inert conditions. 


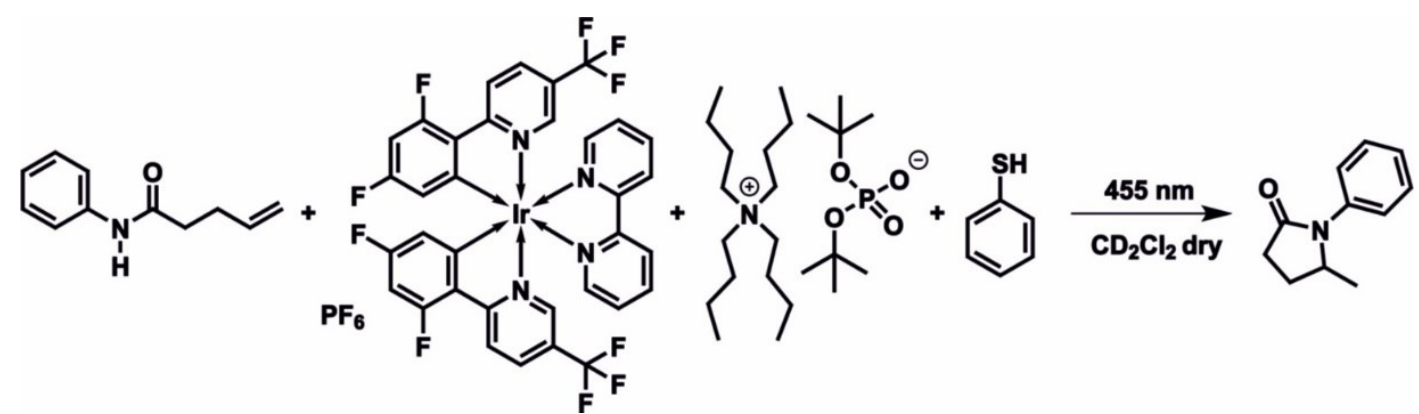

Scheme S1. Photoredox catalytic hydroamidation of $N$-phenylpent-4-enamide in presence of phosphate base, thiophenol and iridium photocatalyst with blue light.

The sample was prepared according to the general procedure (vide supra) using $N$-phenylpent-4-enamide (59 mg, $333 \mu \mathrm{mol})$, base (30 mg, $66.6 \mu \mathrm{mol})$, thiophenol $(3.4 \mu \mathrm{l}, 33.3 \mu \mathrm{mol})$ and Ir-photocatalyst $(6.8 \mathrm{mg}, 6.6 \mu \mathrm{mol})$ in $\mathrm{CD}_{2} \mathrm{Cl}_{2}(3.3 \mathrm{~mL})$. The reaction was followed via insitu illumination inside the NMR spectrometer. The corresponding amide degradation and product evolution curves are plotted in Scheme S2.

For the determination of the amounts by integration, the amide signal at 5.85-5.92 ppm (m, $1 \mathrm{H})$ and the lactam signal at $4.29 \mathrm{ppm}(\mathrm{q}, 1 \mathrm{H})$ were used and the corresponding regions were baseline corrected prior to integration.

After an initial linear conversion, the product formation was completed after around 30 hours. The comparison of the ${ }^{1} \mathrm{H}$ NMR spectra before illumination and after $\approx 51$ hours in Scheme $\mathrm{S} 3$ shows full conversion of the amide to the lactam product. The chemical shifts were referenced to $\mathrm{CD}_{2} \mathrm{Cl}_{2}\left(5.32 \mathrm{ppm}^{1}\right)$. Octamethylcyclotetrasiloxan (OMS) was added as internal NMR standard but was not included for the interpretation. The resulting product amount of above $100 \%$ is possibly a result of improper relaxation parameters or inaccuracy of integration. The complete spectra are shown at the end of the chapter (Scheme S4).

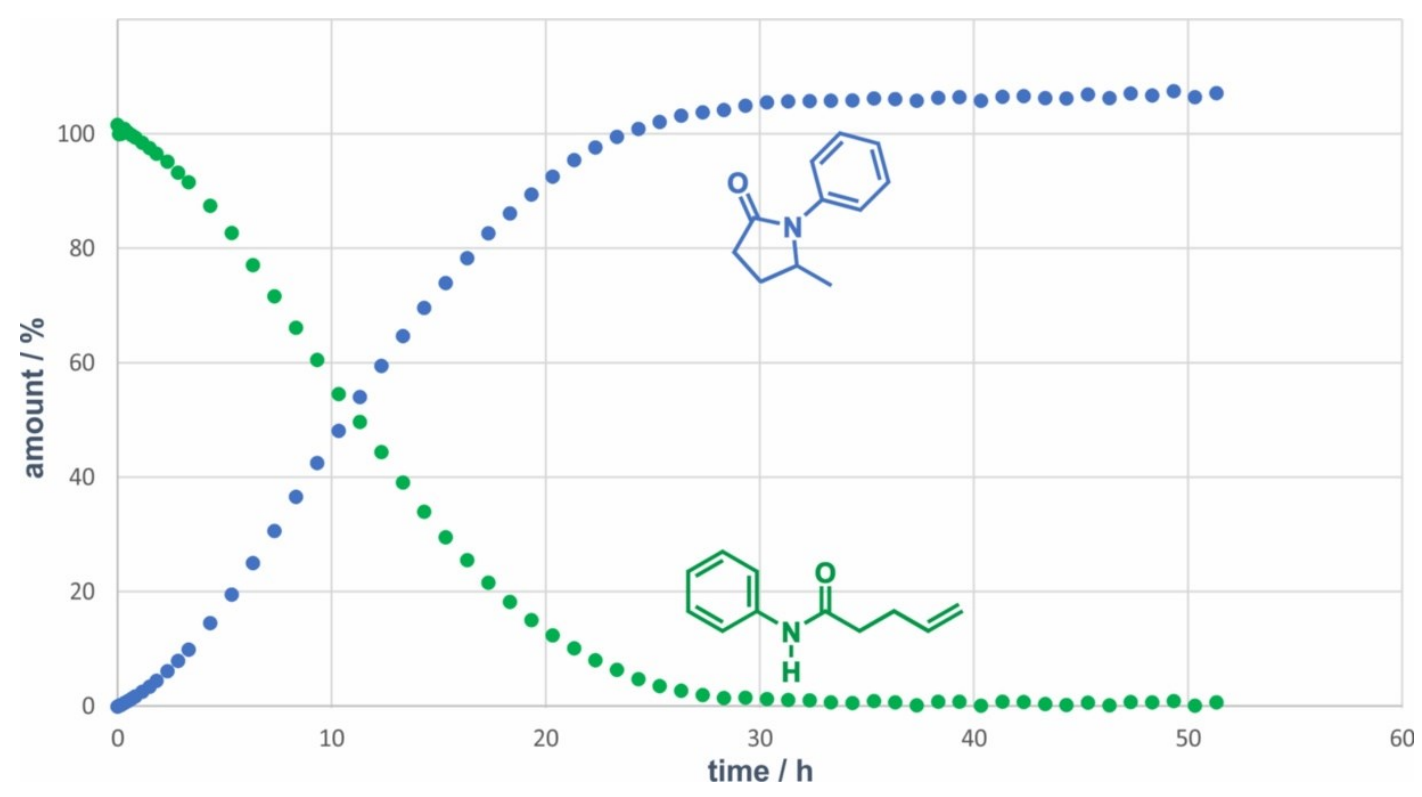

Scheme S2. In-situ reaction profile for the hydroamidation of $N$-phenylpent-4-enamide using thiophenol as hydrogen atom donor followed by NMR. 


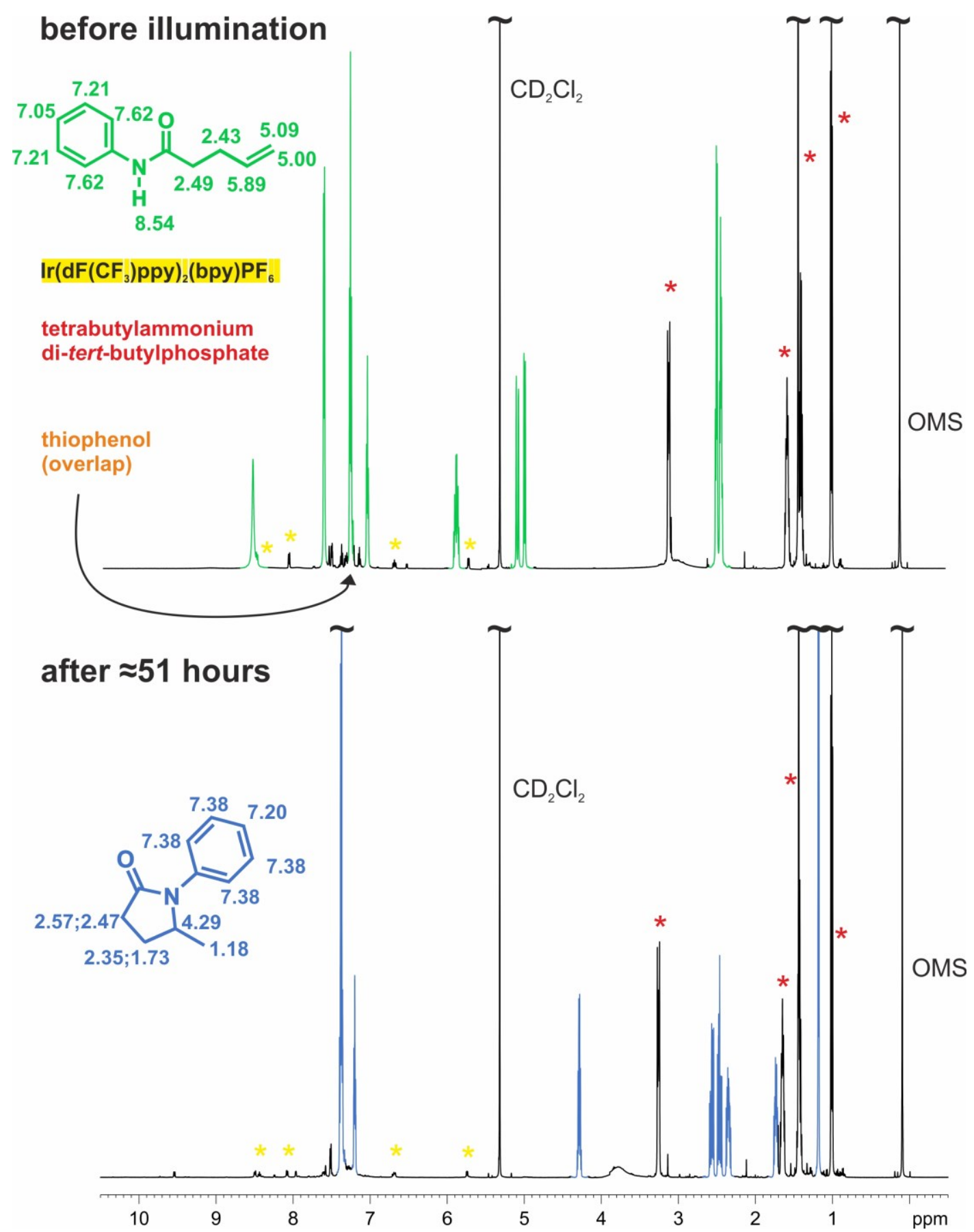

Scheme S3. Excerpt of the ${ }^{1} \mathrm{H}$ NMR spectra before starting the illumination (top) and after around 51 hours of illumination (bottom). The $\mathrm{N}$-phenylpent-4-enamide substrate signals are highlighted in green, the phosphate base signals in red, the photocatalyst signals in yellow and thiophenol is overlapped in the aromatic region. The product signals are marked in blue. The comparison of the spectra shows complete amide consumption, product formation and no formation of by-products. 


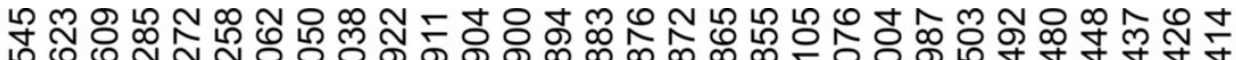 め}

\section{before illumination}

(complete spectrum)

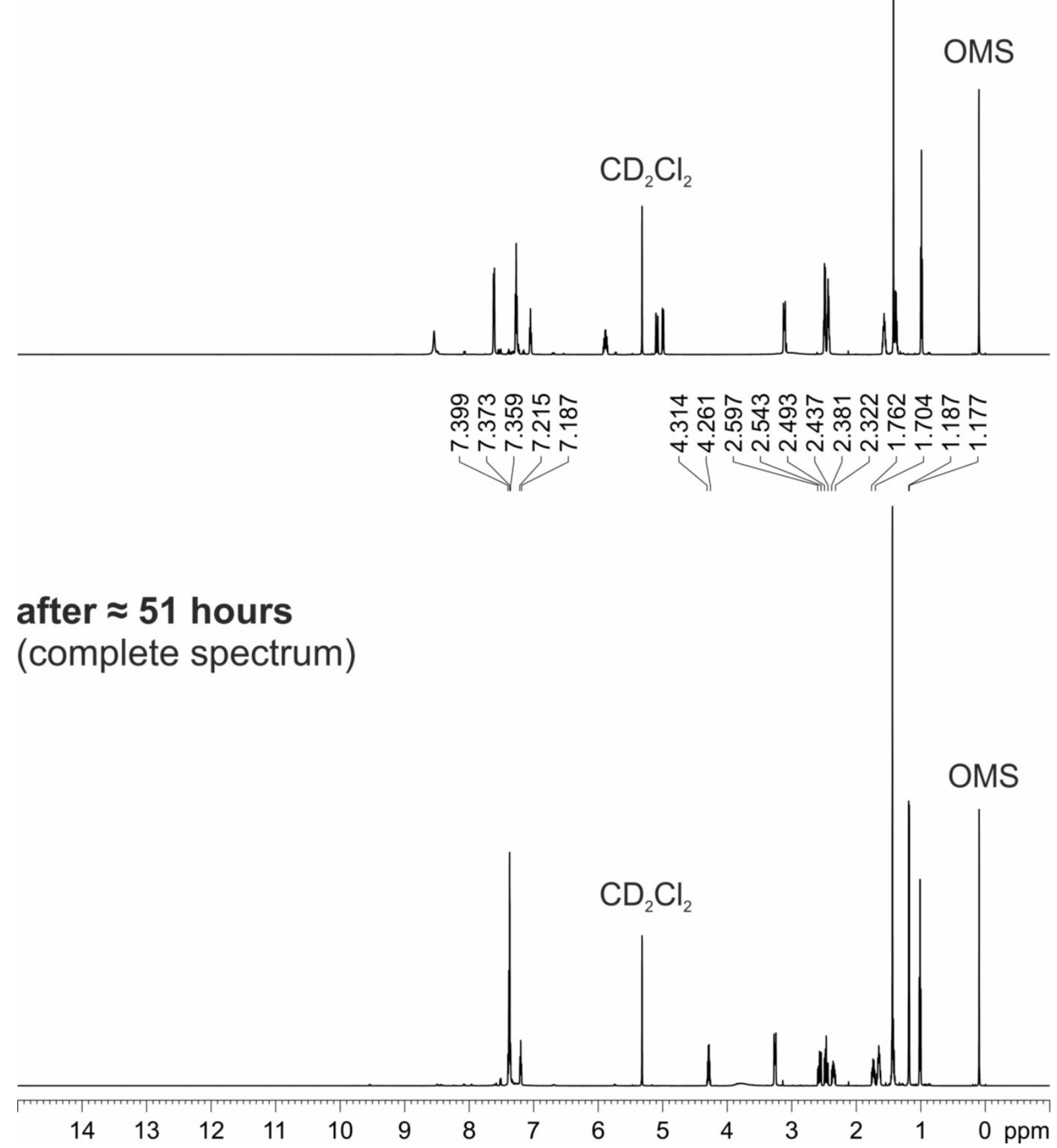

Scheme S4. Full ${ }^{1}$ H-NMR spectra of the photoredox catalytic hydroamidation reaction of $N$-phenylpent-4-enamide in presence of phosphate base, thiophenol and Ir-photocatalyst before illumination with blue light (top) and after around 51 hours (bottom); the peaks are labelled for substrate and product. 


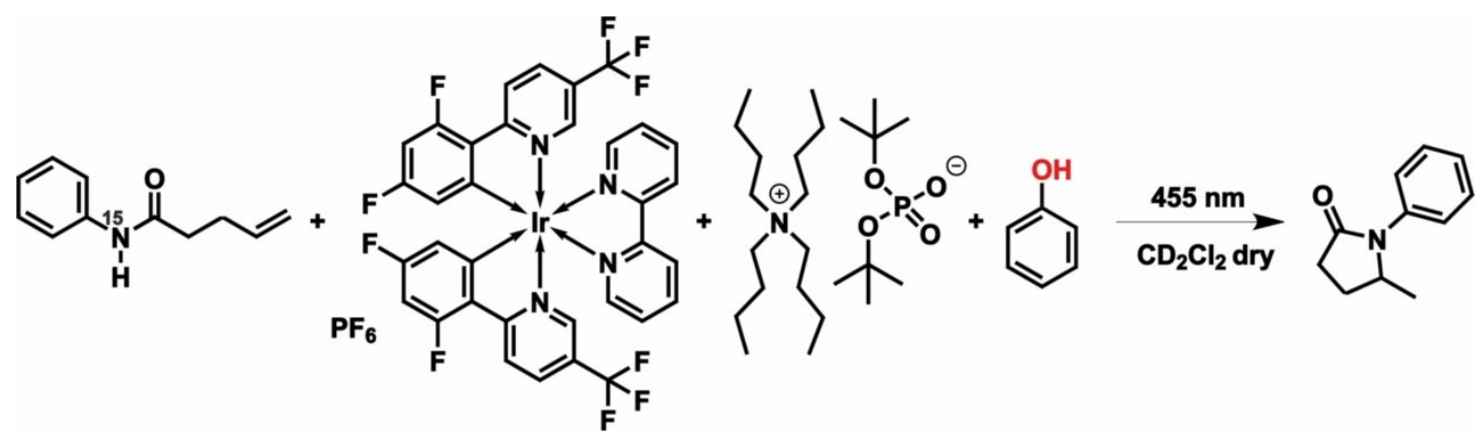

Scheme S5. Photoredox catalytic hydroamidation of ${ }^{15} \mathrm{~N}$-phenylpent-4-enamide in presence of base and phenol with blue light.

The sample was prepared according to the general procedure (vide supra) using ${ }^{15} N$-phenylpent-4-enamide (29 mg, $\left.166.5 \mu \mathrm{mol}\right)$, base (15 $\mathrm{mg}, 33.3 \mu \mathrm{mol})$, phenol $(1.6 \mathrm{mg}, 16.7 \mu \mathrm{mol})$ and Ir-photocatalyst $(3.4 \mathrm{mg}, 3.3 \mu \mathrm{mol})$ in $\mathrm{CD}_{2} \mathrm{Cl}_{2}(1.7 \mathrm{~mL})$. The reaction was followed via insitu illumination inside the NMR spectrometer. The corresponding amide degradation and product evolution curves are plotted in Scheme S6.

For the determination of the amounts by integration, the amide signal at 5.85-5.92 ppm $(\mathrm{m}, 1 \mathrm{H})$ and the lactam signal at $4.29 \mathrm{ppm}(\mathrm{q}, 1 \mathrm{H})$ were used without baseline correction prior to integration. The chemical shifts were referenced to $\mathrm{CD}_{2} \mathrm{Cl}_{2}\left(5.32 \mathrm{ppm}^{1}\right)$.

The reaction profiles in Scheme S6 show only marginal substrate conversion and product formation (0.1\% after $19 \mathrm{~h})$. The corresponding ${ }^{1} \mathrm{H}$ NMR spectra are shown in Scheme S7 and the complete spectra at this end of the chapter (Scheme S8).

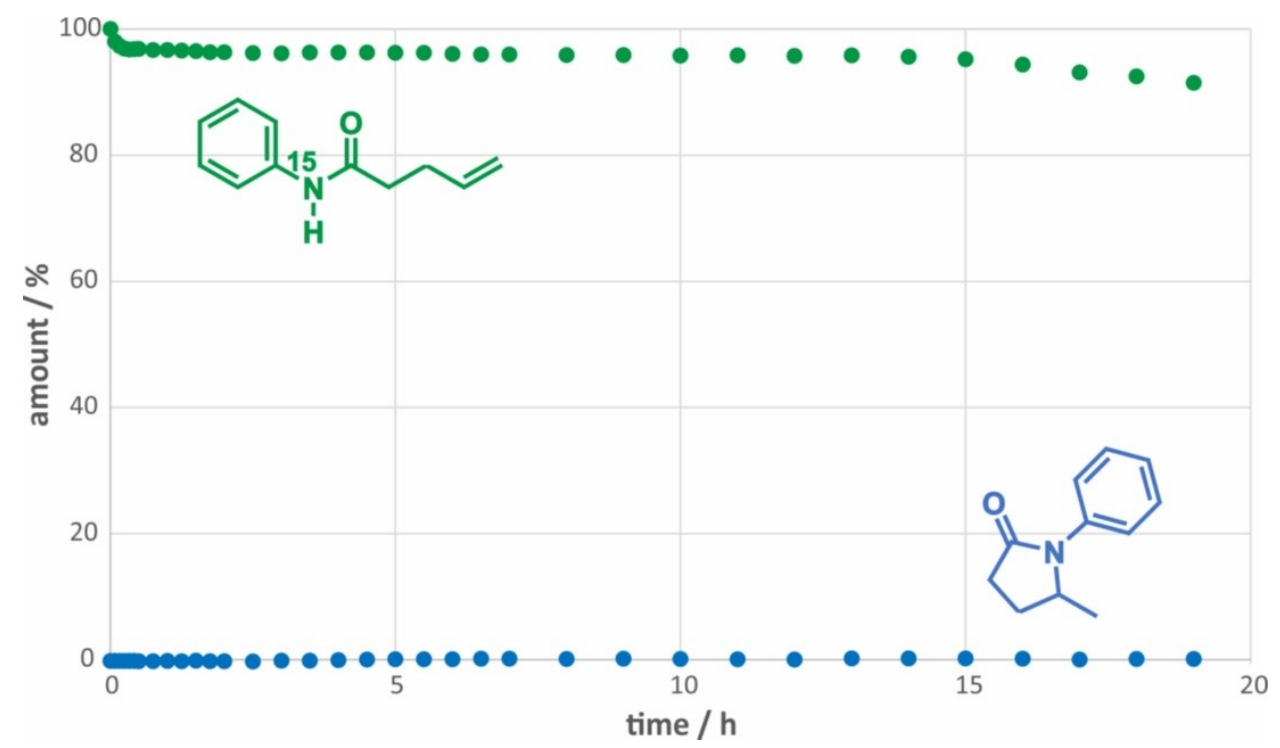

Scheme S6. In-situ reaction profile for the hydroamidation of ${ }^{15} \mathrm{~N}$-phenylpent-4-enamide using phenol as hydrogen atom donor followed by NMR. 


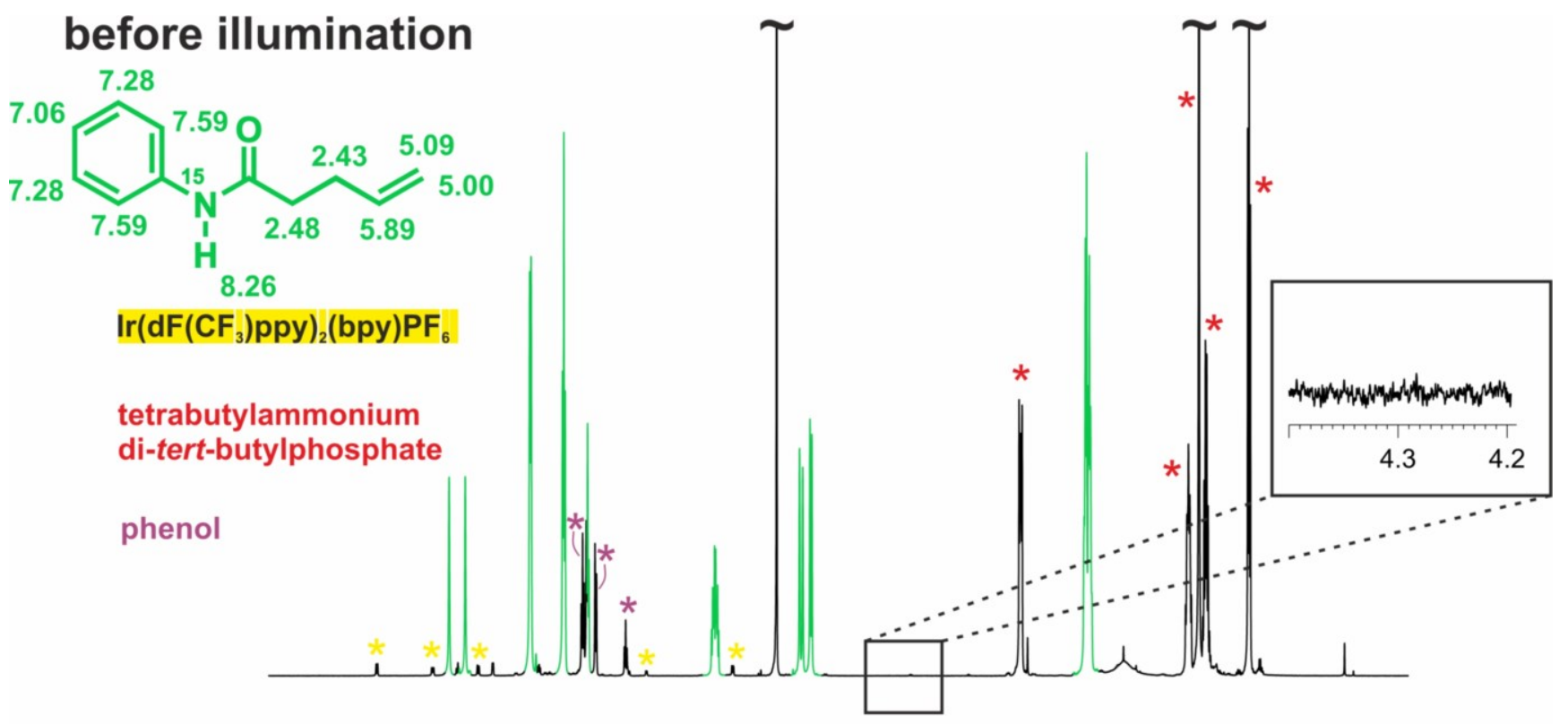

\section{after $\approx 19$ hours}<smiles>O=C1CCC2CCCCC12Nc1ccccc1</smiles>

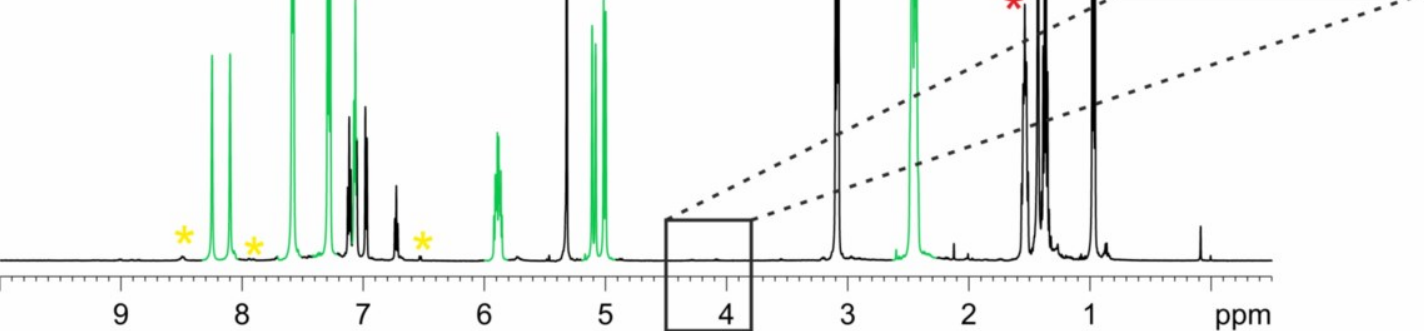

Scheme S7. Excerpt of the ${ }^{1} \mathrm{H}$ NMR spectra before starting the illumination (top) and after around 19 hours of illumination (bottom). The ${ }^{15} \mathrm{~N}$-phenylpent-4-enamide substrate signals are highlighted in green, the phosphate base signals in red, the photocatalyst signals in yellow and phenol in purple. The product signals are marked in blue. The comparison of the spectra shows bare amide consumption and product formation. The product signal is shown in the excerpt (right part). 


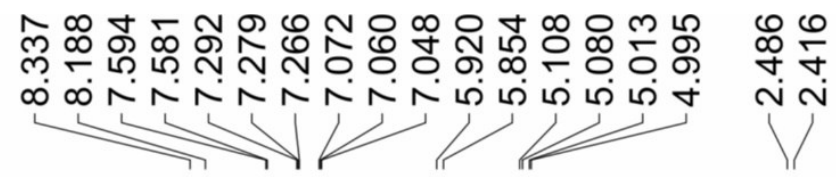

\section{before illumination \\ (complete spectrum)}

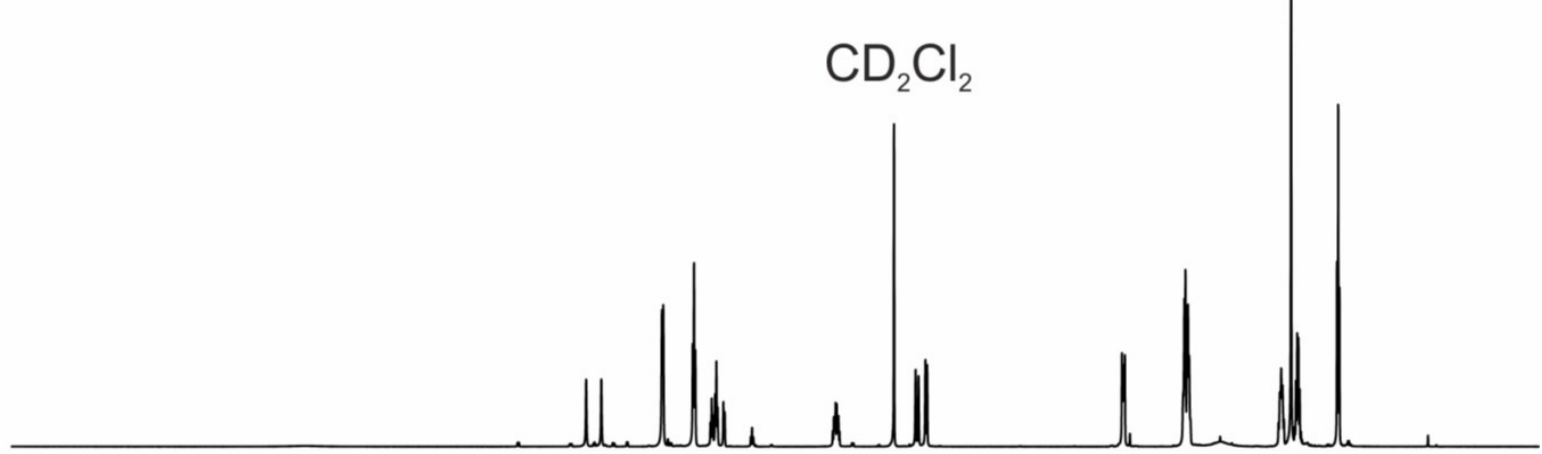

స๐

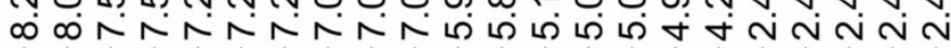

after $\approx 19$ hours

(complete spectrum)

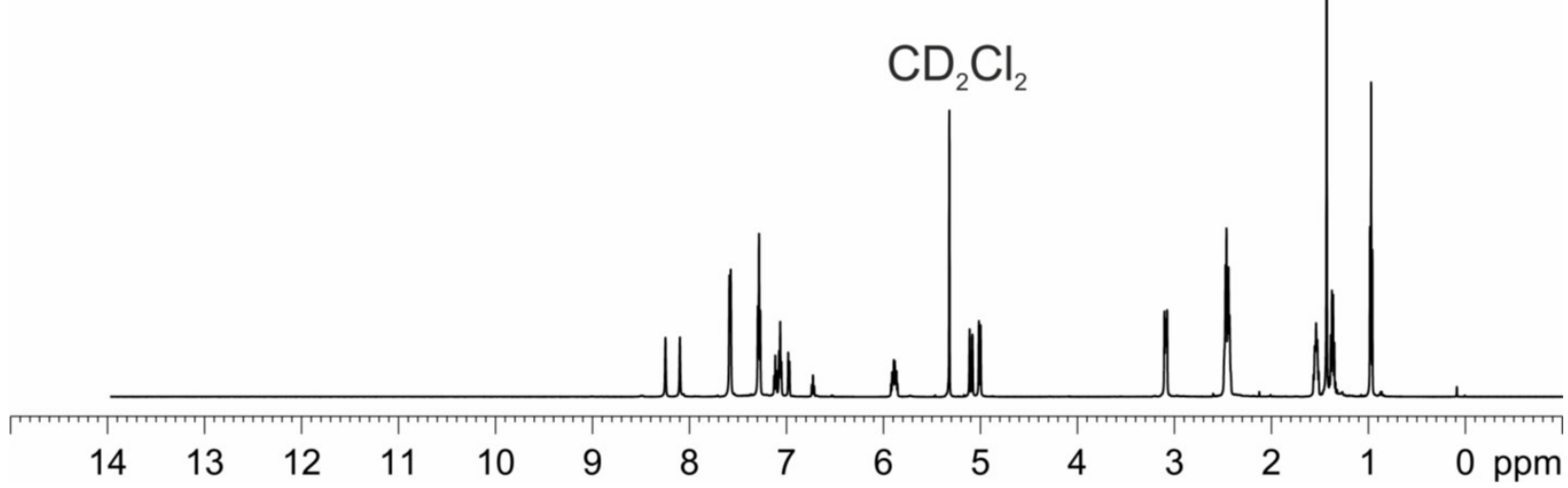

Scheme S8. Full ${ }^{1} \mathrm{H}-\mathrm{NMR}$ spectra of the photoredox catalytic hydroamidation reaction of ${ }^{15} \mathrm{~N}$-phenylpent-4-enamide in presence of phosphate base, phenol and Ir-photocatalyst before illumination with blue light (top) and after around 19 hours (bottom); the peaks are labelled for substrate and for the only base line separated signal of the product (4.29 ppm). 


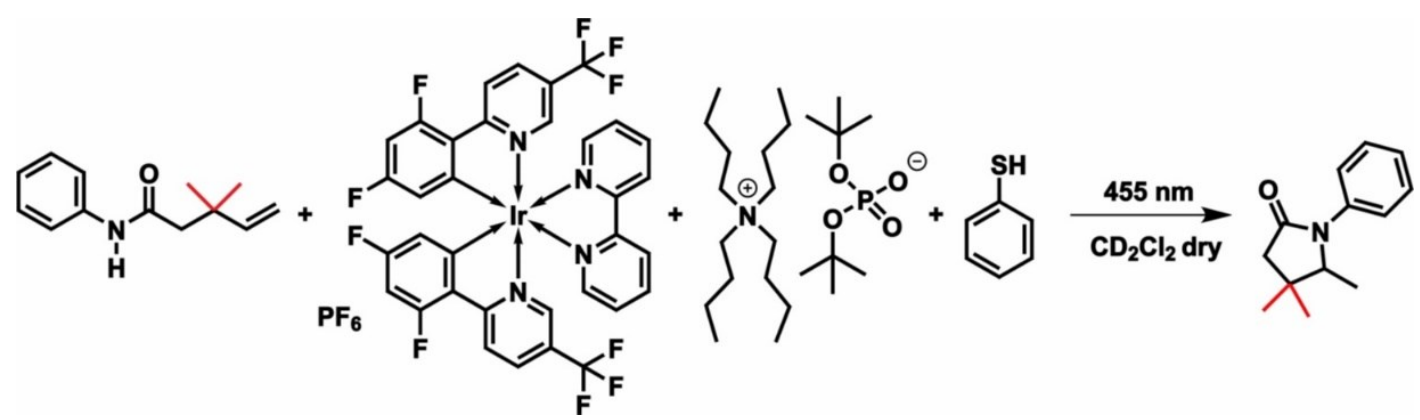

Scheme S9. Photoredox catalytic hydroamidation of 3,3-dimethyl- $N$-phenylpent-4-enamide in presence of base and thiophenol with blue light.

The sample was prepared according to the general procedure (vide supra) using 3,3-dimethyl- $N$-phenylpent-4-enamide (34 mg, $166.5 \mu \mathrm{mol})$, base $(15 \mathrm{mg}, 33.3 \mu \mathrm{mol})$, thiophenol $(1.7 \mu \mathrm{l}, 16.7 \mu \mathrm{mol})$ and Ir-photocatalyst $(3.4 \mathrm{mg}, 3.3 \mu \mathrm{mol})$, in $\mathrm{CD}_{2} \mathrm{Cl}_{2}(1.65 \mathrm{ml})$. The reaction was followed via in-situ illumination inside the NMR spectrometer.

The 3,3-dimethyl- $N$-phenylpent-4-enamide was used to exclude self-conversion of the amide starting material which is possible for $N$ phenylpent-4-enamide. ${ }^{2}$ The corresponding amide degradation and product evolution curves are plotted in Scheme S10. For the determination of the amounts by integration, the amide signal at $6.03 \mathrm{ppm}(\mathrm{dd}, 1 \mathrm{H})$ and the lactam signal at $3.86 \mathrm{ppm}(\mathrm{q}, 1 \mathrm{H})$ were used and the corresponding regions were baseline corrected prior to integration.

After an initial linear conversion, the product formation was completed after around 10 hours. The comparison of the ${ }^{1} \mathrm{H} N \mathrm{NR}$ spectra before illumination and after $\approx 21$ hours in Scheme S11 shows full conversion of the amide to the lactam product. The chemical shifts were referenced to $\mathrm{CD}_{2} \mathrm{Cl}_{2}\left(5.32 \mathrm{ppm}^{1}\right)$. The complete spectra are shown at the end of the chapter (Scheme S12).

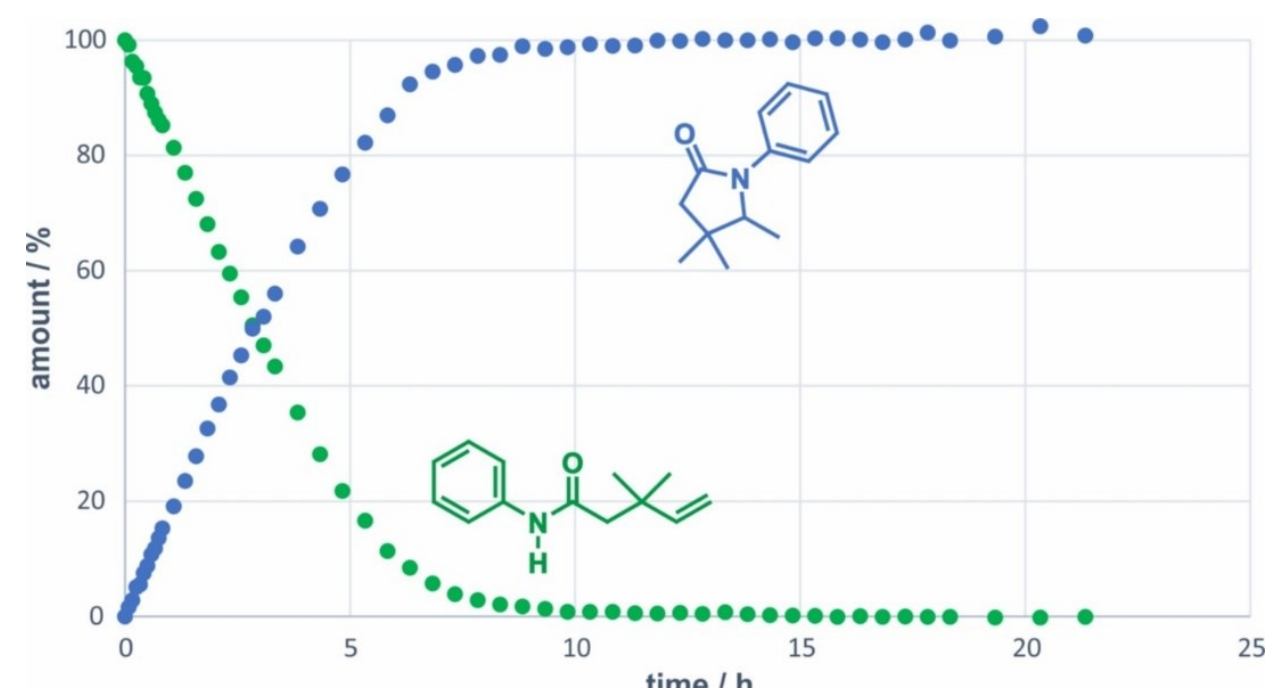

Scheme S10. In-situ reaction profile for the hydroamidation of 3,3-dimethyl- $N$-phenylpent-4-enamide with thiophenol as hydrogen atom donor followed by NMR. 

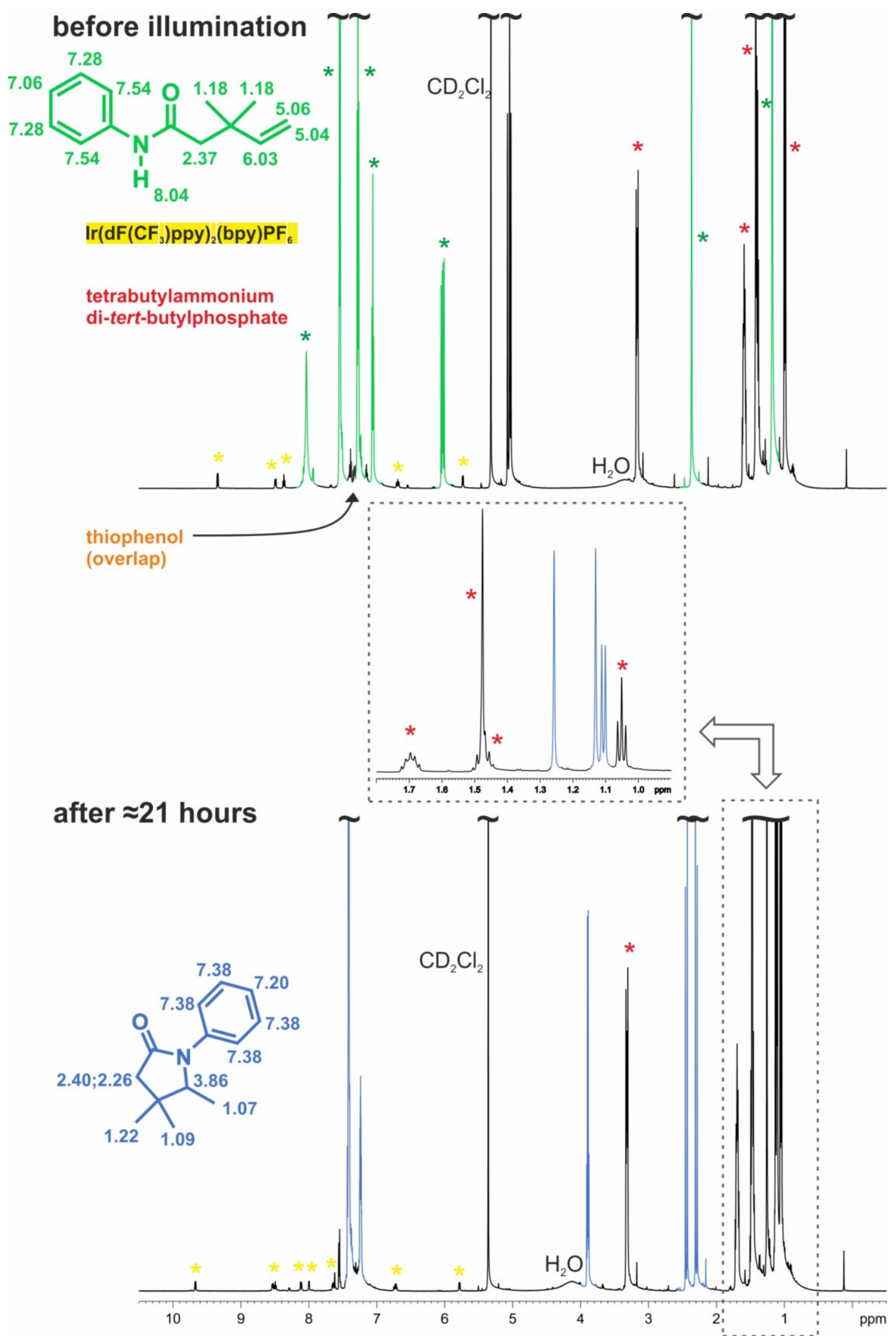

Scheme S11. Excerpt of the ${ }^{1} \mathrm{H}$ NMR spectra before starting the illumination (top) and after around 21 hours of illumination (bottom). The 3,3-dimethyl- $N$-phenylpent-4-enamide substrate signals are highlighted in green, the phosphate base signals in red, the photocatalyst signals in yellow and thiophenol is overlapped in the aromatic region. The product signals are marked in blue. The crowded region in the dashed box is clarified with an inlet. The comparison of the spectra shows complete amide consumption, product formation and no formation of side products. 


\section{before illumination \\ (complete spectrum)}

(n)

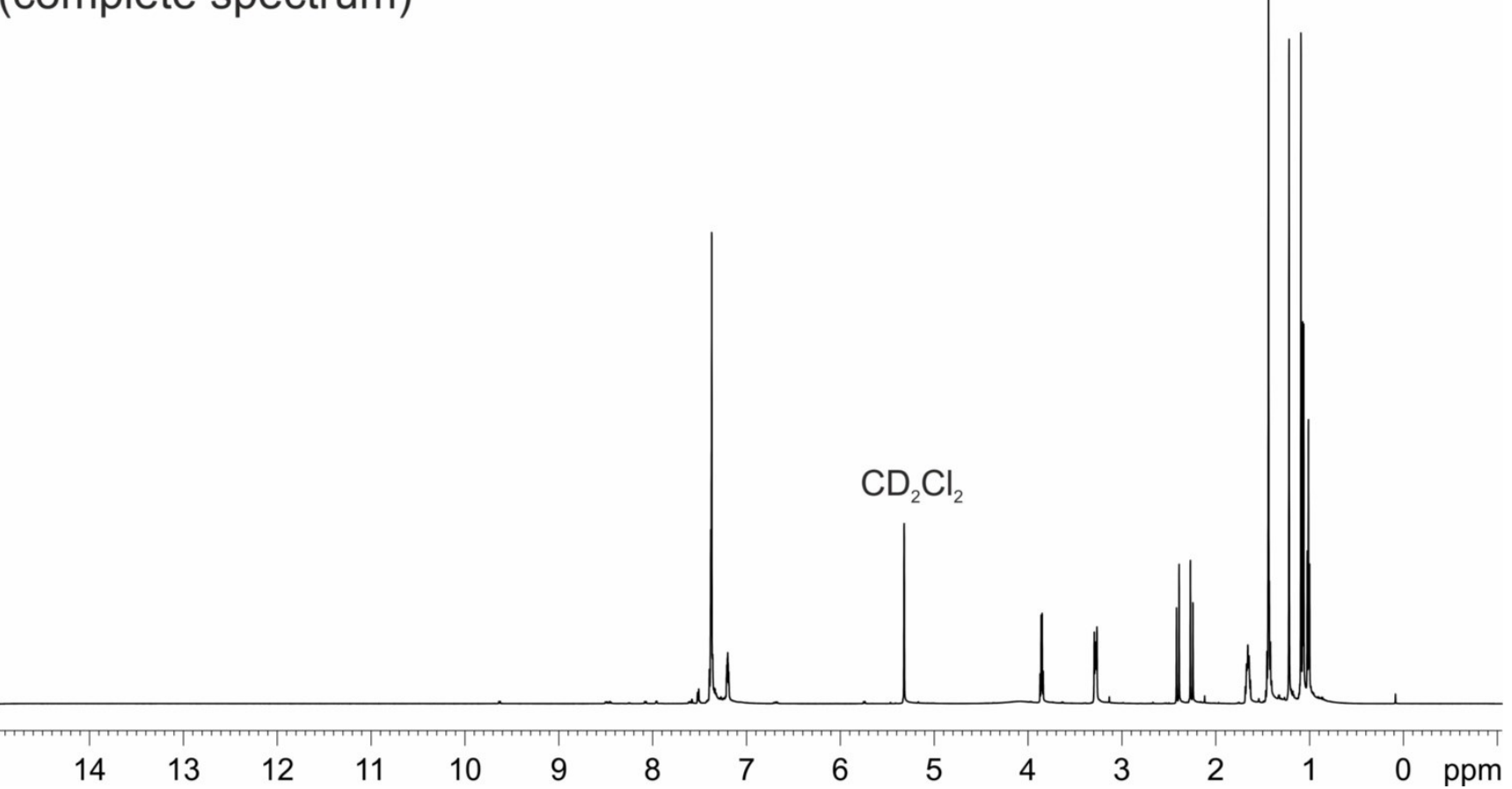

Scheme S12. Full ${ }^{1} \mathrm{H}-\mathrm{NMR}$ spectra of the photoredox catalytic hydroamidation reaction of 3,3-dimethyl- $N$-phenylpent-4-enamide in presence of phosphate base, thiophenol and Ir-photocatalyst before illumination with blue light (top) and after around 21 hours (bottom). 


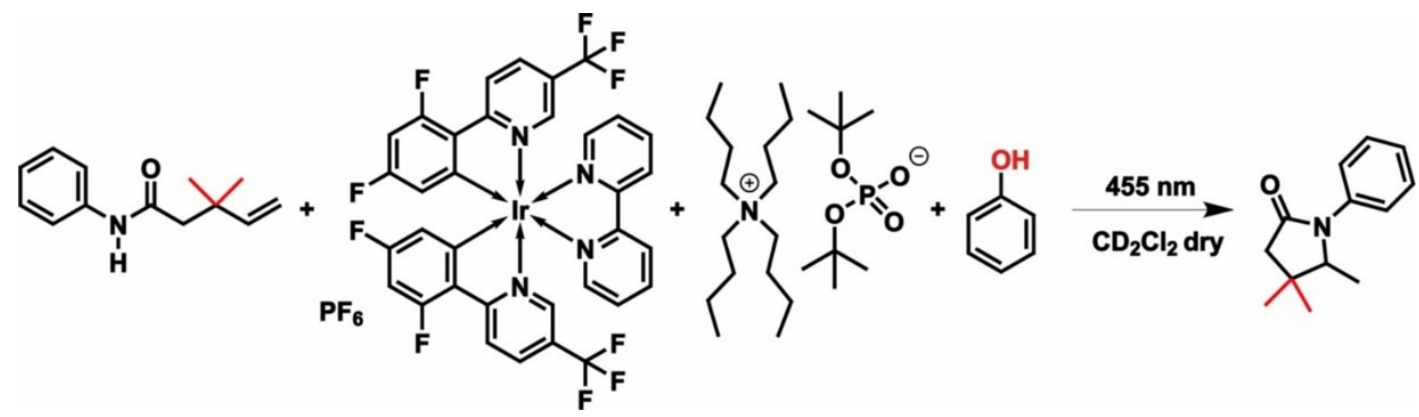

Scheme S13. Photoredox catalytic hydroamidation of 3,3-dimethyl- $N$-phenylpent-4-enamide in presence of base and phenol with blue light.

The sample was prepared according to the general procedure (vide supra) using 3,3-dimethyl- $N$-phenylpent-4-enamide (34 mg, $167 \mu \mathrm{mol})$, base ( $15 \mathrm{mg}, 33.3 \mu \mathrm{mol})$, phenol (1.6 mg, $16.7 \mu \mathrm{mol})$ and Ir-photocatalyst $(3.4 \mathrm{mg}, 3.3 \mu \mathrm{mol})$, in $\mathrm{CD}_{2} \mathrm{Cl}_{2}(1.65 \mathrm{ml})$. The reaction was followed via in-situ illumination inside the NMR spectrometer.

Again, the 3,3-dimethyl- $N$-phenylpent-4-enamide was used to exclude self-conversion of the amide starting material which is possible for $\mathrm{N}$-phenylpent-4-enamide (chapter 3.3). The corresponding amide degradation and product evolution curves are plotted in scheme S14. For the determination of the amounts by integration, the amide signal at $6.03 \mathrm{ppm}(\mathrm{dd}, 1 \mathrm{H})$ and the lactam signal at $3.86 \mathrm{ppm}(\mathrm{q}, 1 \mathrm{H})$ were used and the corresponding regions were baseline corrected prior to integration. The chemical shifts were referenced to $\mathrm{CD}_{2} \mathrm{Cl}_{2}\left(5.32 \mathrm{ppm}^{1}\right)$.

The reaction profiles in Scheme S14a show only marginal substrate conversion and product formation (1.7 \% after $18.3 \mathrm{~h})$. Regarding the amounts around $12 \%$ of by-product formation is probable. The excerpt of the product formation rate (first 3,3 hours) in Scheme S14b indicates no inhibition of the photocatalyst. In the ${ }^{1} \mathrm{H}$ spectra (Scheme S15, bottom), an additional triplet at 4.46 ppm predict the formation of an amidyl by-product, which was not further identified. The complete spectra are shown at this end of the chapter (Scheme S16).

a)

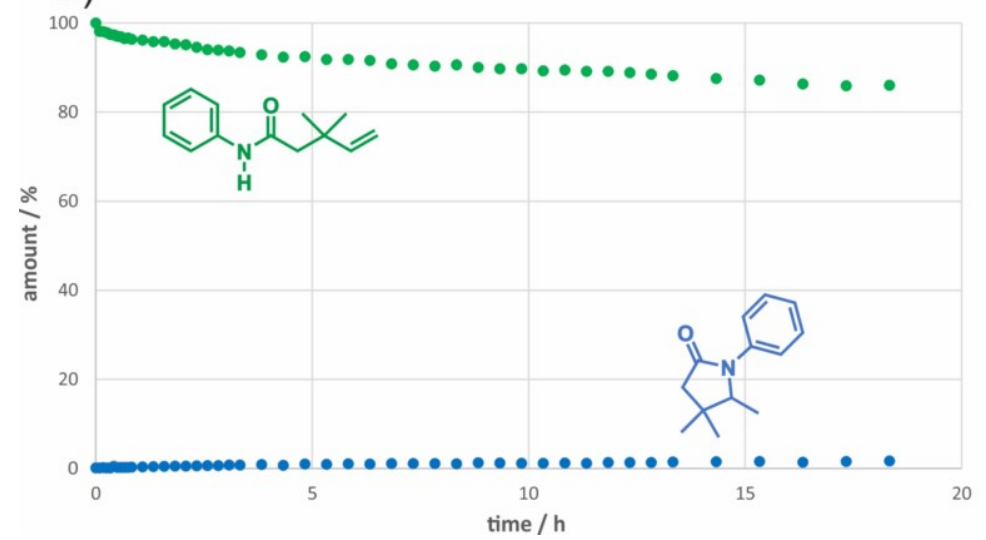

b)

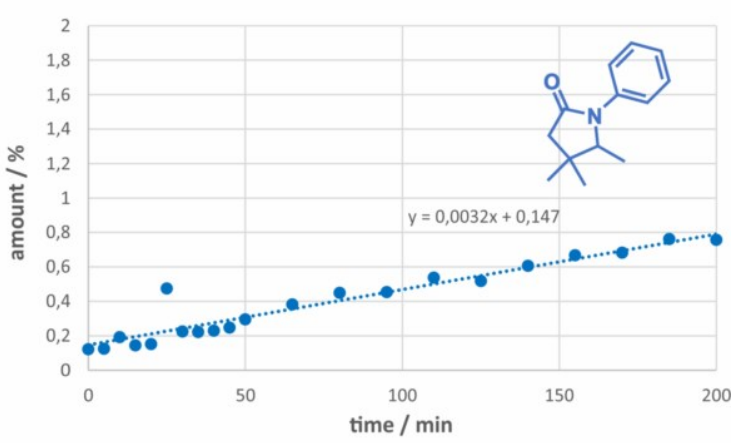

Scheme S14. a) In-situ reaction profile for the hydroamidation of 3,3-dimethyl- $N$-phenylpent-4-enamide using phenol as hydrogen atom donor followed by NMR; b) excerpt of the product formation rate (first 3,3 hours) and corresponding linear equation of the trendline. 


\section{before illumination}

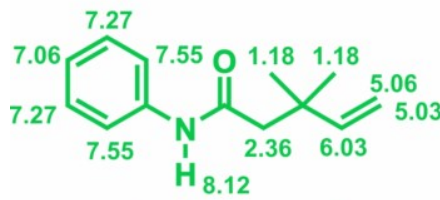

tetrabutylammonium di-tert-butylphosphate

$\operatorname{Ir}\left(\mathrm{dF}\left(\mathrm{CF}_{3}\right) \mathrm{ppy}\right)_{2}(\mathrm{bpy}) \mathrm{PF}_{6}$

phenol

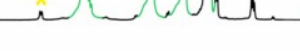

after $\approx 18$ hours
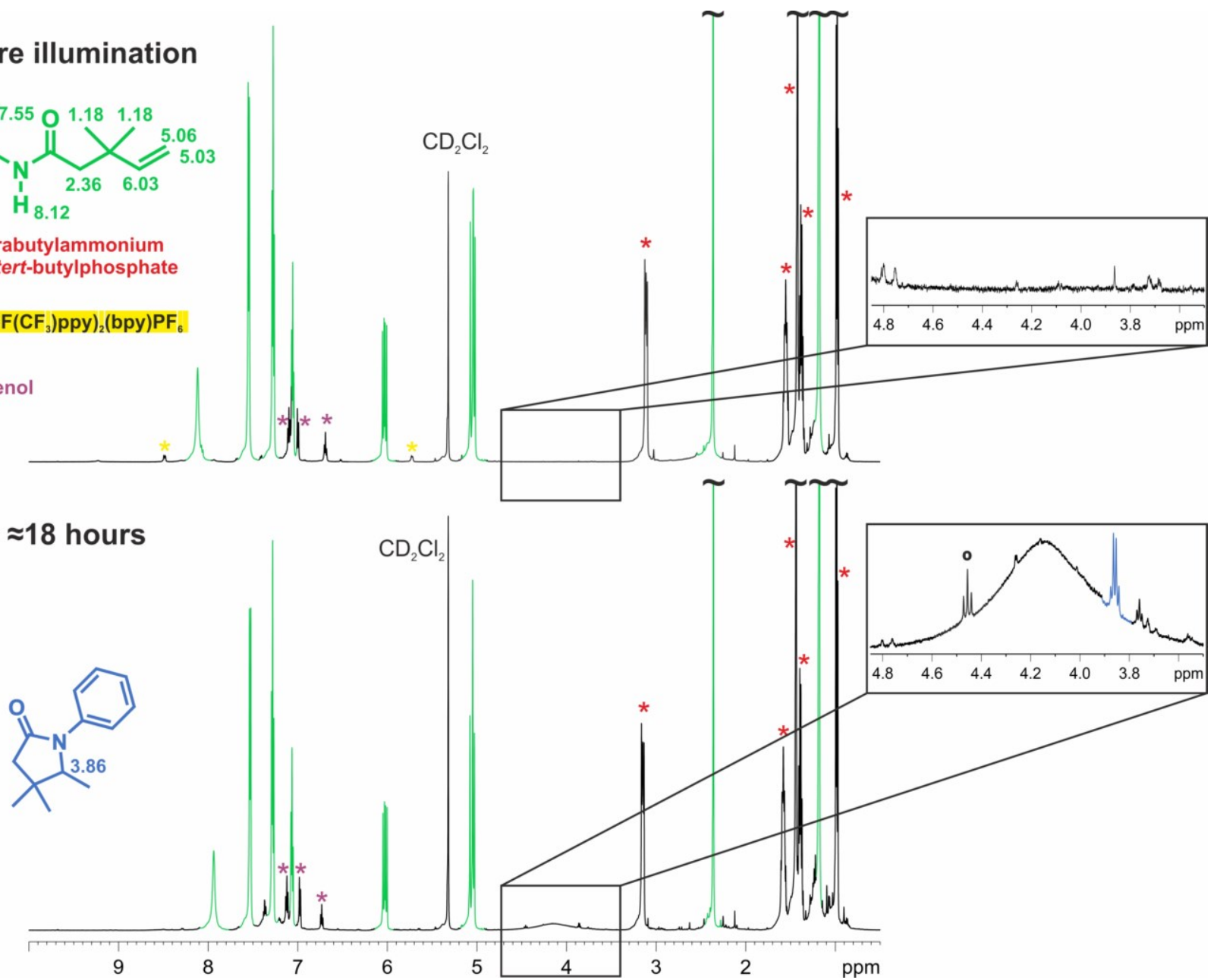

Scheme S15. Excerpt of the ${ }^{1} \mathrm{H}$ NMR spectra before starting the illumination (top) and after around 18 hours of illumination (bottom). The 3,3-dimethyl- $N$-phenylpent-4-enamide substrate signals are highlighted in green, the phosphate base signals in red, the photocatalyst signals in yellow and the phenol signals in purple. The product signals are marked in blue. The comparison of the spectra shows only marginal product formation and the generation of a by-product (triplet marked with ${ }^{\mathbf{o}}$ in the inlet). 


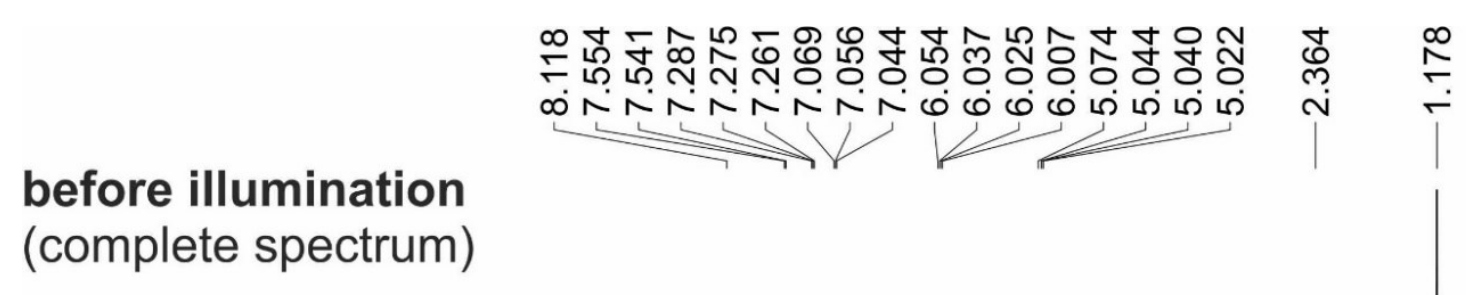
(complete spectrum)

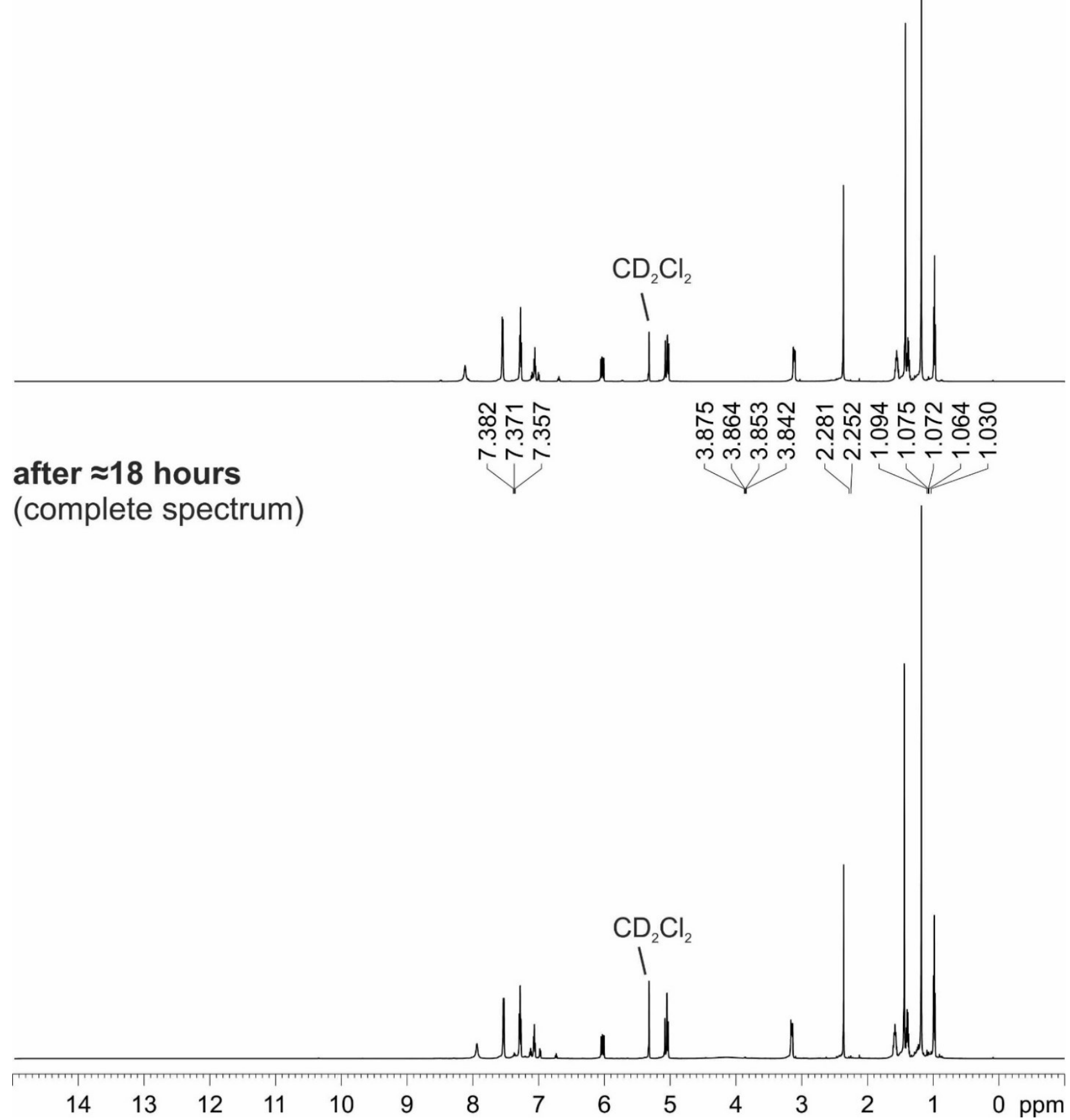

Scheme S16. Full ${ }^{1} \mathrm{H}-\mathrm{NMR}$ spectra of the photoredox catalytic hydroamidation reaction of 3,3-dimethyl- $N$-phenylpent-4-enamide in presence of phosphate base, phenol and Ir-photocatalyst before illumination with blue light (top) and after around 18 hours (bottom). 


\subsection{Initial rate kinetics using $\mathrm{PhSH}, \mathrm{Ph}_{2} \mathrm{~S}_{2}$ and mixtures thereof}

Sample preparation:

The samples were prepared according to the procedure applied by Knowles et al. ${ }^{2}$

A screw cap Schlenk tube was charged with 3,3-dimethyl- $N$-phenylpent-4-enamide (1 equiv.; $0.1 \mathrm{mmol} ; 20.3 \mathrm{mg}$ ), tetrabutylammonium ditert-butylphosphate (1 equiv.; $0.1 \mathrm{mmol} ; 45.2 \mathrm{mg}$ ) and $\operatorname{Ir}\left(\mathrm{dF}\left(\mathrm{CF}_{3}\right) \text { ppy) }\right)_{2}$ (bpy)PF 6 (0.02 equiv., $\left.2 \mathrm{~mol} \% ; 2 \mu \mathrm{mol} ; 2.0 \mathrm{mg}\right)$. In case of using diphenyldisulfide ( 0.5 equiv., 1 equiv., 0.7 equiv. and 0.8 equiv., respectively) the solid was added as well. The mixture was flushed with argon. Dry $\mathrm{CD}_{2} \mathrm{Cl}_{2}(1 \mathrm{ml}$; sample concentration of $100 \mathrm{mM}$ ) was added followed by thiophenol if used (1 equiv., 0.3 equiv. and 0.2 equiv., respectively). The mixture was degassed using freeze-pump-thaw technique and subsequently transferred into an amberized NMR tube under inert conditions.

The reactions were followed via in-situ illumination inside the NMR spectrometer. For the determination of the amounts by integration, the amide signal at 5.85-5.92 ppm $(\mathrm{m}, 1 \mathrm{H})$ and the lactam signal at $3.86 \mathrm{ppm}(\mathrm{q}, 1 \mathrm{H})$ were used and the corresponding regions were baseline corrected prior to integration.

The corresponding amide degradation and product evolution curves of the first 18 min including the linear slopes and the corresponding equations are plotted in Scheme S17. From the slopes the immense acceleration of the hydroamidations using mixtures of $\mathrm{PhSH}_{\text {and }} \mathrm{Ph}_{2} \mathrm{~S}_{2}$ is visible. 


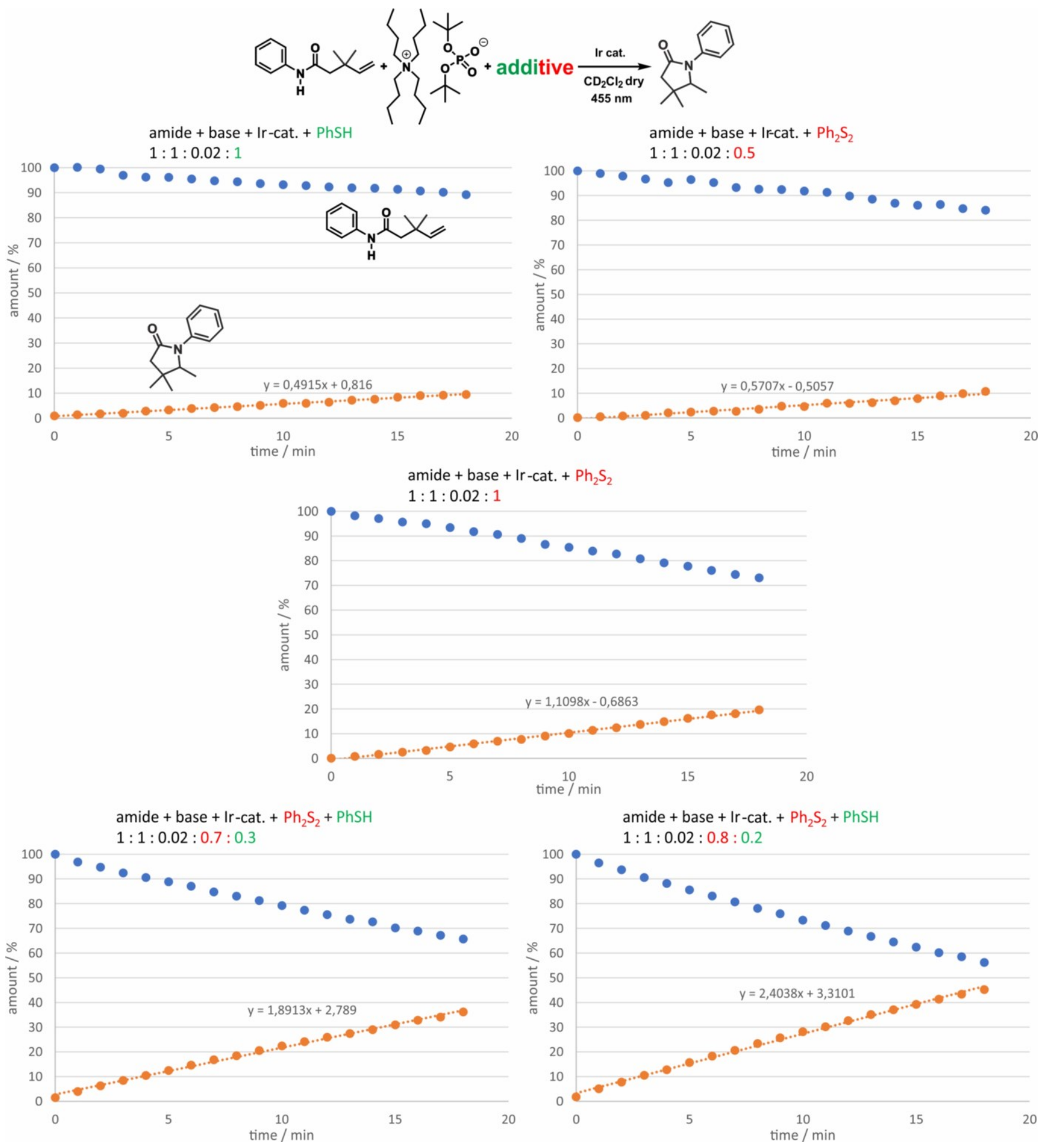

Scheme S17. Comparison of the initial rate kinetics for the hydroamidation reactions of 3,3-dimethyl- $N$-phenylpent-4-enamide using PhSH and $\mathrm{Ph}_{2} \mathrm{~S}_{2}$ as additives or a mixture thereof. The reactions were followed by in-situ ${ }^{1} \mathrm{H}$ NMR and an immense acceleration of the photoredox catalysis was achieved by a combination of both thiol species; the dimethyl substrate was used in order to exclude self-HAT. 


\subsection{Initial rate kinetics using different amounts of base and acid}

\section{Sample preparation:}

In general, the samples were prepared as described in chapter 3.5.

A screw cap Schlenk tube was charged with 3,3-dimethyl- $N$-phenylpent-4-enamide (1 equiv.; $0.1 \mathrm{mmol} ; 20.3 \mathrm{mg}$ ), diphenyldisulfide (1 equiv.; $0.1 \mathrm{mmol} ; 21.8 \mathrm{mg})$ and $\operatorname{Ir}\left(\mathrm{dF}\left(\mathrm{CF}_{3}\right) \text { ppy }\right)_{2}$ (bpy) $\mathrm{PF}_{6}(0.02$ equiv., $2 \mathrm{~mol} \%$; $2 \mu \mathrm{mol} ; 2.0 \mathrm{mg})$. Except for the reference mixture without acid, different mixtures of tetrabutylammonium di-tert-butylphosphate ( 0.7 equiv., 0.8 equiv., 0.9 equiv., respectively) and phosphoric acid dibutylester ( 0.3 equiv., 0.2 equiv., 0.1 equiv., respectively) were added as well. The mixture was flushed with argon. $\mathrm{Dry} \mathrm{CD}_{2} \mathrm{Cl}_{2}(1 \mathrm{ml}$; sample concentration of $100 \mathrm{mM}$ ) was added. The mixture was degassed using freeze-pump-thaw technique and subsequently transferred into an amberized NMR tube under inert conditions.

The reactions were followed via in-situ illumination inside the NMR spectrometer and the spectra were evaluated as described in chapter 3.5 .

The corresponding amide degradation and product evolution curves of the first 18 min including the linear slopes and the corresponding equations are plotted in Scheme S18. From the slopes the immense acceleration of the hydroamidations by adding phosphoric acid dibutylester is visible.

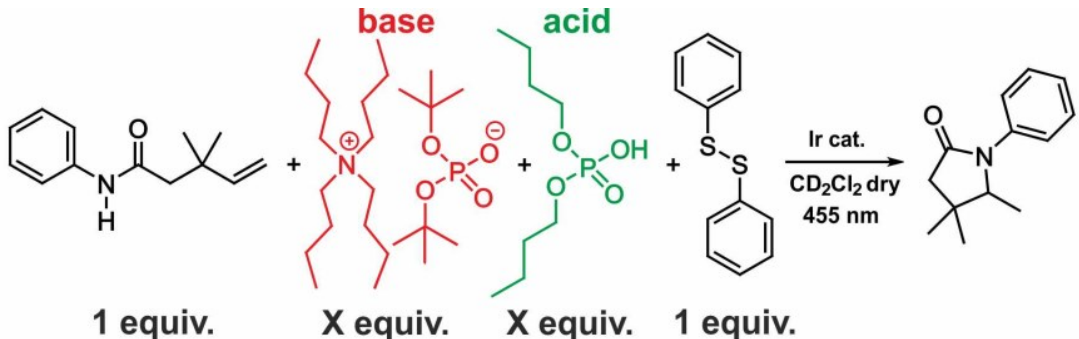

1 equiv. $\quad X$ equiv. $\quad X$ equiv. 1 equiv.
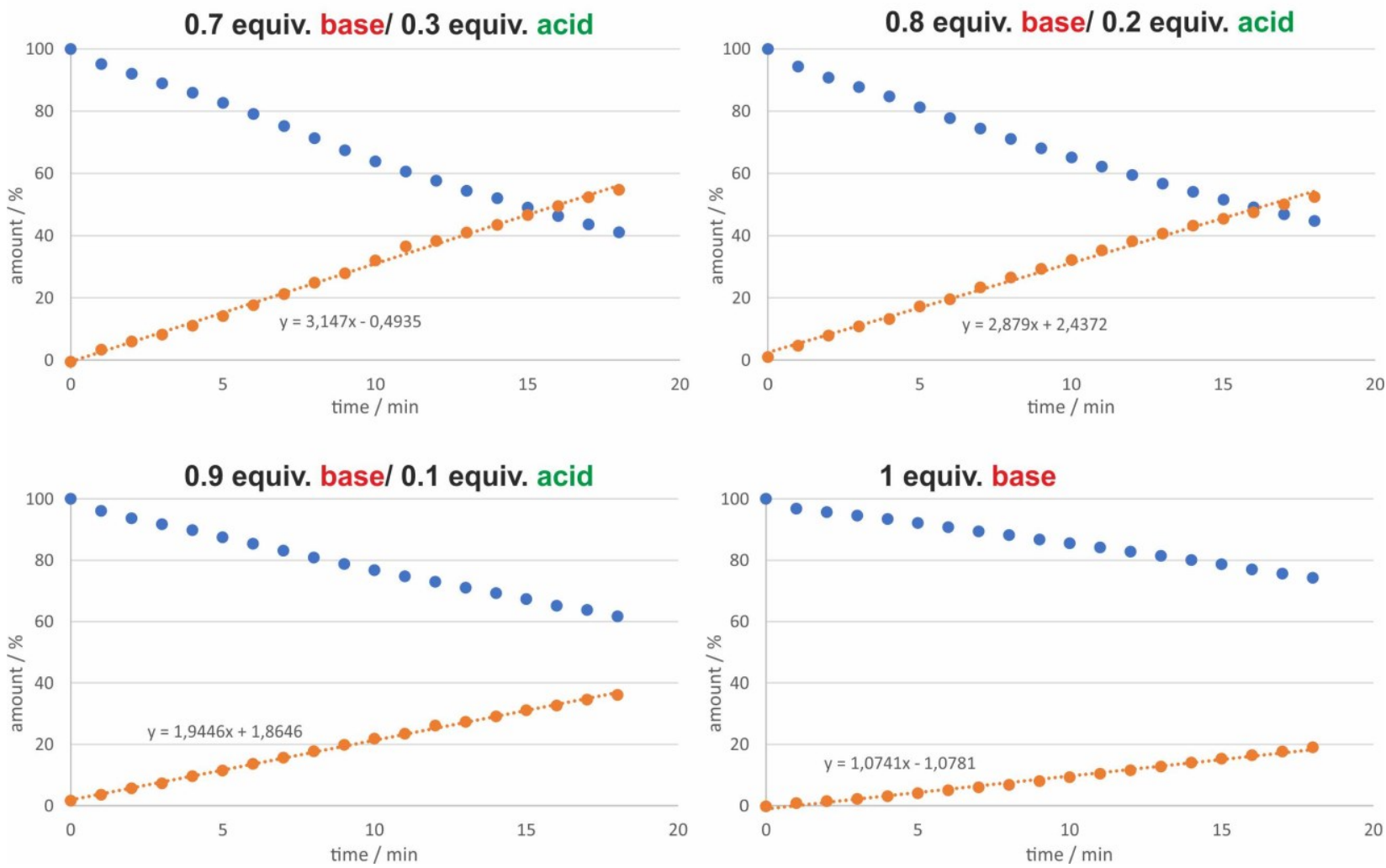

Scheme S18. Comparison of the initial rate kinetics for the hydroamidation reactions of 3,3-dimethyl- $N$-phenylpent-4-enamide using 1 equiv of $\mathrm{Ph}_{2} \mathrm{~S}_{2}$ and different mixtures of base and acid. The reactions were followed by in-situ ${ }^{1} \mathrm{H}$ NMR and an immense acceleration of the photoredox catalysis was achieved by adding the acid; the dimethyl substrate was used in order to exclude self-HAT. 
3.7 Initial rate kinetics using different amounts of base and acid in equiv. relevant for synthesis

Sample preparation:

In general, the samples were prepared as described in chapter 3.6 however using the synthetically relevant equivalents of the species.

A screw cap Schlenk tube was charged with 3,3-dimethyl- $N$-phenylpent-4-enamide ( 1 equiv.; 0.25 mmol; $50.8 \mathrm{mg}$ ), diphenyldisulfide ( 0.1 equiv.; $0.03 \mathrm{mmol} ; 5.5 \mathrm{mg}$ ) and $\operatorname{Ir}\left(\mathrm{dF}\left(\mathrm{CF}_{3}\right)\right.$ ppy)2(bpy)PF6 $(0.02$ equiv., $2 \mathrm{~mol} \%$; $5 \mu \mathrm{mol} ; 5.0 \mathrm{mg})$. For the reference mixture without acid tetrabutylammonium di-tert-butylphosphate $(0.2$ equiv., $0.05 \mathrm{mmol}, 22.6 \mathrm{mg})$ was added and for the mixtures containing base and acid 0.14 equiv. or 0.16 equiv. of base and 0.06 equiv. or 0.04 equiv. of phosphoric acid dibutylester were added. The mixture was flushed with argon. Dry $\mathrm{CD}_{2} \mathrm{Cl}_{2}$ (2.5 ml; sample concentration of $100 \mathrm{mM}$ ) was added. The mixture was degassed using freeze-pump-thaw technique and subsequently transferred into an amberized NMR tube under inert conditions.

The reactions were followed via in-situ illumination inside the NMR spectrometer and the spectra were evaluated as described in chapter 3.5 .

The corresponding amide degradation and product evolution curves of the first 18 min including the linear slopes and the corresponding equations are plotted in Scheme S19. From the slopes the immense acceleration of the hydroamidations by adding phosphoric acid dibutylester is visible.
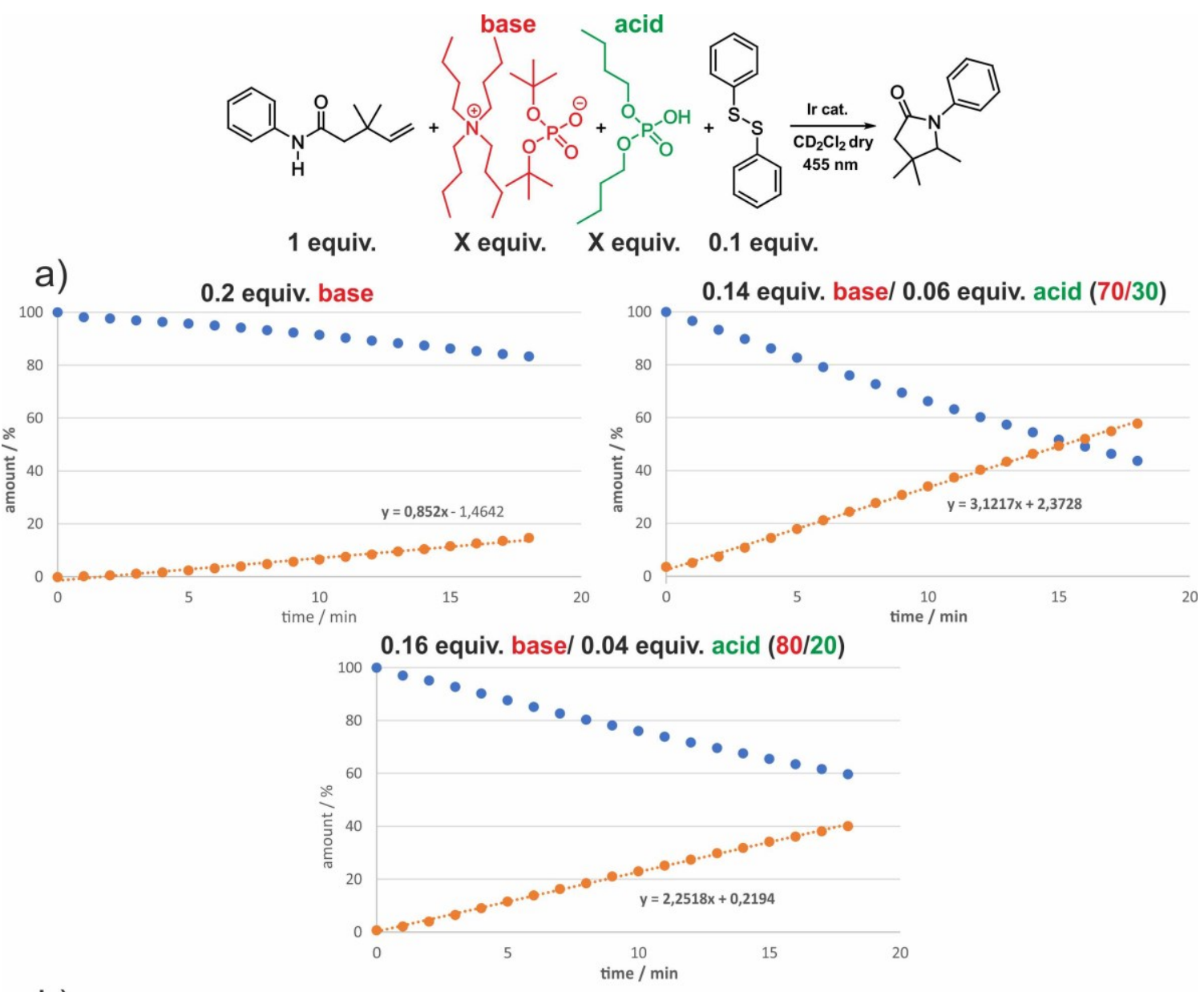

b)

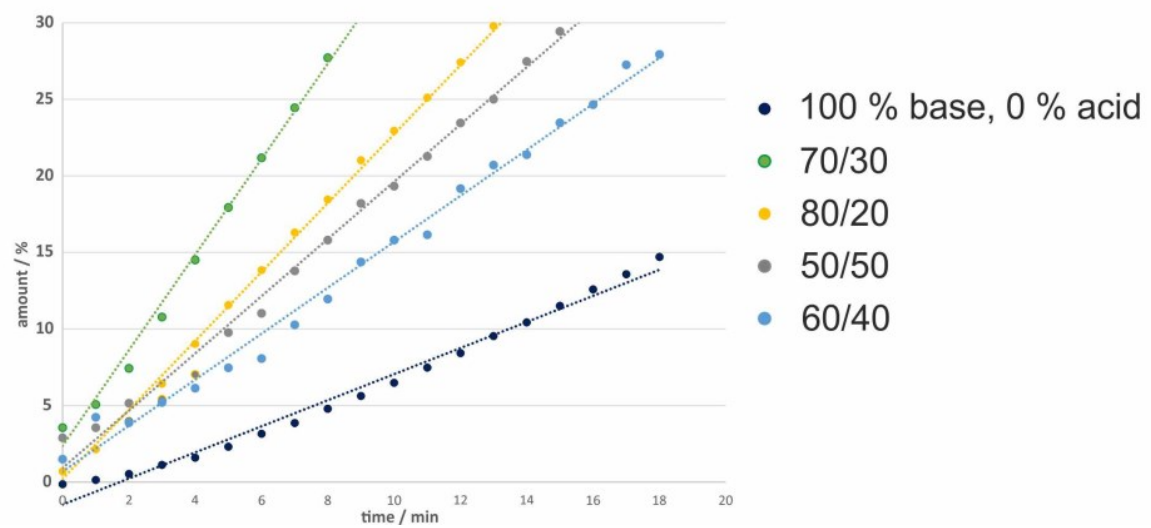

Scheme S19. a) Comparison of the initial rate kinetics for the hydroamidation reactions of 3,3-dimethyl- $N$-phenylpent-4-enamide using 0.1 equiv. of $\mathrm{Ph}_{2} \mathrm{~S}_{2}$ and different mixtures of base and acid. The reactions were followed by in-situ ${ }^{1} \mathrm{H}$ NMR and an immense acceleration of the photoredox catalysis was achieved by adding the acid; the dimethyl substrate was used in order to exclude self-HAT: b) mixtures of 50/50 and $60 / 40$ of base/acid added to Figure $7 \mathrm{~b}$ show a maximum acceleration of the reaction for a 70/30 mixture. 


\subsection{Light intensity dependent initial rate kinetics}

For the study of the impact of the light intensity on the reaction rates, a mixture containing amide/base/ $\mathrm{Ph}_{2} \mathrm{~S}_{2}$ and a mixture containing amide/base+acid (70:30)/ $\mathrm{Ph}_{2} \mathrm{~S}_{2}$ prepared exactly as written in chapter 3.7 were measured.

The results are presented in Figure 8b in the main text as well as in Scheme S20. After 9 minutes of illumination at 0.5 A the light intensity was reduced to $50 \%(0.25 \mathrm{~A})$. Again after 9 minutes the intensity was reduced to $25 \%$ by going down to $0.13 \mathrm{~A}$. Lastly, it was switched back to $100 \%(0.5 \mathrm{~A})$. In our illumination setup the different values for the applied current linearly correlate with the light intensity. ${ }^{5}$ Therefore, the time slots shown in Figure $8 \mathrm{~b}$ represent $100 \%, 50 \%$ and $25 \%$ light intensity.

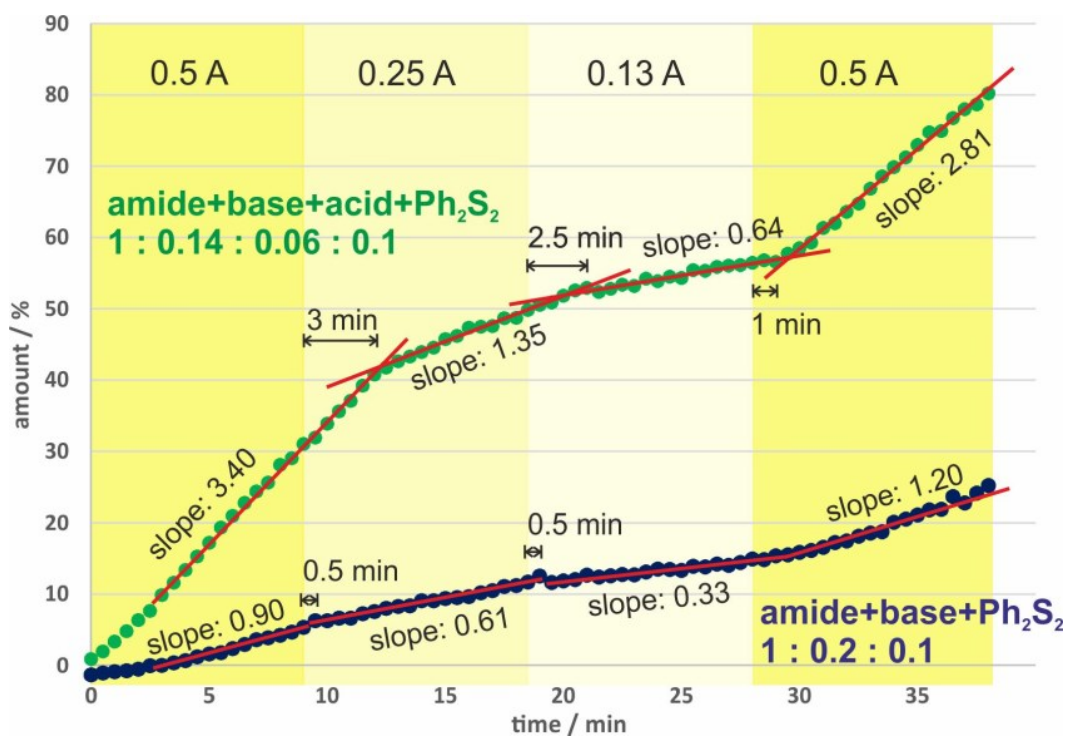

Scheme S20. Light intensity dependent reaction profiles of a mixture of amide/base + acid(70:30)/ $\mathrm{Ph}_{2} \mathrm{~S}_{2}$ (green curve) and of a mixture of amide/base $/ \mathrm{Ph}_{2} \mathrm{~S}_{2}$ (blue curve). For details of sample preparation, see chapter 3.7. The red lines represent the different slopes of the linear parts and thus highlight the different time intervals for persisting reaction rates after reducing the light intensity (by reducing the applied current). The initial lower slope of the blue curve is in agreement with the mechanistic proposal of an off-cycle equilibrium with $\mathrm{Ph}_{2} \mathrm{~S}_{2}$, which consumes in the beginning the photogenerated amidyl radical. At the moment this amidyl reservoir is filled the equilibrium between photogeneration, off-cycle equilibrium with $\mathrm{Ph}_{2} \mathrm{~S}_{2}$, and abreaction via cyclization creates a constant overall reaction rate (slope 0.90 ). This finds its repetition upon increasing the light intensity in the last part of the profile.

\section{Low temperature NMR spectroscopic studies}

\section{General information:}

The NMR spectroscopic measurements of the ${ }^{1} \mathrm{H},{ }^{15} \mathrm{~N}$ and ${ }^{31} \mathrm{P}$ NMR spectra were performed in dry $\mathrm{CD}_{2} \mathrm{Cl}_{2}$ at $180 \mathrm{~K}$ on a Bruker Avance III HD $600(600.13 \mathrm{MHz})$ and a $5 \mathrm{~mm}$ TBI-F probe head with a z-gradient $(53.5 \mathrm{Gauss} / \mathrm{cm})$. The temperature of $180 \mathrm{~K}$ was controlled by a BVTE 3900

The ${ }^{1} \mathrm{H}$ NMR spectra were referenced on TMS $(0 \mathrm{ppm}) .{ }^{1}$ The ${ }^{15} \mathrm{~N}$ and ${ }^{31} \mathrm{P}$ spectra were referenced according to $v_{\text {heteronucleus }}=v_{\mathrm{TMS}} \mathrm{x} \Xi_{\text {reference }}$ $/ 100 \%$ published by Harris et al. ${ }^{6}{ }^{v}$ TMS refers to the measured ${ }^{1} \mathrm{H}$ resonance of TMS. The corresponding frequency ratios $\Xi_{\text {reference }}$ were used: $\Xi\left({ }^{15} \mathrm{~N}\right)=10.132912 \%\left(\mathrm{NH}_{3}\right.$ liquid), $\Xi\left({ }^{31} \mathrm{P}\right)=40.480742 \%\left(\mathrm{H}_{3} \mathrm{PO}_{4} 85 \%\right) .{ }^{6}$ The data were processed and plotted with Topspin 3.2 (Bruker). The Figures were generated using the Topspin Plot Editor, Chem Draw Professional and Corel Draw 2017.

The two- and three-component samples were prepared as 1:1 and 1:1:1 mixtures $(50 \mathrm{mM})$, respectively. Due to the hygroscopic properties of the phosphate base, residual $\mathrm{H}_{2} \mathrm{O}$ is observable in the ${ }^{1} \mathrm{H}$ NMR spectra.

In the following section, the complete spectra with information about the chemical shifts, integrals and the assignment of the different compounds are depicted. 


\subsection{Identification of phosphate dimer $\mathbf{1}$ and the thiol species}

In every sample containing phosphate base and thiophenol the formation of new thiol species in the aromatic region of the ${ }^{1} \mathrm{H}$ NMR spectra is visible (chapter 4.5.1 and main text). In the following section, some of the generated thiol species are identified.

From a partial acid-base reaction between thiophenol and phosphate base, thiolate and phosphoric acid are generated (Scheme S21). The phosphoric acid adds to a phosphate furnishing the phosphate dimer 1, which is assumed to play the key role for the required aggregation for an efficient photo redox catalytic hydroamidation reaction (see main text). The broad ${ }^{1} \mathrm{H}$ signal at $16.43-16.51 \mathrm{ppm}$ for every PhSH/base containing mixture indicates the formation of a strong hydrogen bond. Similar dimers were already identified in our group. ${ }^{78}$

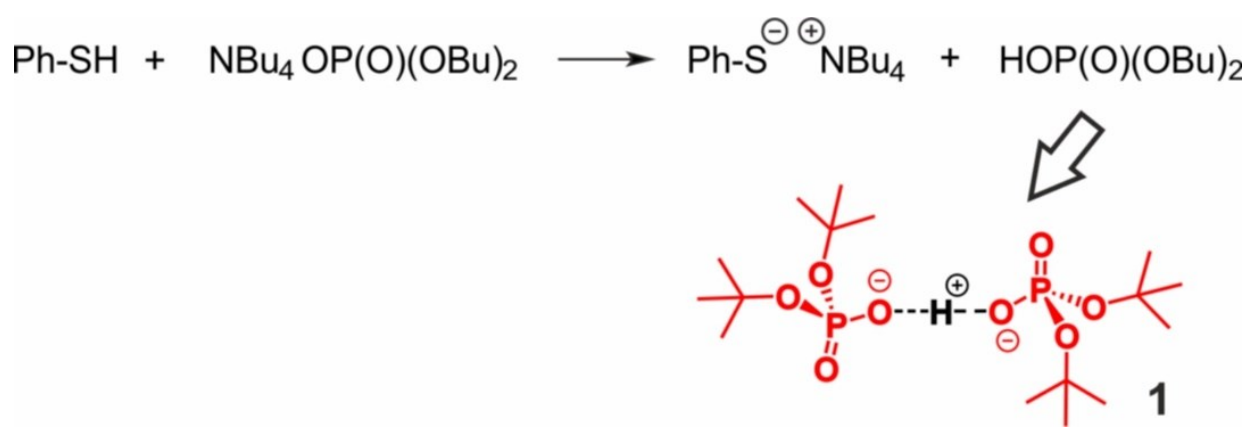

Scheme S21. Via partial protonation of the phosphate base by thiophenol the crucial dimer $\mathbf{1}$ is generated.

For the identification of the generated thiol species selective 1D TOCSY experiments were conducted for the amide/base mixture. As depicted in Scheme S22, the excitation of two different signals in the aromatic region yielded at least two new independent thiol species besides $\mathrm{PhSH}$ itself. The signals for species 1 overlap with species 2 and $\mathrm{PhSH}$. 


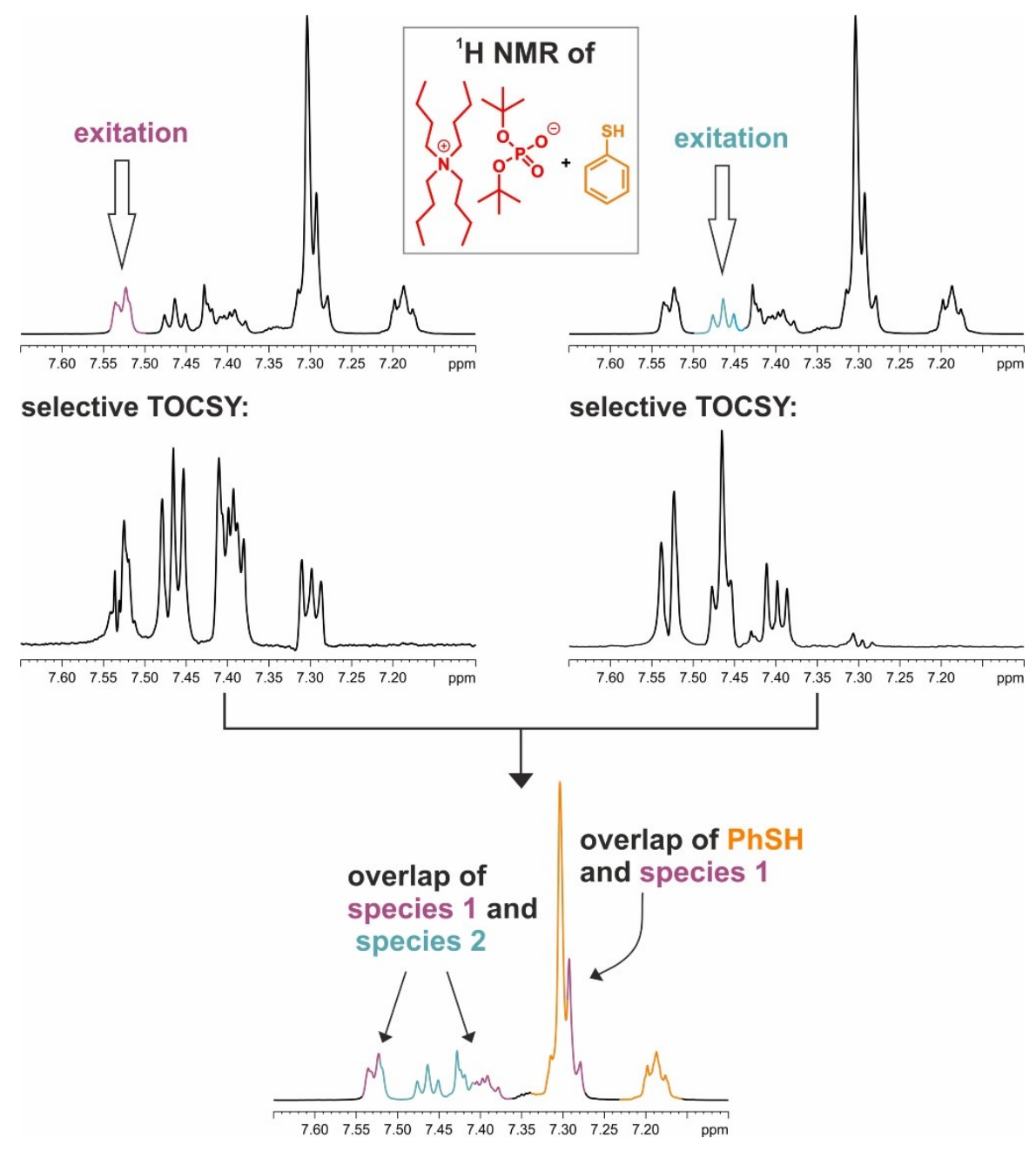

Scheme S22. Via selective 1D TOCSY experiments, the existence of at least two new thiol species, apart from thiophenol itself, was identified for the amide/base mixture (1:1). From the excitation of the purple and blue signals (top), the overlap of at minimum two thiol species in the aromatic region was identified. The spectra were measured in $\mathrm{CD}_{2} \mathrm{Cl}_{2}$ at $180 \mathrm{~K}$.

As the identification of the thiol species was complicated because of the overlap in the aromatic region, 4-methoxythiophenol was chosen for further NMR analysis due to better separation of the signals in the spectrum. In Scheme S23, the spectrum of a 1:1 mixture of 4methoxythiophenol and phosphate base is depicted (bottom). The formation of three new thiol species is clearly visible. After oxidizing 4methoxypyridine by adding iodine, the signals for the pure substituted thiophenol completely disappeared and the signals of the disulfide increased. Thus, the blue marked doublet could be identified as the oxidation product.

The oxidation of thiophenol to its corresponding disulfide dimer in presence of a base and oxygen is well known in literature (Scheme S24) and is triggered by residual oxygen in this case. ${ }^{910}$ As the 4-methoxythiophenol/base sample was prepared under oxygen atmosphere the disulfide generation could be identified. But the photocatalytic mixture is prepared under argon atmosphere and such transformation is therefore unlikely.

By comparing the integrals of the residual thiol signals (Scheme S23, purple signals) with the proton signal of the phosphate dimer $\mathbf{1}$, the generation of the two thiol species corresponds to one phosphor dimer. Thus, we assume two different thiolate species with tetrabutylammonium thiolate as the main compound.

Furthermore, via Diffusion-ordered Spectroscopy (DOSY; see chapter 4.6.2) the volumes for the different thiol species were obtained. The higher value for the thiolate (declared as thiolate 1) in comparison to pure 4-methoxythiophenol can be described by the attachment of tetrabutylammonium as counterion, although the volume is smaller than expected for a combined aggregate (thiolate monomer value: $\mathrm{V}=$ $125 \AA^{3}$; ammonium monomer value: $\mathrm{V}=302 \AA^{3}$; DOSY derived volume for the thiolate 1 species: $\mathrm{V}=192 \AA^{3}$, see chapter 4.6.2, Table 1). Furthermore, the reduced ammonium volume $\left(\mathrm{V}=955 \AA^{3}\right)$ in comparison to the pure phosphate/ammonium mixture $\left(\mathrm{V}_{\text {ammonium }}=2399 \AA^{3}\right)$ hint at its release from the phosphate according to the generation of thiolate and phosphoric acid. Moreover, a second thiolate signal (thiolate 2) was identified, which we assume as thiophenolate being complexed by H-bond formation as the DOSY derived volume is larger than for thiolate $1\left(\mathrm{~V}=539 \AA^{3}\right)$. For the disulfide a volume of $355 \AA^{3}$ was obtained, which follows the expected value of dimer generation. 


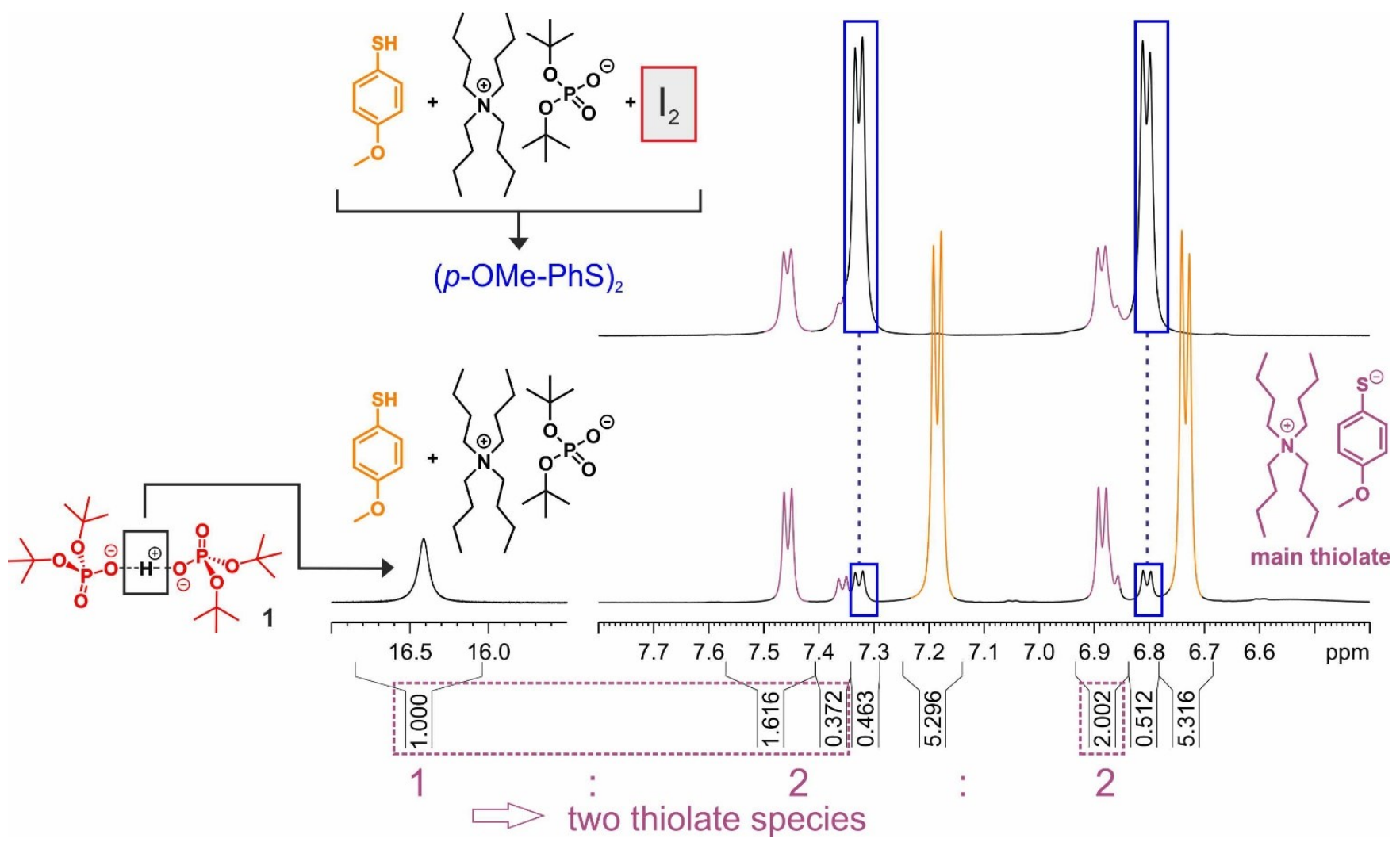

Scheme S23. By the comparison of the ${ }^{1} \mathrm{H}$ NMR spectra of a 4-methoxythiophenol/phosphate base mixture (bottom) and after addition of iodine (top) the oxidation product 4-methoxydiphenylsulfide (blue) was identified. Moreover, the signal at $\sim 16.4$ ppm was assigned as proton of dimer 1 generated by a partial acid/base reaction between thiol and base and two thiolate anion species (purple) were identified because the sum of the aromatic protons refer to one equivalent of dimer. As main thiolate we propose tetrabutylammonium thiolate.

a)

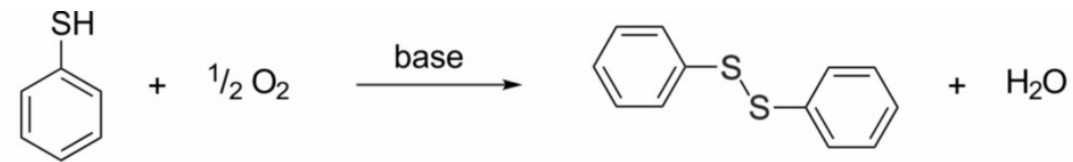

\section{b)}

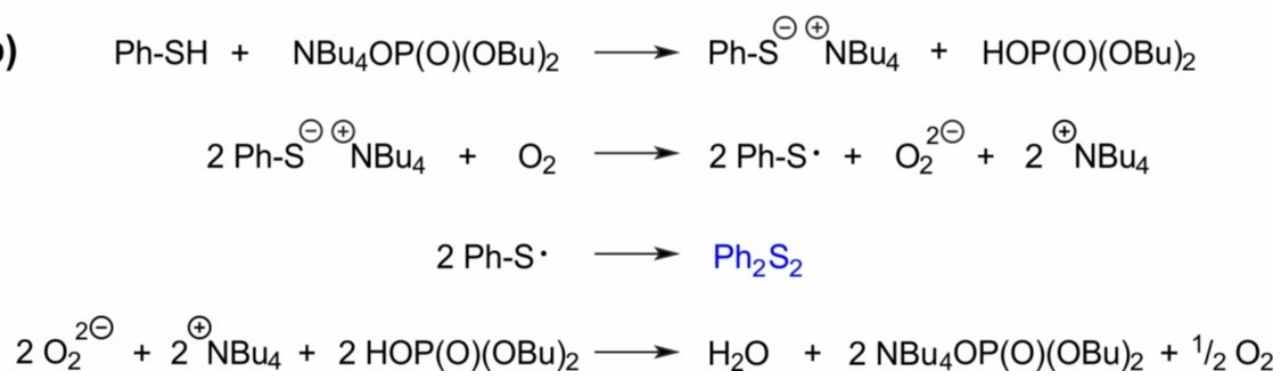

Scheme S24. a) Literature known oxidation of thiophenol in presence of oxygen and base to the corresponding diphenyl disulfide and $\mathrm{H}_{2} \mathrm{O}$. ${ }^{11}$ b) Postulated oxidation process with phosphate bases.

Transferring these results to the sample containing unsubstituted thiophenol, we compared the chemical shifts of sodium thiolate with our $\mathrm{PhSH} / \mathrm{phosphate}$ base mixture. In Scheme S25a, the thiolate was verified for the $\mathrm{PhSH} / \mathrm{base}$ mixture and assigned by the comparison of its low temperature ${ }^{1} \mathrm{H}$ NMR spectrum with the spectrum of sodium thiolate (purple signals). Moreover, the thiolate was also identified in the amide/base/PhSH mixture. Therefore, species 1 of the selective TOCY analysis (Scheme S22) refers to tetrabutylammonium thiolate. The light blue marked signals of other generated thiol species were not further investigated. 

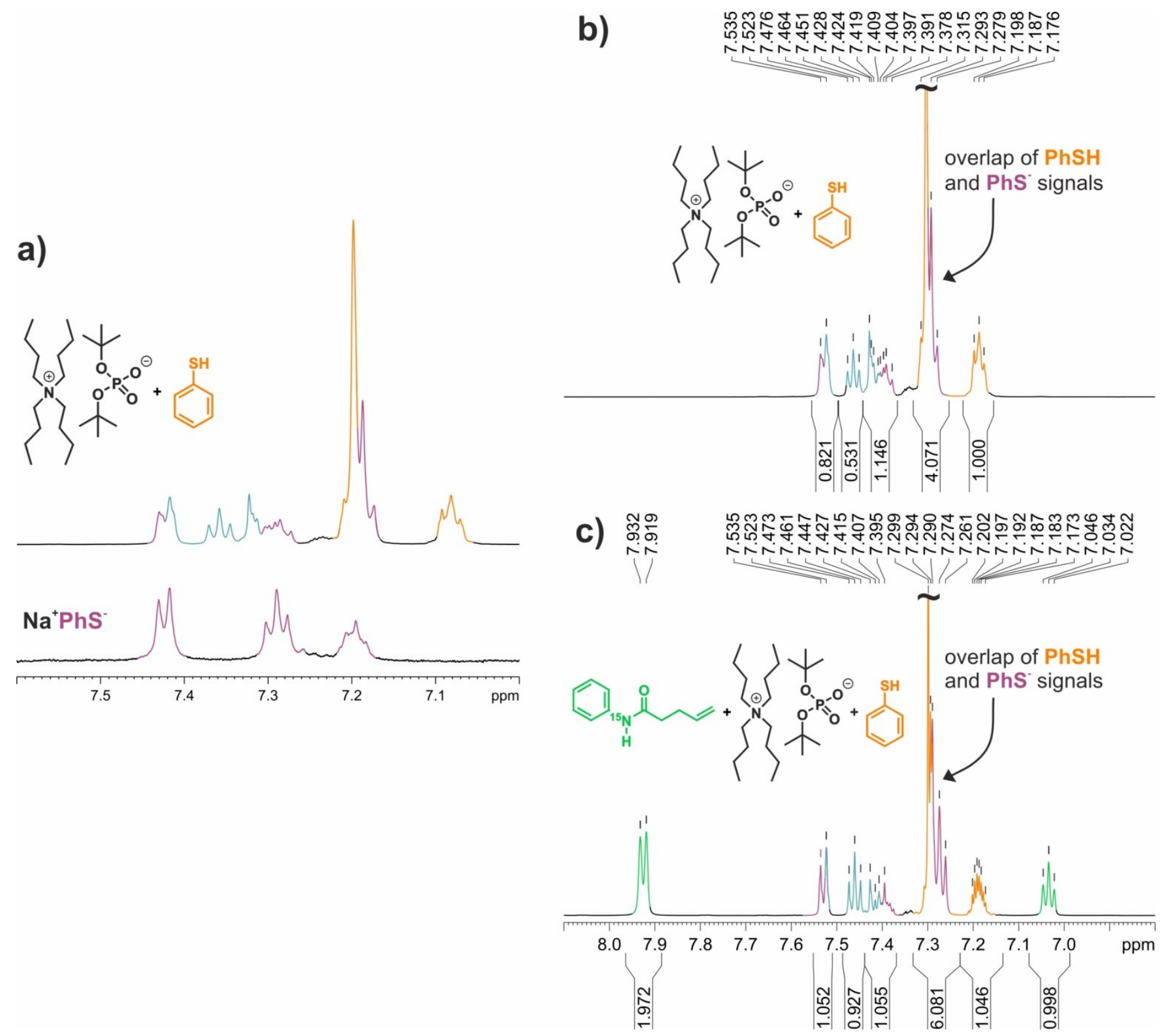

Scheme S25. a) The comparison of the ${ }^{1} \mathrm{H}$ NMR spectra of sodium thiolate and the $\mathrm{PhSH} / \mathrm{base}$ mixture verifies the existence of a thiolate in the samples containing b) tetrabutylammonium di-tert-butylphosphate and $\mathrm{PhSH}$ and c) ${ }^{15} \mathrm{~N}$-phenylpent-4-enamide, tetrabutylammonium di-tert-butylphosphate and $\mathrm{PhSH}$; the spectra were measured in $\mathrm{CD}_{2} \mathrm{Cl}_{2}$ at $180 \mathrm{~K}$.

\subsection{Identification of phosphate dimer 1 in the photocatalytic reaction mixture}

Substituting thiophenol by phosphoric acid dibutylester and diphenyldisulfide in order to furnish the phosphate dimer $\mathbf{1}$ an immense acceleration of the photocatalytic hydroamidation reaction was obtained (see chapters 3.6 and 3.7). In addition, we identified the proton signal of the dimer in the photocatalytic reaction mixture $\left({ }^{15} \mathrm{~N}\right.$-phenylpent-4-enamide (1 equiv.), tetrabutylammonium di-tert-butylphosphate ( 0.2 equiv.), thiophenol ( 0.1 equiv.) and photocatalyt ( 0.02 equiv.); for details of sample preparation see chapter 3.1 ) by conducting low temperature ${ }^{1} \mathrm{H}$ NMR studies. In Scheme S26, the related ${ }^{1} \mathrm{H}$ spectrum of the mixture at $180 \mathrm{~K}$ before starting the illumination is shown. The corresponding signal of the dimer was persitent during illumination, however, at this temperature no product formation was observed. 


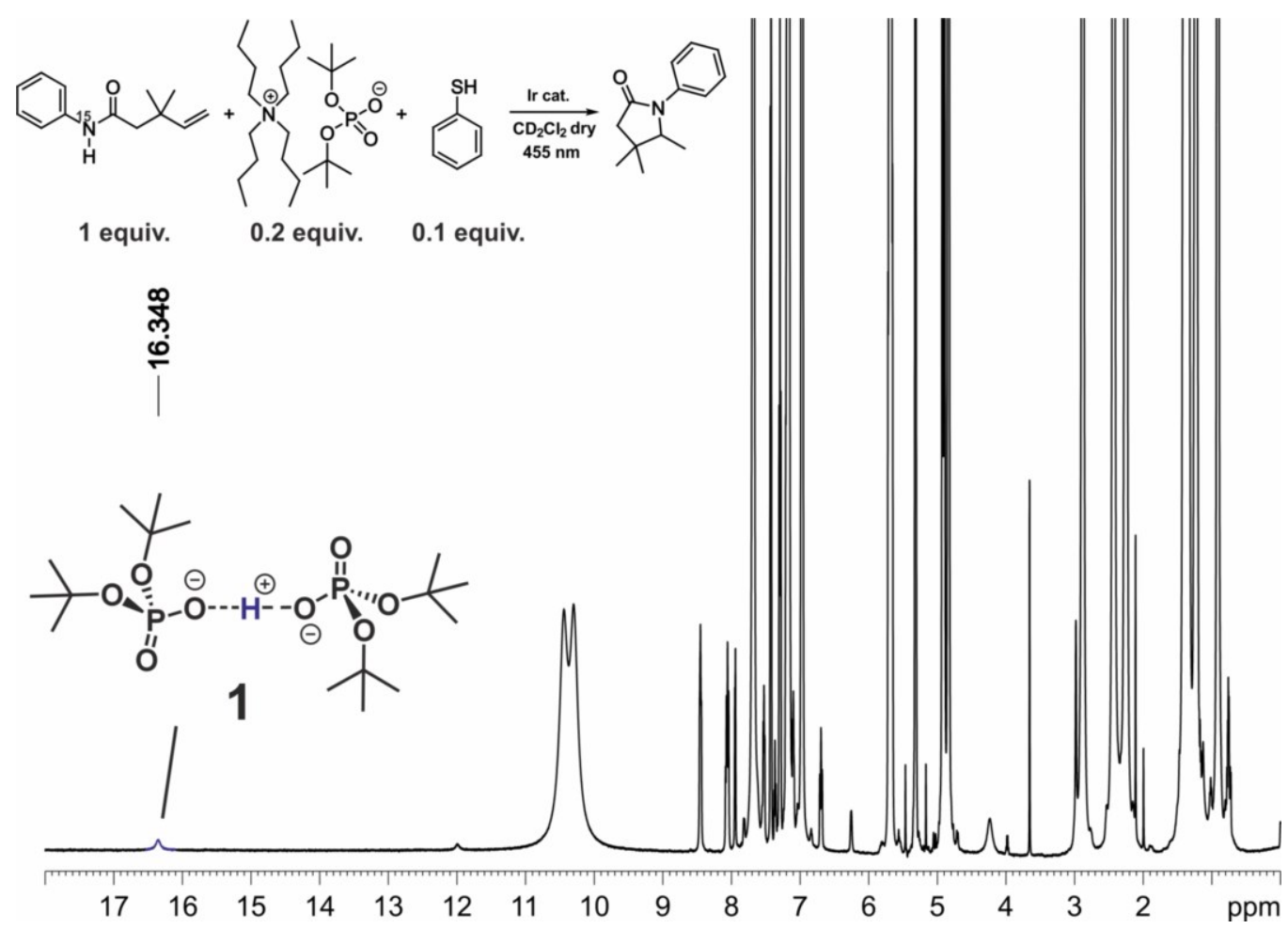

Scheme S26. ${ }^{1} \mathrm{H}$ NMR spectrum of the photocatalytic reaction mixture at $180 \mathrm{~K}$ before starting the illumination reveals the existence of phosphate dimer $\mathbf{1}$.

\subsection{Identification of phosphate dimer 1 in the base/acid mixture}

In chapter 3.6 and 3.7 , the immense acceleration of the photocatalytic hydroamidation reaction by directly adding phosphoric acid dibutylester instead of thiophenol was shown. As we identified the phosphate dimer 1 inside the thiophenol containing reaction mixture and demonstrated its impact on the proton pathway of this photocatalytic transformation, we hoped to create this dimer directly by using a mixture of base and acid without thiophenol. In order to prove the existence of dimer $\mathbf{1}$ inside the amide/base/acid solution, low temperature ${ }^{1} \mathrm{H}$ and ${ }^{31} \mathrm{P}$ measurements were performed. In Scheme S27, excerpts of the ${ }^{1} \mathrm{H}$ (a) and ${ }^{31} \mathrm{P}$ (b) spectra of the ${ }^{15} N$-phenylpent-4enamide/tetrabutylammonium di-tert-butylphosphate/phosphoric acid dibutylester mixture (1:1:1) are presented. A 1:1:1 mixture (50 mM) was prepared and the measurements were performed at $180 \mathrm{~K}$ in order to be able to compare the spectra with those in chapter 4.4.

As highlighted in Scheme S27, the spectra show the corresponding signals of dimer 1 (for comparison, see Figure 3 in the main text and Scheme S34 in chapter 4.5.1 and Schemes S43,44 in chapter 4.5.3) and thus formation of the crucial H-bond mediated dimer was proven. Due to the 1:1 ratio of phosphate and phosphoric acid, a new ${ }^{1} \mathrm{H}$ signal at $15.25 \mathrm{ppm}$ and two new ${ }^{31} \mathrm{P}$ signals at -2.1 and $-2.4 \mathrm{ppm}$ appeared. These are typical chemical shift combinations of phosphoric acids (most probably of the phosphoric acids, acid dimers or oligomers) and indicate as expected an equilibrium between tetrabutylammonium phosphates and phosphoric acids at these high concentrations of phosphoric acid. Therefore, reduced amounts of phosphoric acids (10\%-30\%) were used for the kinetic studies presented in Figure S18. 

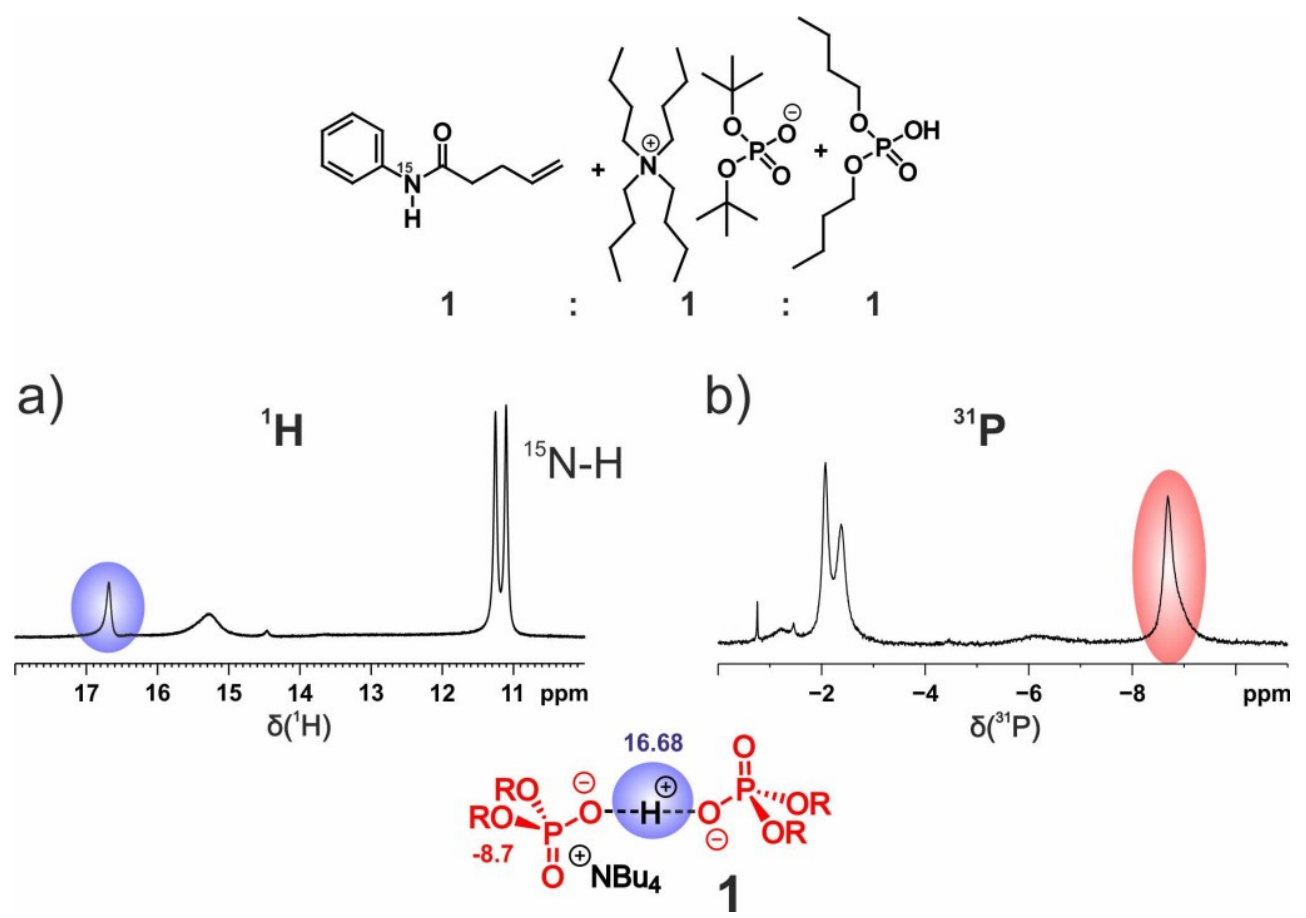

Scheme S27. a) ${ }^{1} \mathrm{H}$ and b) ${ }^{31} \mathrm{P}$ NMR spectra of a mixture containing ${ }^{15} \mathrm{~N}$-phenylpent-4-enamide, tetrabutylammonium di-tertbutylphosphate and phosphoric acid dibutylester $(1: 1: 1)$ in $\mathrm{CD}_{2} \mathrm{Cl}_{2}$ at $180 \mathrm{~K}$ revealed the existence of dimer $\mathbf{1}$. The additional signals in both spectra show the typical chemical shift combination of phosphoric acids (or their dimers or trimers). Therefore, reduced amounts of phosphoric acid were used for the kinetic studies shown in Figure S18.

\subsection{Hydrogen bond donor and acceptor abilities according to Hunter}

The hydrogen bond donor and acceptor abilities of the different species used for the hydrogen bonding and aggregation analysis are estimated from the publication of Hunter and summarized in Scheme S28. ${ }^{12}$ For dichloromethane (DCM), thiophenol and phenol, the values were directly taken from the tables on page 5316 in this publication. For the amide functionality, the values were read out of Figure $7 \mathrm{c}$. The phosphonate diester value was chosen as approximation for the phosphate base. The graph in Scheme S28b shows the resulting interactions for each species solved in dichloromethane. As such, phenyl-amides and phenol tend to aggregate in solution while thiophenol and the phosphonate diester should undergo solute-solvent interactions and are therefore predicted to exist as monomers.

These assumptions are in line with our hydrogen bond investigations, as $N$-phenylpent-4-enamide as well as phenol form aggregates in $\mathrm{CD}_{2} \mathrm{Cl}_{2}$. 
a)

\begin{tabular}{lcc} 
& $\begin{array}{c}\text { acceptor } \\
\text { ability }\end{array}$ & $\begin{array}{c}\text { donor } \\
\text { ability }\end{array}$ \\
\hline DCM & 1.1 & 1.9 \\
thiophenol & 2.2 & 1.8 \\
$\begin{array}{l}\text { amide/phenyl- } \\
\text { amide }\end{array}$ & 8.3 & $3.3^{\text {[a] }}$ \\
$\begin{array}{l}\text { phosphonate } \\
\text { diester } \\
\text { phenol }\end{array}$ & 8.9 & $\approx 0$ \\
& 2.7 & 3.8
\end{tabular}

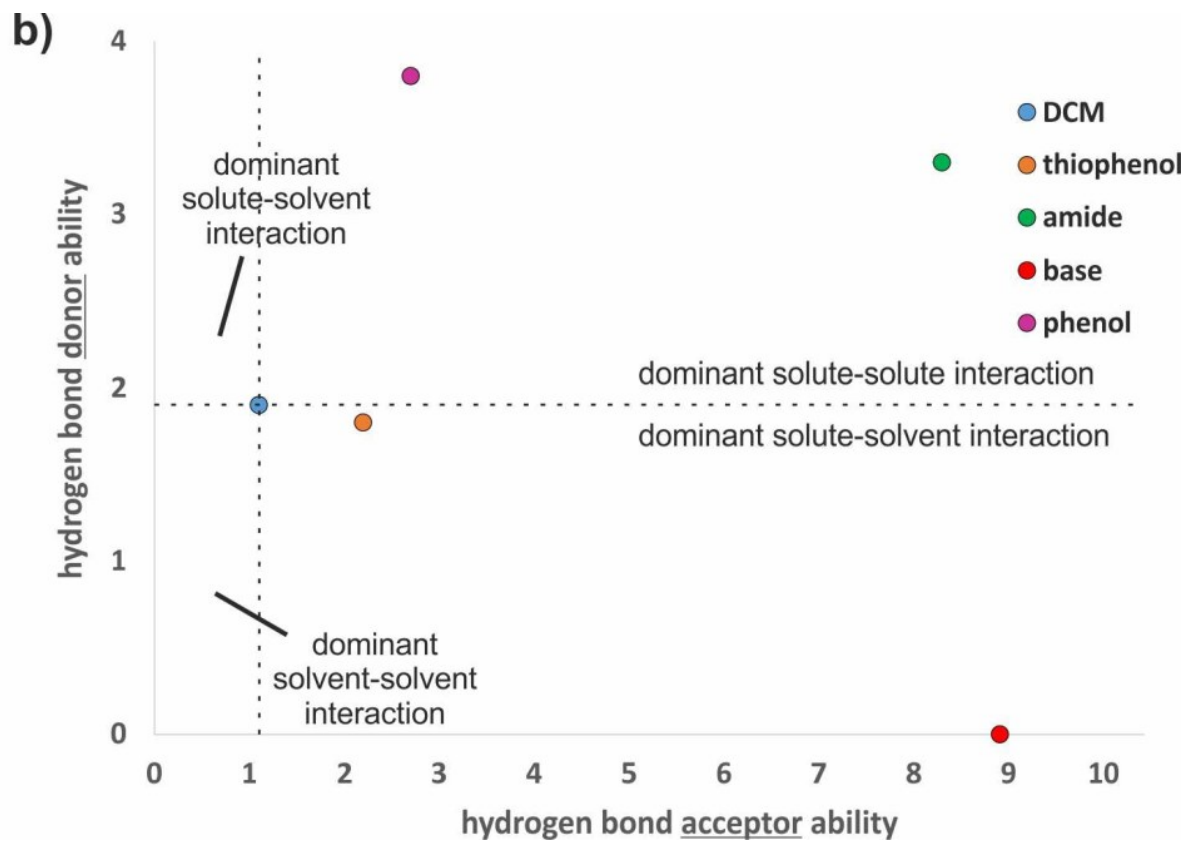

b) hydrogen bond acceptor ability

Scheme S28. a) Hydrogen bond acceptor and donor abilities of the corresponding functionalities applied for our hydrogen bond and aggregation analysis according to Hunter. ${ }^{12}$ b) The graphical presentation of the values suggests the formation of amide as well as phenol aggregates in DCM. In contrast, thiophenol and the phosponate diester as equivalent for the phosphate base are supposed to exist as monomers.

\subsection{Hydrogen bond investigations}

In the following sections, the complete NMR spectra of the different mixtures at $180 \mathrm{~K}$ are depicted and fully assigned.

\subsection{1 $\quad{ }^{1} \mathrm{H}$ NMR spectra}




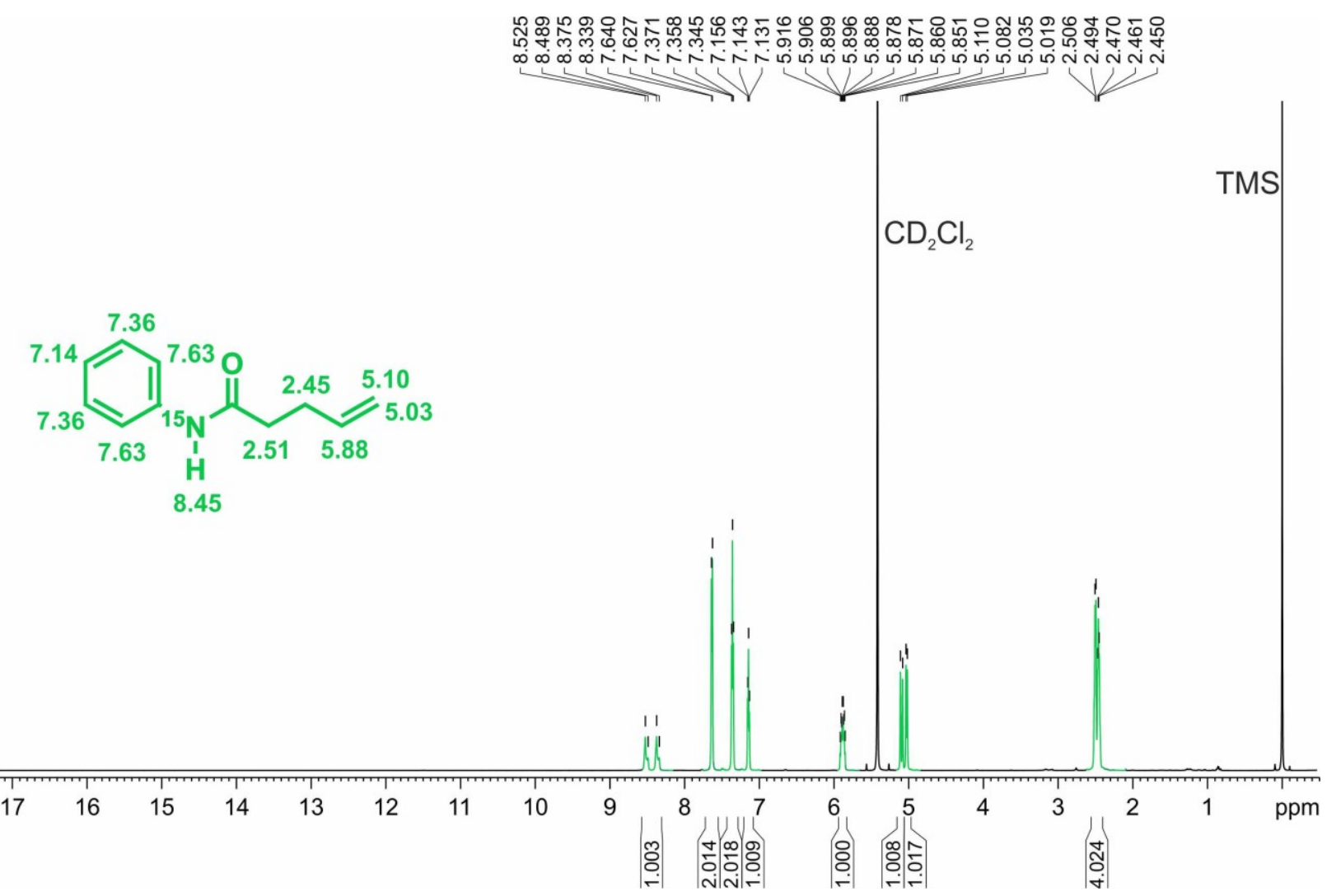

Scheme S29. Full ${ }^{1} \mathrm{H}$ NMR spectrum of ${ }^{15} \mathrm{~N}$-phenylpent-4-enamide $(50 \mathrm{mM})$ in $\mathrm{CD}_{2} \mathrm{Cl}_{2}$ at $180 \mathrm{~K}$. The chemical shifts are referenced to TMS (0 ppm).
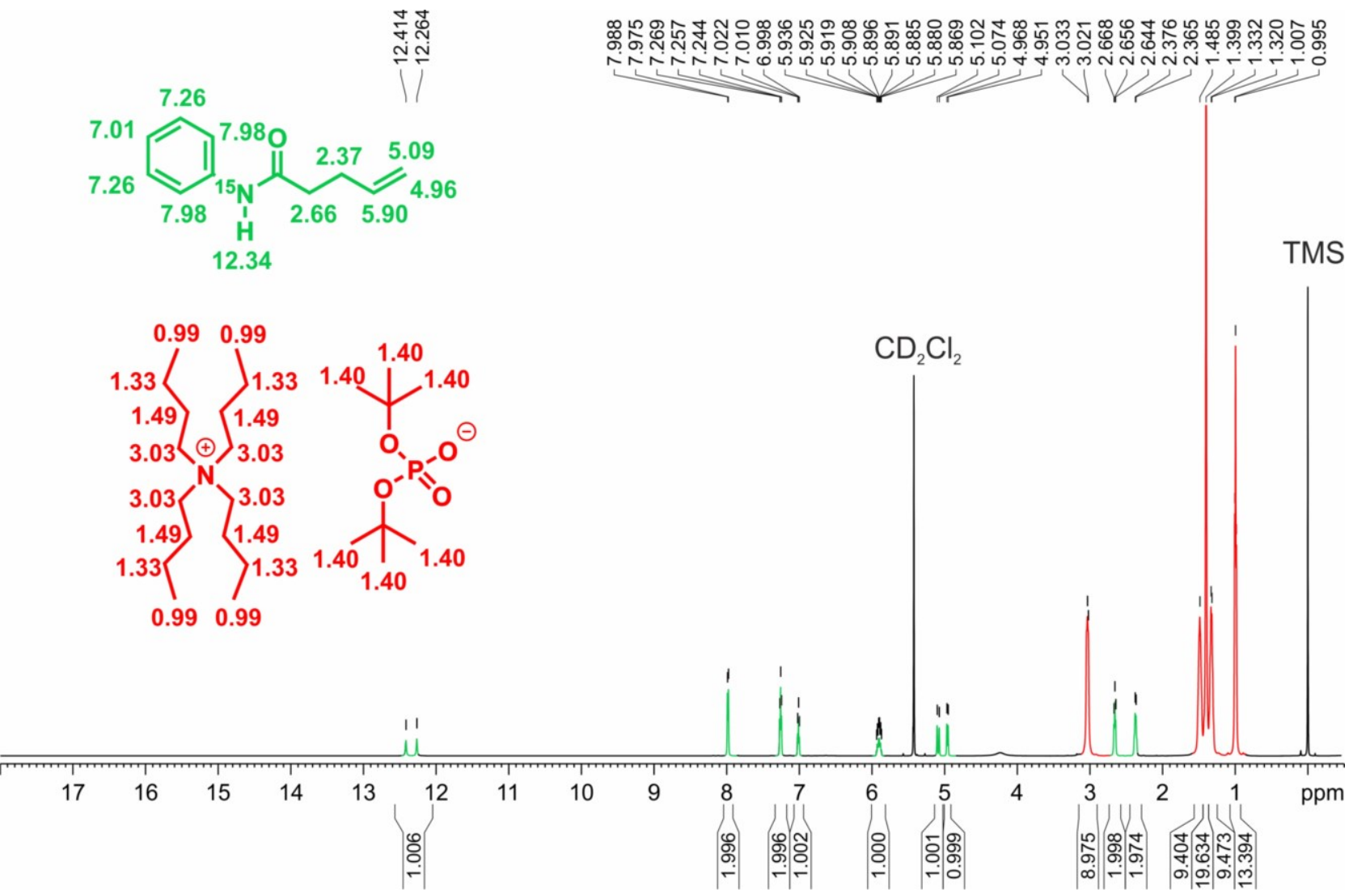

Scheme S30. Full ${ }^{1} \mathrm{H}$ NMR spectrum of the 1:1 mixture $(50 \mathrm{mM})$ of ${ }^{15} \mathrm{~N}$-phenylpent-4-enamide and tetrabutylammonium di-tertbutylphosphate in $\mathrm{CD}_{2} \mathrm{Cl}_{2}$ at $180 \mathrm{~K}$. The chemical shifts are referenced to TMS $(0 \mathrm{ppm})$. 


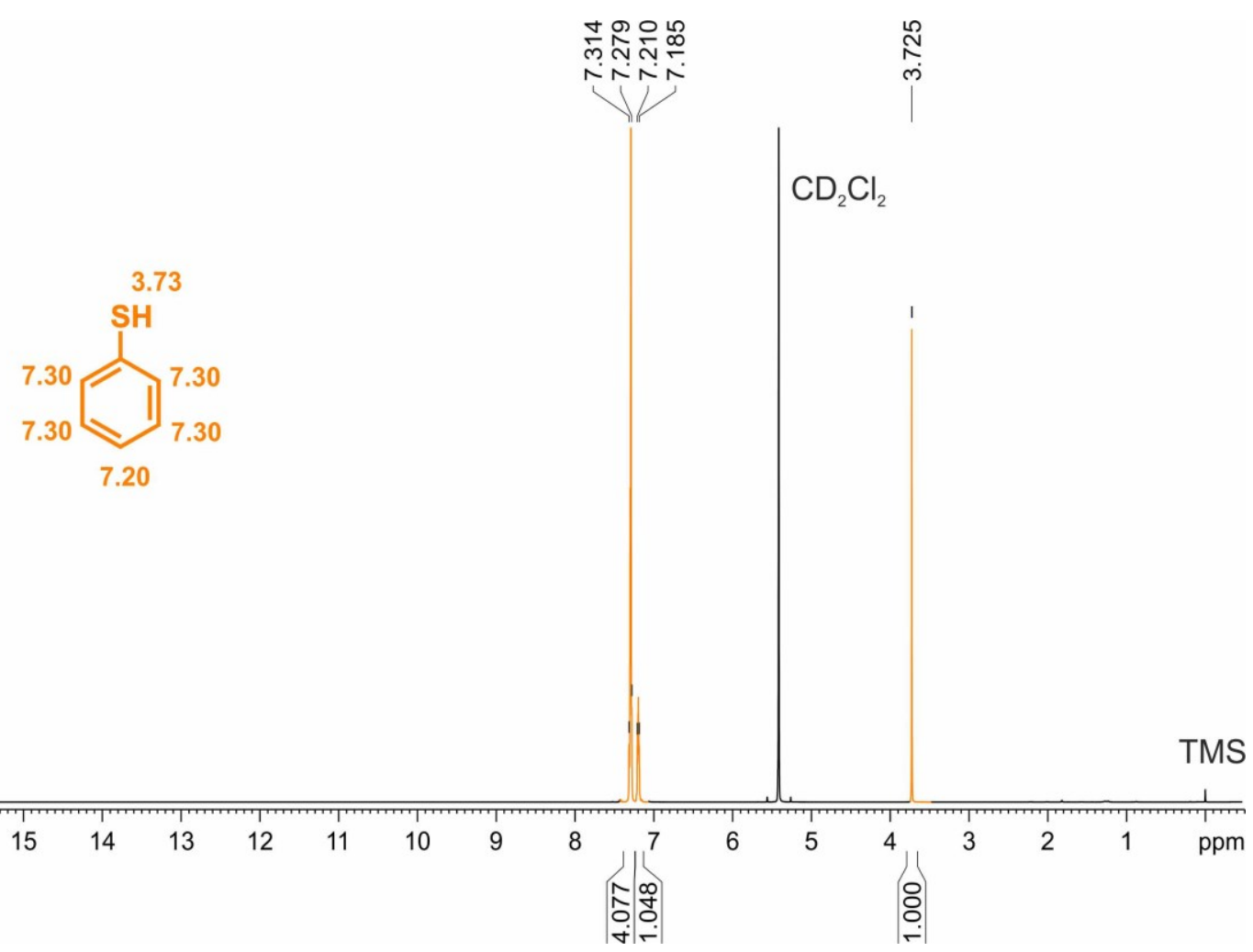

Scheme S31. Full ${ }^{1} \mathrm{H}$ NMR spectrum of thiophenol $(50 \mathrm{mM})$ in $\mathrm{CD}_{2} \mathrm{Cl}_{2}$ at $180 \mathrm{~K}$. The chemical shifts are referenced to TMS (0 ppm).
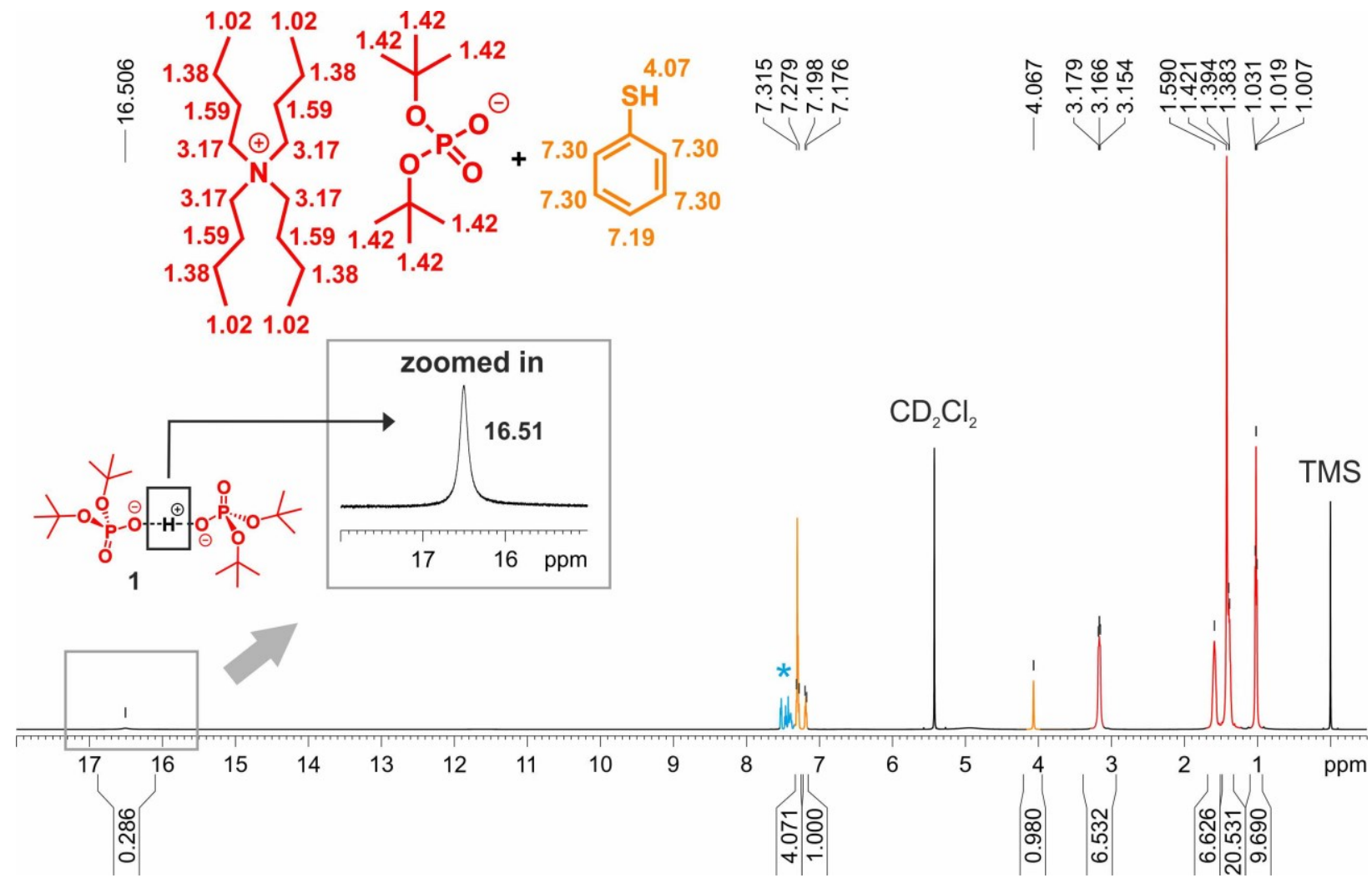

Scheme S32. Full ${ }^{1} \mathrm{H}$ NMR spectrum of the $1: 1$ mixture $(50 \mathrm{mM})$ of tetrabutylammonium di-tert-butylphosphate and $\mathrm{PhSH}$ in $\mathrm{CD}_{2} \mathrm{Cl}_{2}$ at $180 \mathrm{~K}$. For better resolution, the excerpt shows the amplified the signal at $16.51 \mathrm{ppm}$. The chemical shifts are referenced to TMS $(0 \mathrm{ppm})$. * Other thiol species formed whenever PhSH and base are present. They are discussed in chapter 4.1. 


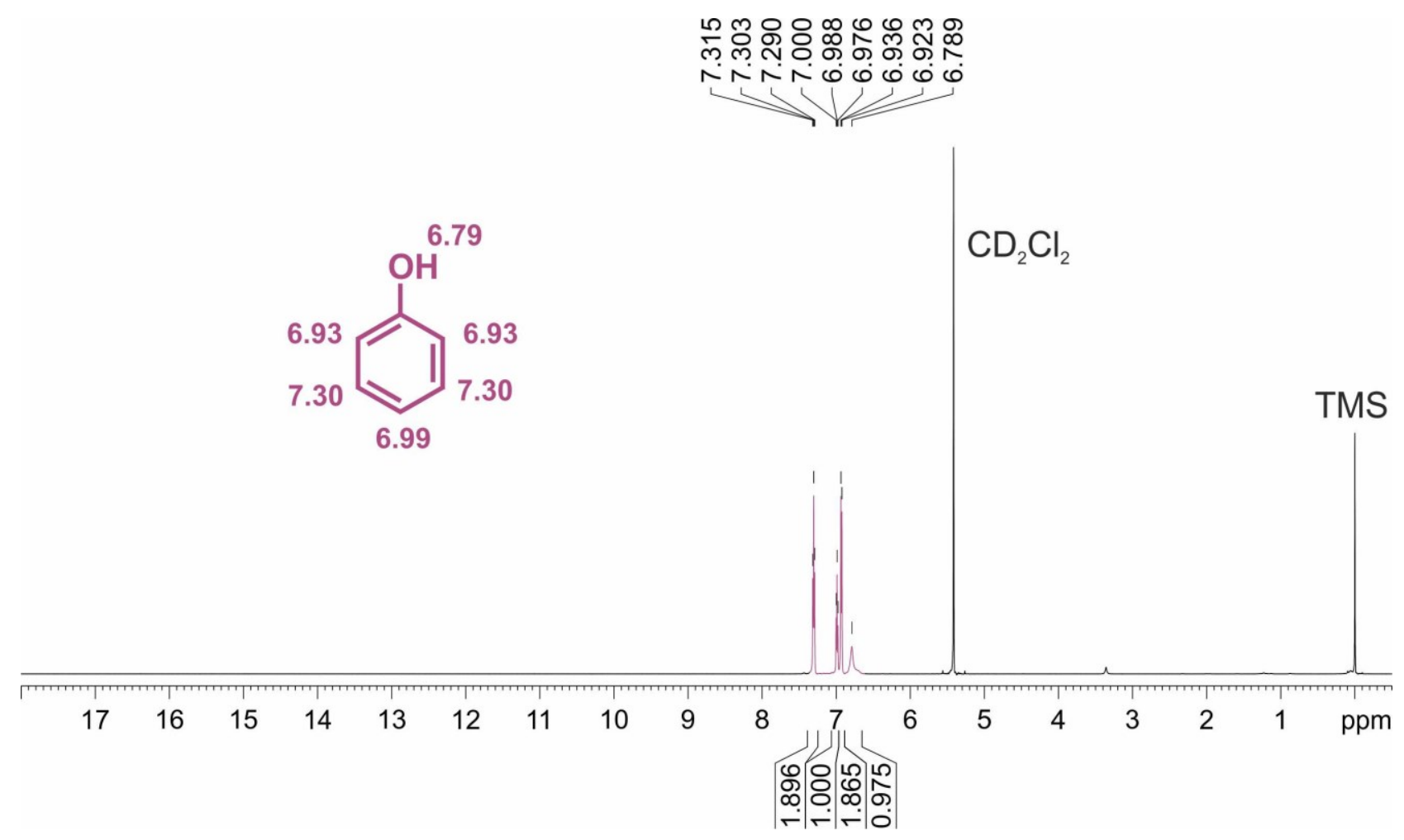

Scheme S33. Full ${ }^{1} \mathrm{H}$ NMR spectrum of phenol $(50 \mathrm{mM})$ in $\mathrm{CD}_{2} \mathrm{Cl}_{2}$ at $180 \mathrm{~K}$. The chemical shifts are referenced to TMS (0 ppm). 

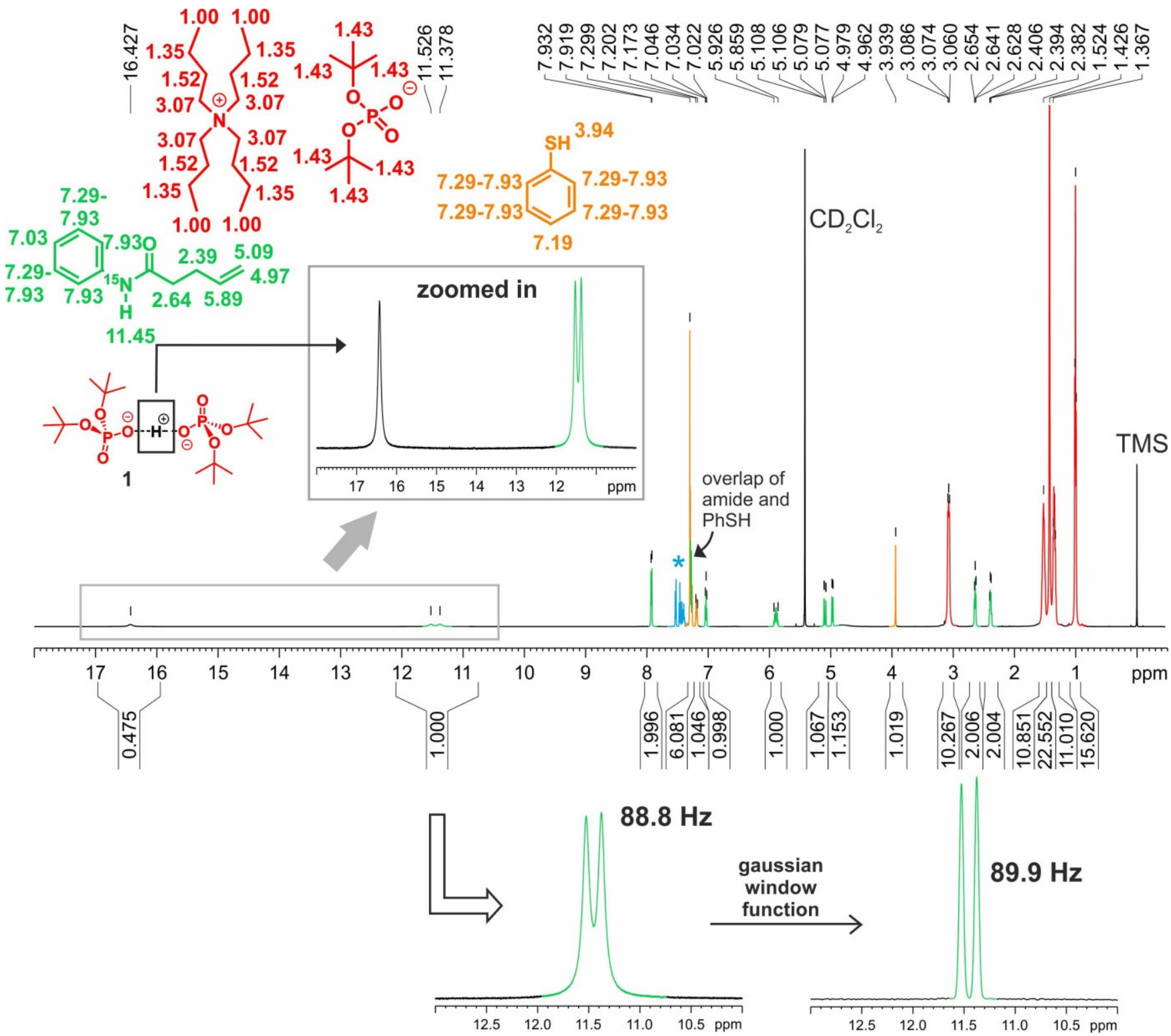

Scheme S34. Full ${ }^{1} \mathrm{H}$ NMR spectrum of the 1:1:1 mixture $(50 \mathrm{mM})$ of ${ }^{15} \mathrm{~N}$-phenylpent-4-enamide, tetrabutylammonium di-tertbutylphosphate and $\mathrm{PhSH}$ in $\mathrm{CD}_{2} \mathrm{Cl}_{2}$ at $180 \mathrm{~K}$. For better resolution, the excerpt shows the amplified the signals at 16.43 ppm and 11.45 ppm. For baseline separation of the ${ }^{15} \mathrm{~N}-\mathrm{H}$ doublet, a Gaussian window function was applied. The chemical shifts are referenced to TMS $(0$ $\mathrm{ppm}) .{ }^{*}$ Other thiol species formed whenever PhSH and base are present. They are discussed in chapter 4.1. 


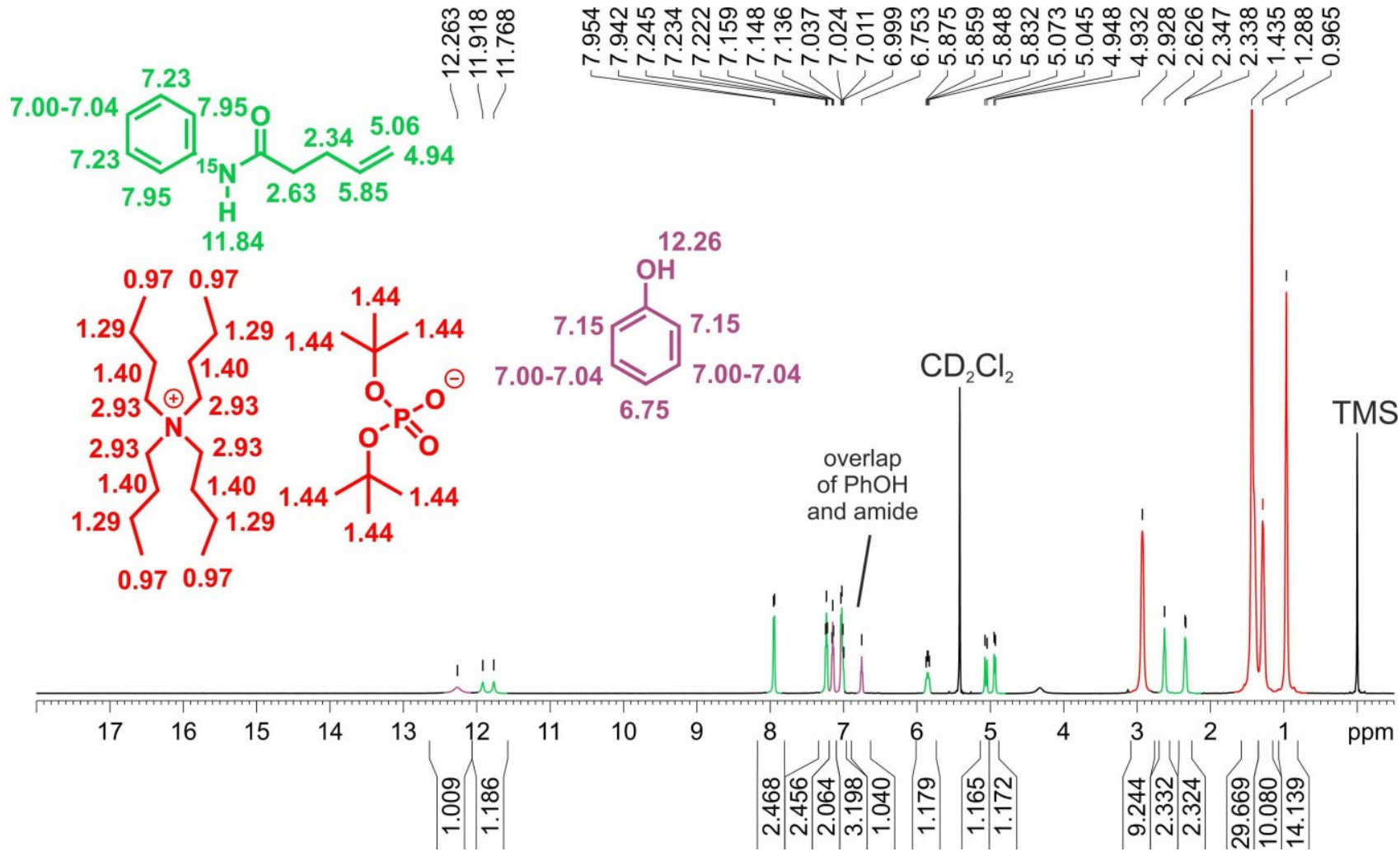

Scheme S35. Full ${ }^{1} \mathrm{H}$ NMR spectrum of the 1:1:1 mixture $(50 \mathrm{mM})$ of ${ }^{15} \mathrm{~N}$-phenylpent-4-enamide, tetrabutylammonium di-tertbutylphosphate and $\mathrm{PhOH}$ in $\mathrm{CD}_{2} \mathrm{Cl}_{2}$ at $180 \mathrm{~K}$. The chemical shifts are referenced to TMS $(0 \mathrm{ppm})$.
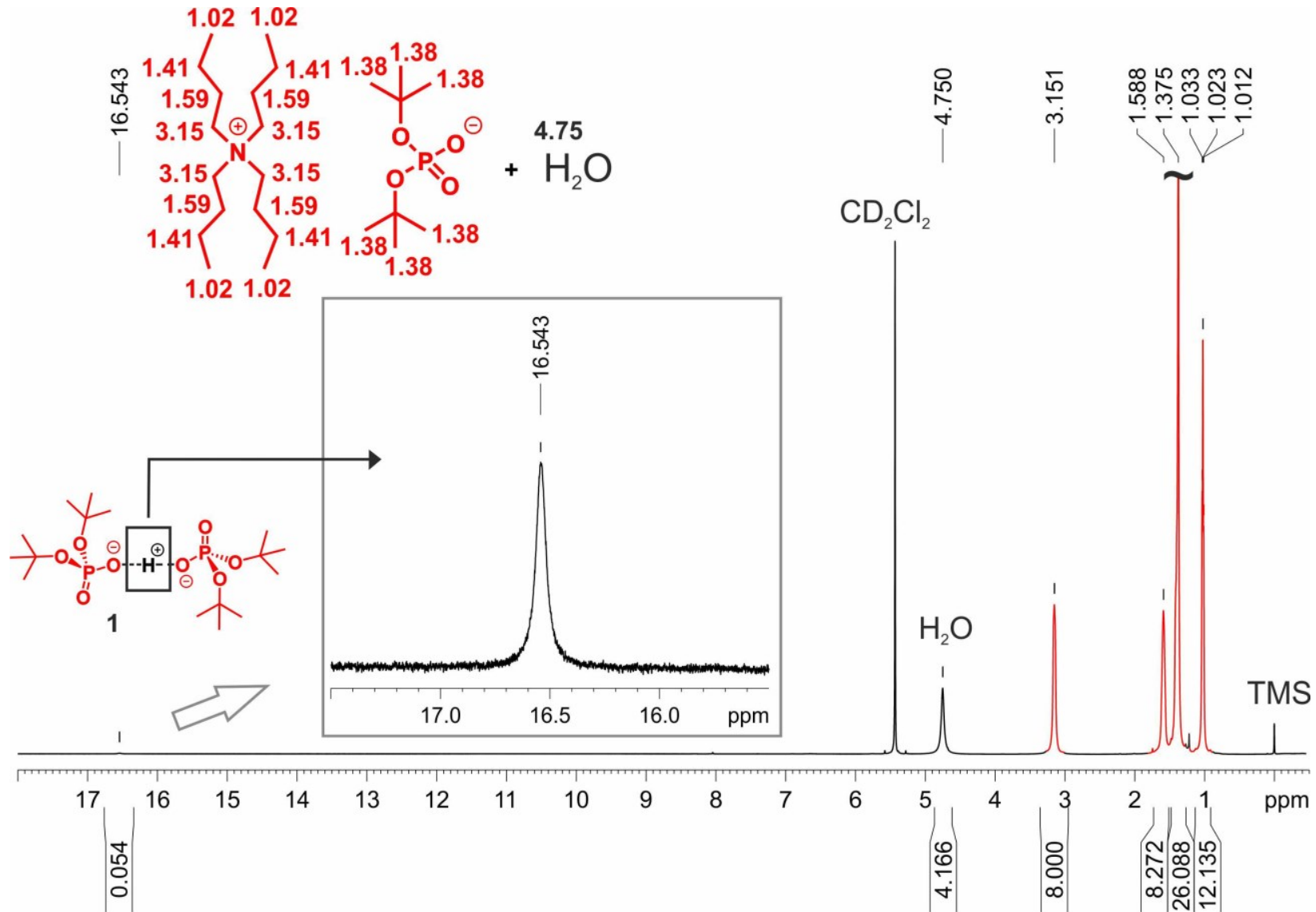

Scheme S36. Full ${ }^{1} \mathrm{H}$ NMR spectrum of tetrabutylammonium di-tert-butylphosphate $(50 \mathrm{mM})$ and $\mathrm{H}_{2} \mathrm{O}\left(45\right.$ equiv.) in $\mathrm{CD}_{2} \mathrm{Cl}_{2}$ at $180 \mathrm{~K}$. For better resolution, the excerpt shows the amplified the signal at $16.54 \mathrm{ppm}$. The chemical shifts are referenced to TMS (0 ppm). 


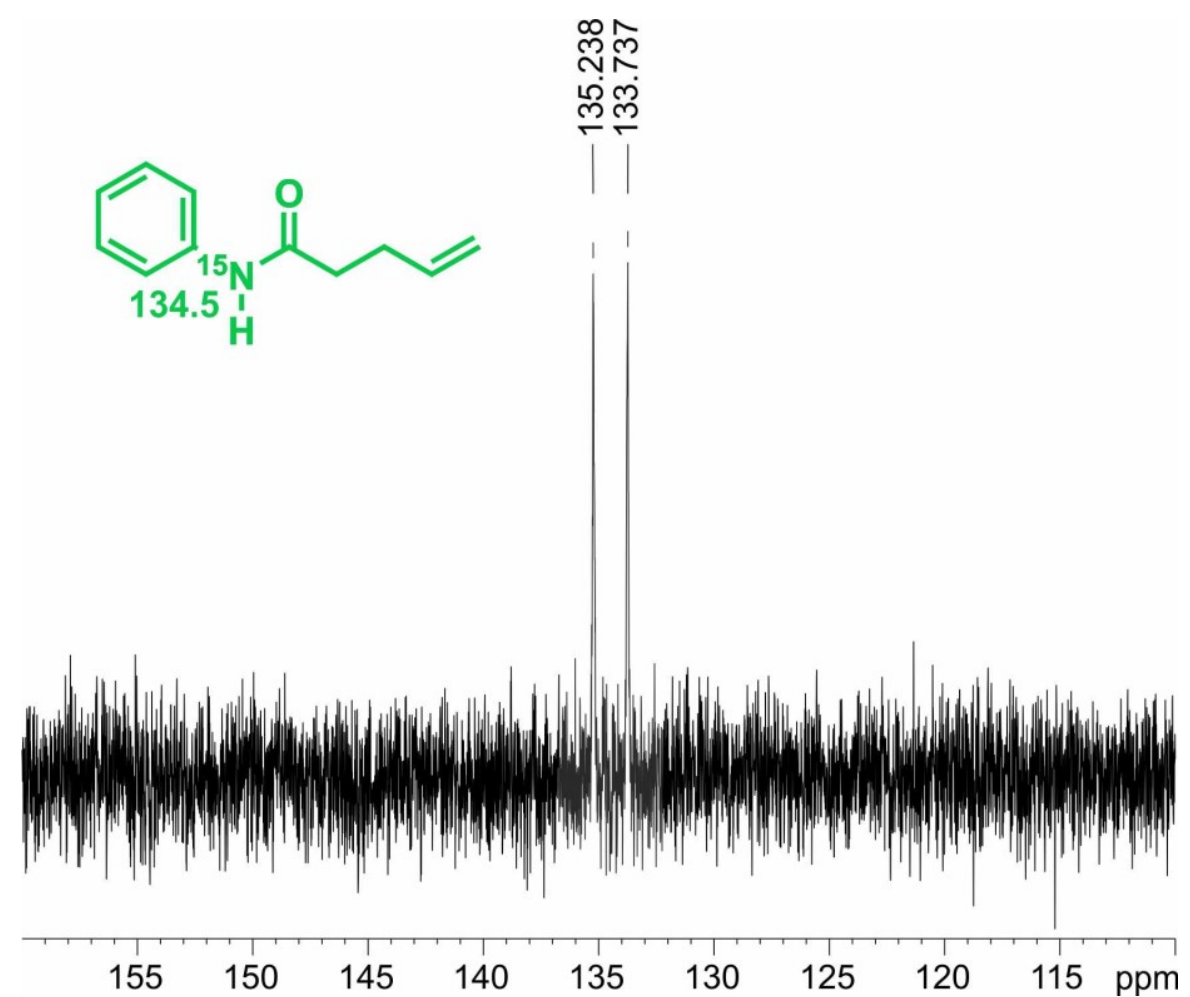

Scheme S37. Full ${ }^{15} \mathrm{~N}$ NMR spectrum of ${ }^{15} \mathrm{~N}$-phenylpent-4-enamide $(50 \mathrm{mM})$ in $\mathrm{CD}_{2} \mathrm{Cl}_{2}$ at $180 \mathrm{~K}$. The chemical shifts are referenced using the ${ }^{1} \mathrm{H}$ resonance of TMS according to the method of Harris et $a l .{ }^{6}$

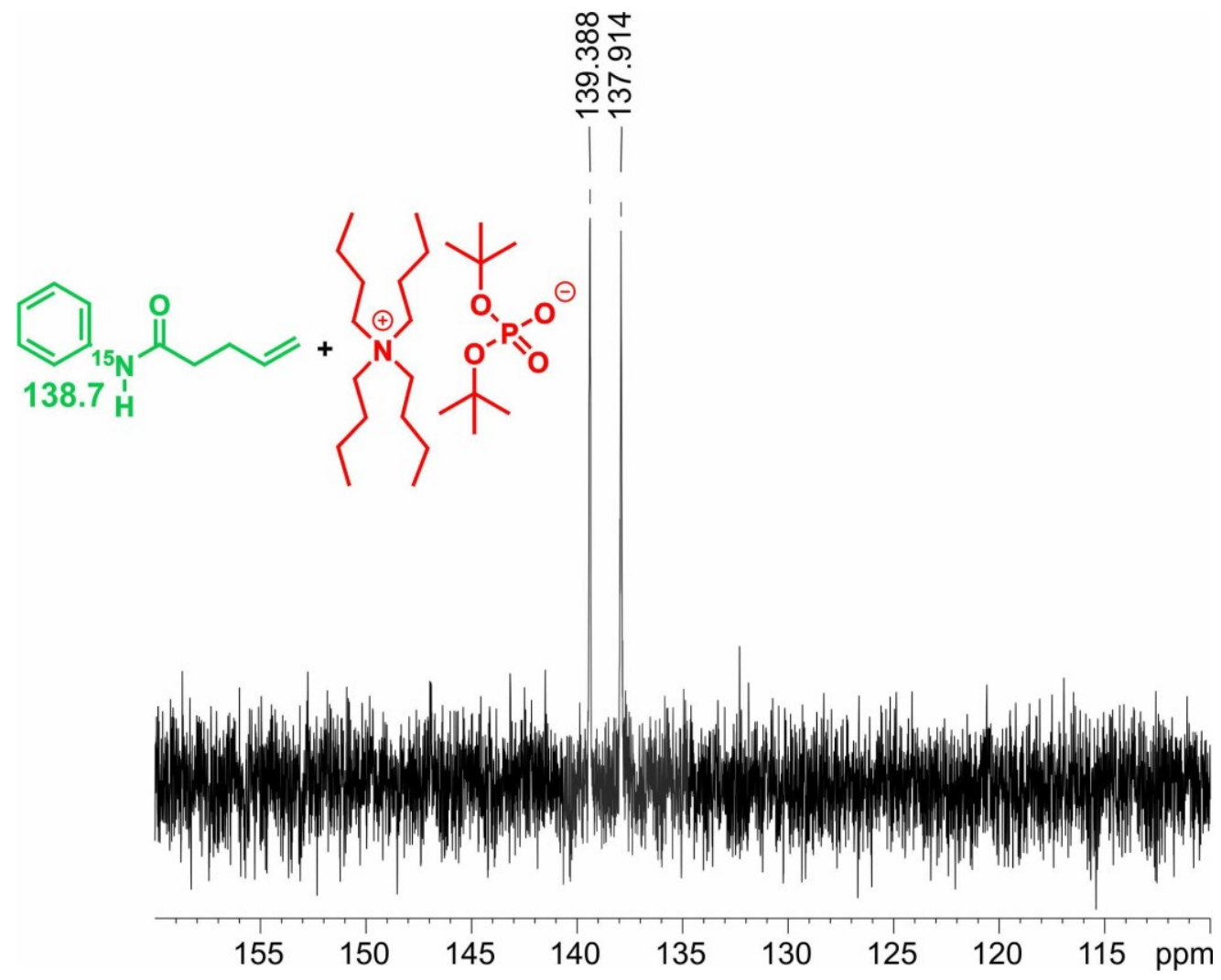

Scheme S38. Full ${ }^{15} \mathrm{~N}$ NMR spectrum of the $1: 1$ mixture $(50 \mathrm{mM})$ of ${ }^{15} \mathrm{~N}$-phenylpent-4-enamide and tetrabutylammonium di-tertbutylphosphate in $\mathrm{CD}_{2} \mathrm{Cl}_{2}$ at $180 \mathrm{~K}$. The chemical shifts are referenced using the ${ }^{1} \mathrm{H}$ resonance of TMS according to the method of Harris et $a l .6$ 


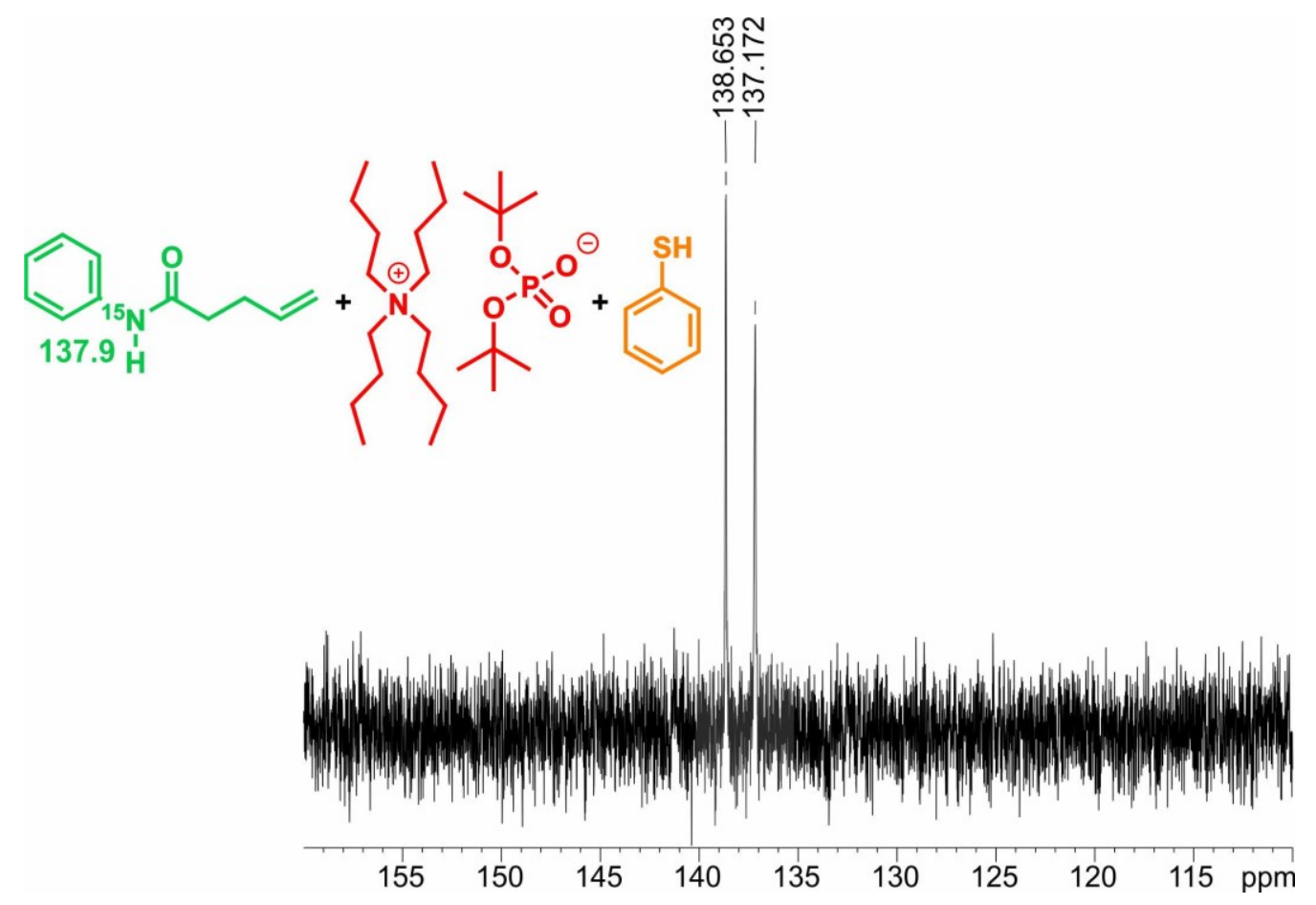

Scheme S39. Full ${ }^{15} \mathrm{~N}$ NMR spectrum of the 1:1:1 mixture $(50 \mathrm{mM})$ of ${ }^{15} \mathrm{~N}$-phenylpent-4-enamide, tetrabutylammonium di-tertbutylphosphate and $\mathrm{PhSH}$ in $\mathrm{CD}_{2} \mathrm{Cl}_{2}$ at $180 \mathrm{~K}$. The chemical shifts are referenced using the ${ }^{1} \mathrm{H}$ resonance of TMS according to the method of Harris et $a .^{6}$

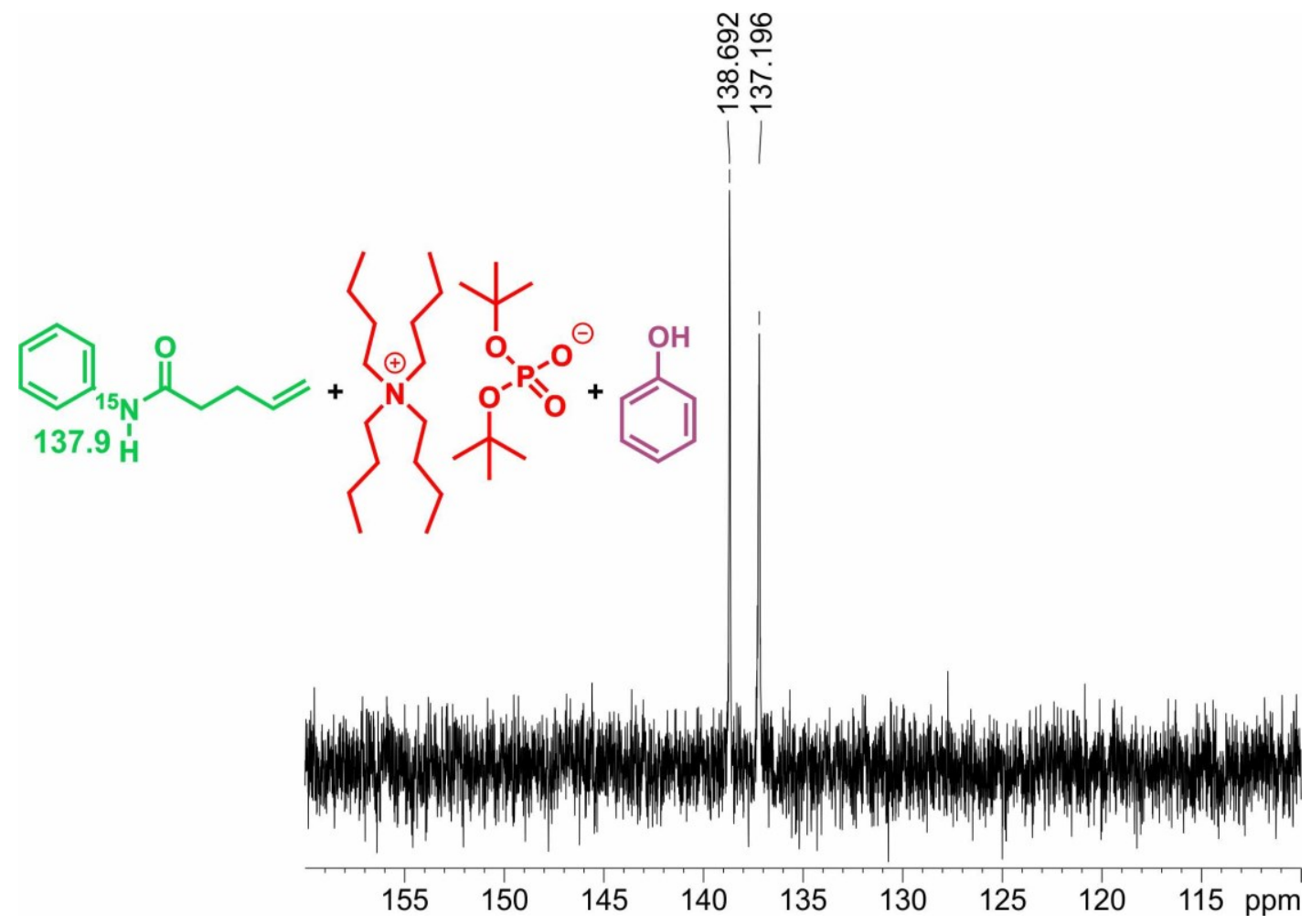

Scheme S40. Full ${ }^{15} \mathrm{~N}$ NMR spectrum of the 1:1:1 mixture $(50 \mathrm{mM})$ of ${ }^{15} \mathrm{~N}$-phenylpent-4-enamide, tetrabutylammonium di-tertbutylphosphate and $\mathrm{PhOH}$ in $\mathrm{CD}_{2} \mathrm{Cl}_{2}$ at $180 \mathrm{~K}$. The chemical shifts are referenced using the ${ }^{1} \mathrm{H}$ resonance of TMS according to the method of Harris et $a .^{6}$ 


\subsection{3 $\quad{ }^{31} \mathrm{P}$ NMR spectra}

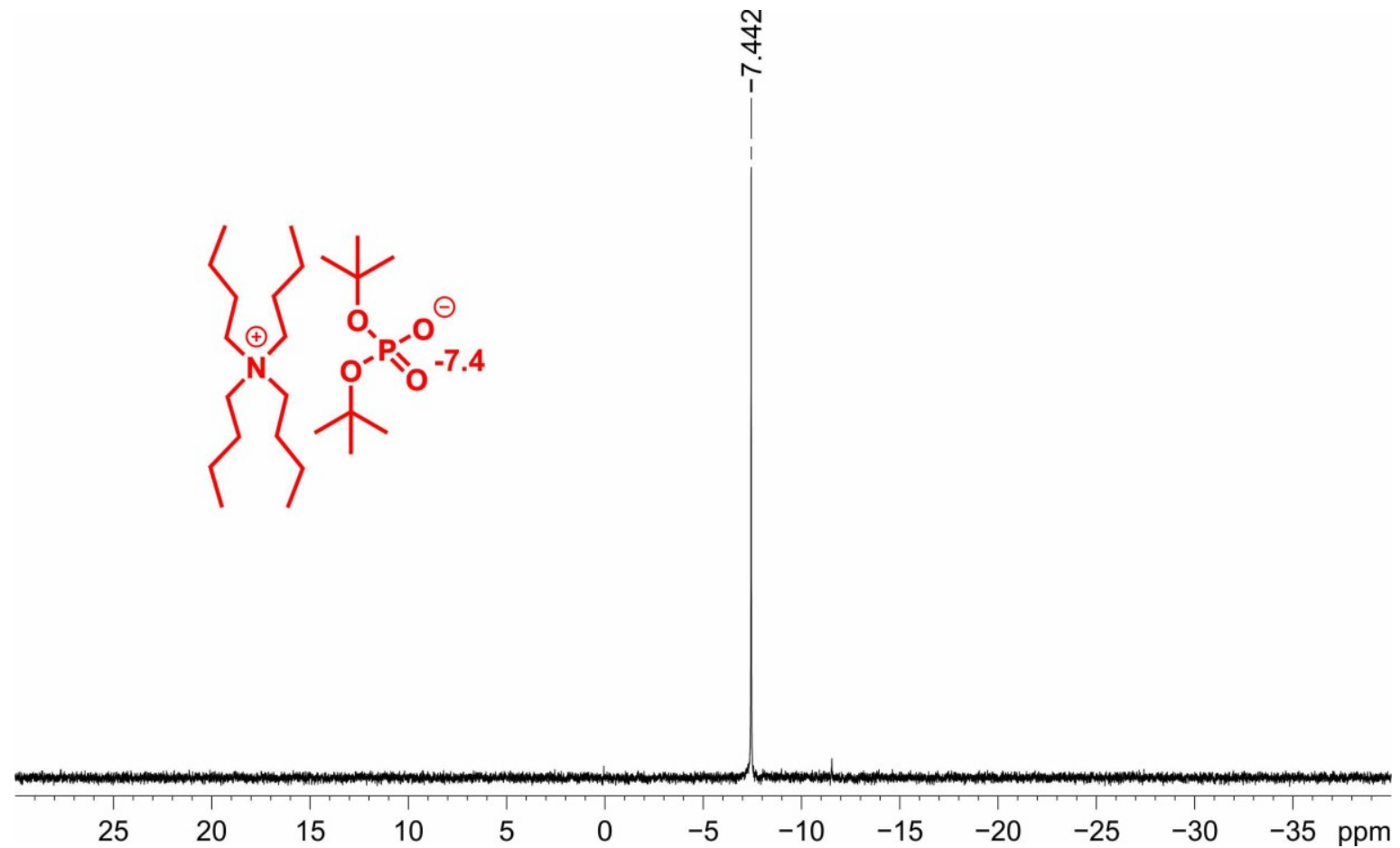

Scheme S41. Full ${ }^{31} \mathrm{P}$ NMR spectrum of tetrabutylammonium di-tert-butylphosphate $(50 \mathrm{mM})$ in $\mathrm{CD}_{2} \mathrm{Cl}_{2}$ at $180 \mathrm{~K}$. The chemical shifts are referenced using the ${ }^{1} \mathrm{H}$ resonance of TMS according to the method of Harris et $a l^{6}{ }^{6}$

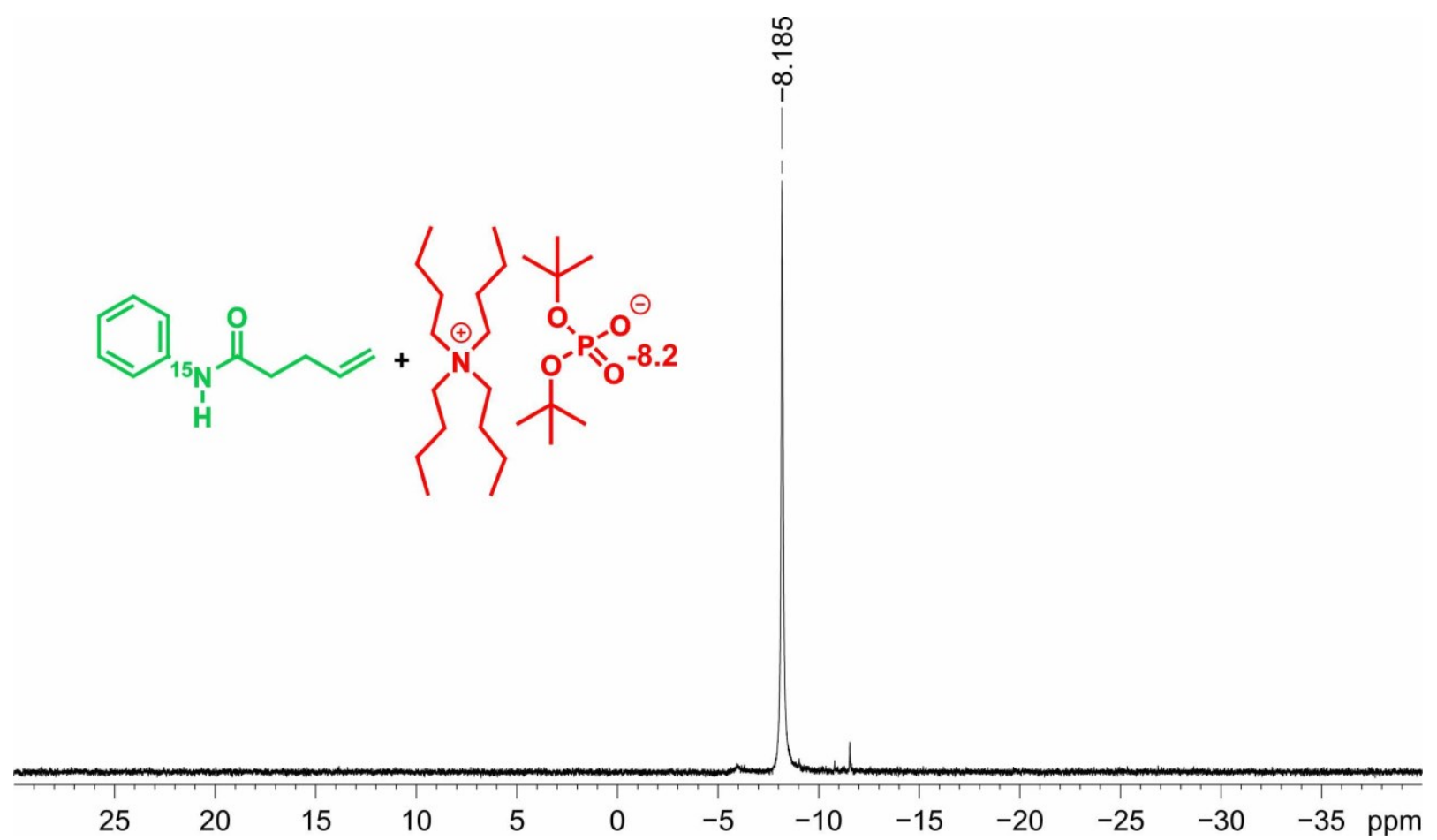

Scheme S42. Full ${ }^{31} \mathrm{P}$ NMR spectrum of the $1: 1$ mixture $(50 \mathrm{mM})$ of ${ }^{15} \mathrm{~N}$-phenylpent-4-enamide and tetrabutylammonium di-tertbutylphosphate in $\mathrm{CD}_{2} \mathrm{Cl}_{2}$ at $180 \mathrm{~K}$. The chemical shifts are referenced using the ${ }^{1} \mathrm{H}$ resonance of TMS according to the method of Harris et $a .^{6}$ 


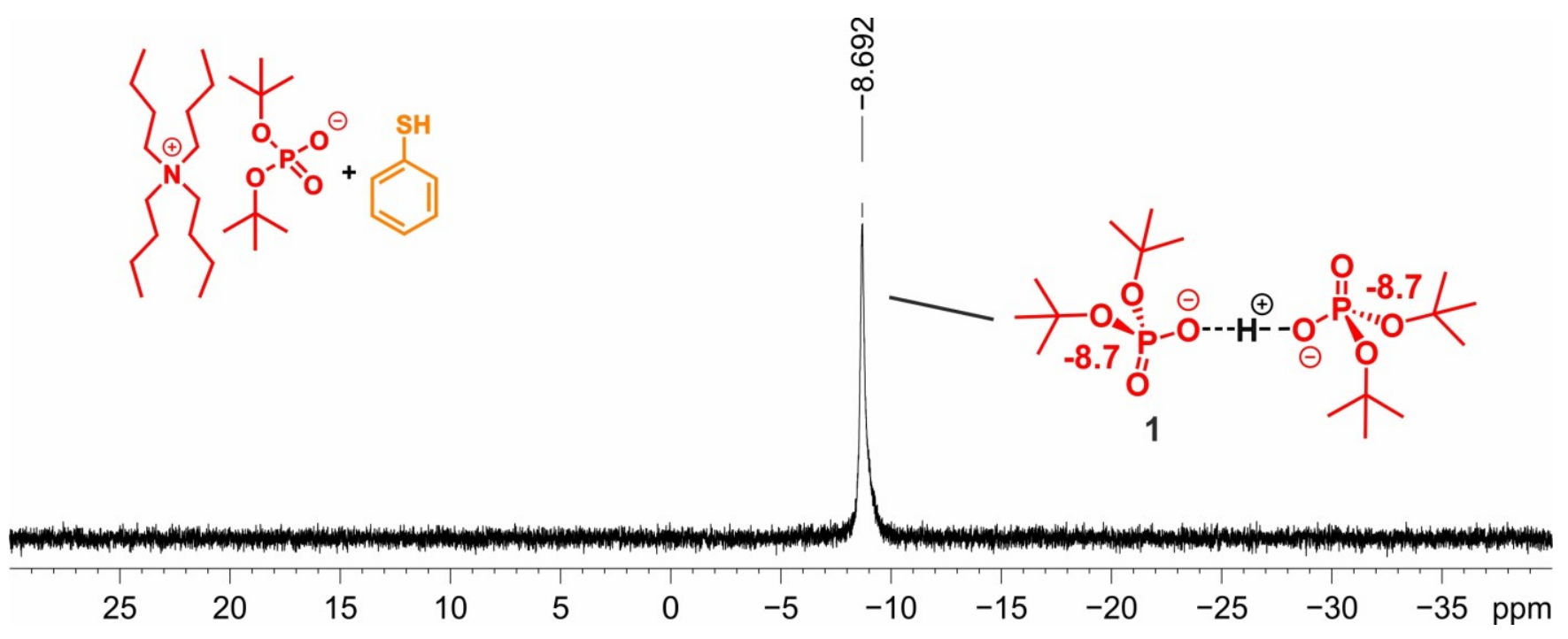

Scheme S43. Full ${ }^{31} \mathrm{P}$ NMR spectrum of the $1: 1$ mixture $(50 \mathrm{mM})$ of tetrabutylammonium di-tert-butylphosphate and $\mathrm{PhSH}$ in $\mathrm{CD}_{2} \mathrm{Cl}_{2}$ at $180 \mathrm{~K}$. The chemical shifts are referenced using the ${ }^{1} \mathrm{H}$ resonance of TMS according to the method of Harris et $a l^{6}{ }^{6}$

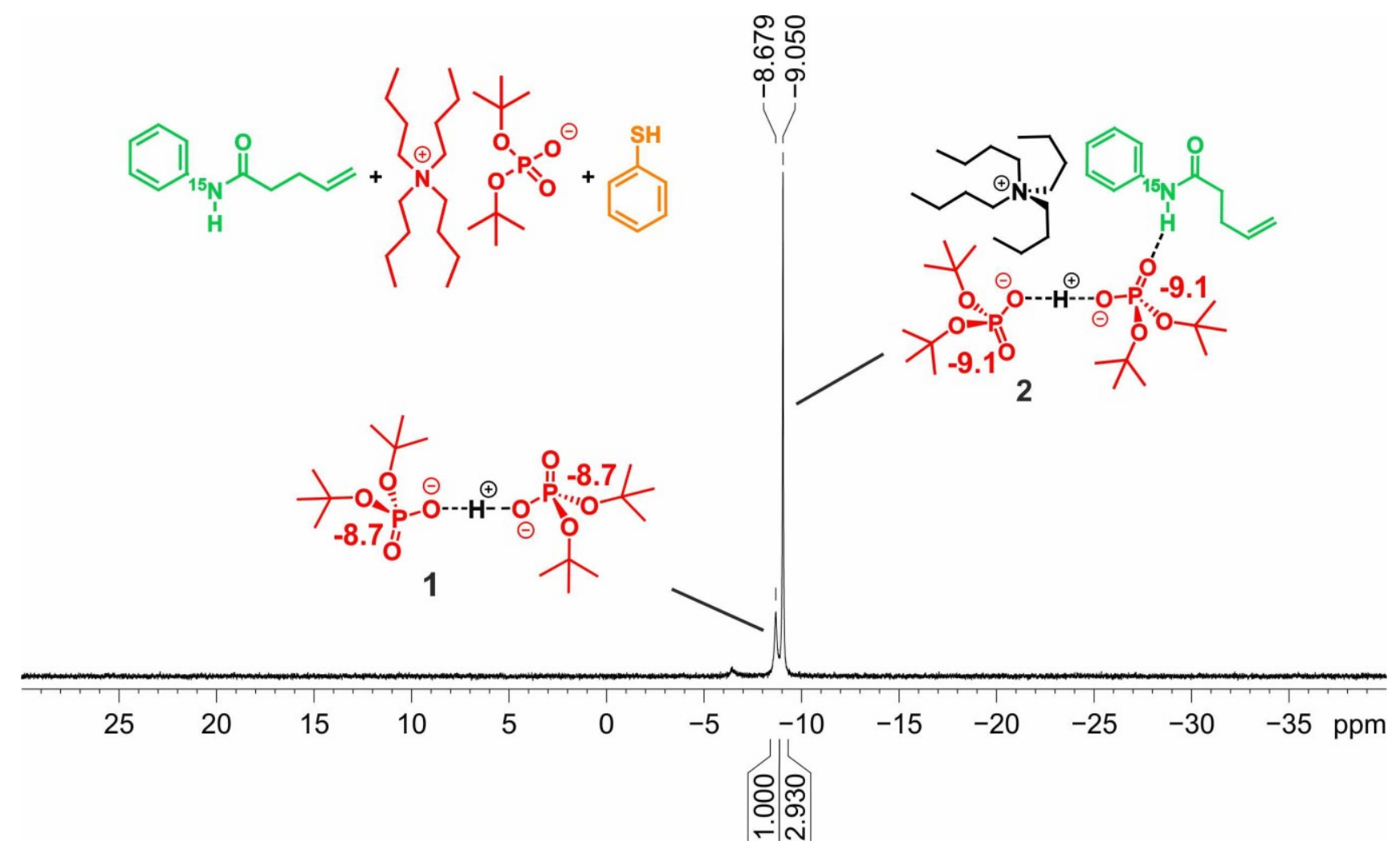

Scheme S44. Full ${ }^{31} \mathrm{P}$ NMR spectrum of the 1:1:1 mixture $(50 \mathrm{mM})$ of ${ }^{15} \mathrm{~N}$-phenylpent-4-enamide, tetrabutylammonium di-tertbutylphosphate and $\mathrm{PhSH}$ in $\mathrm{CD}_{2} \mathrm{Cl}_{2}$ at $180 \mathrm{~K}$. The chemical shifts are referenced using the ${ }^{1} \mathrm{H}$ resonance of TMS according to the method of Harris et $a l^{6}$ 


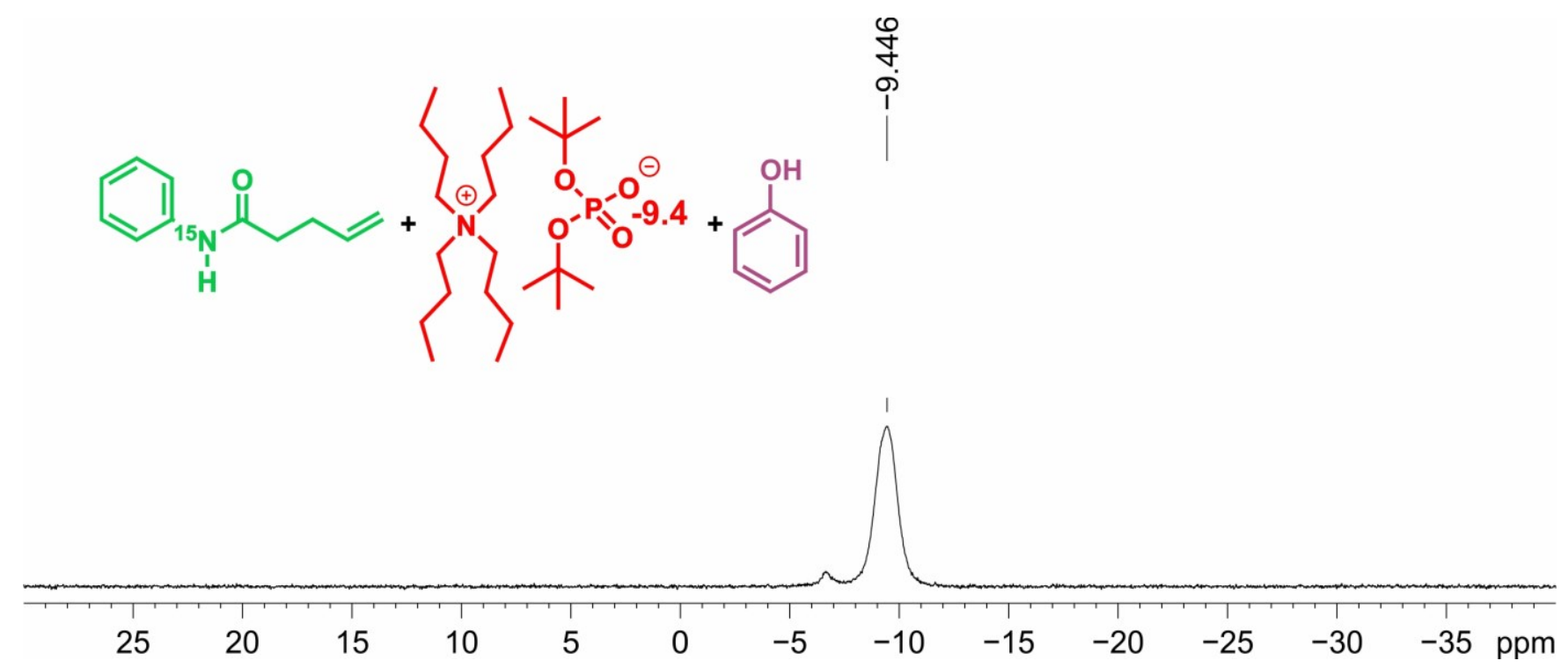

Scheme S45. Full ${ }^{31} \mathrm{P}$ NMR spectrum of the 1:1:1 mixture $(50 \mathrm{mM})$ of ${ }^{15} \mathrm{~N}$-phenylpent-4-enamide, tetrabutylammonium di-tertbutylphosphate and $\mathrm{PhOH}$ in $\mathrm{CD}_{2} \mathrm{Cl}_{2}$ at $180 \mathrm{~K}$. The chemical shifts are referenced using the ${ }^{1} \mathrm{H}$ resonance of TMS according to the method of Harris et $a l .{ }^{6}$ The broad signal hit at the formation of a large phenol involved aggregate.

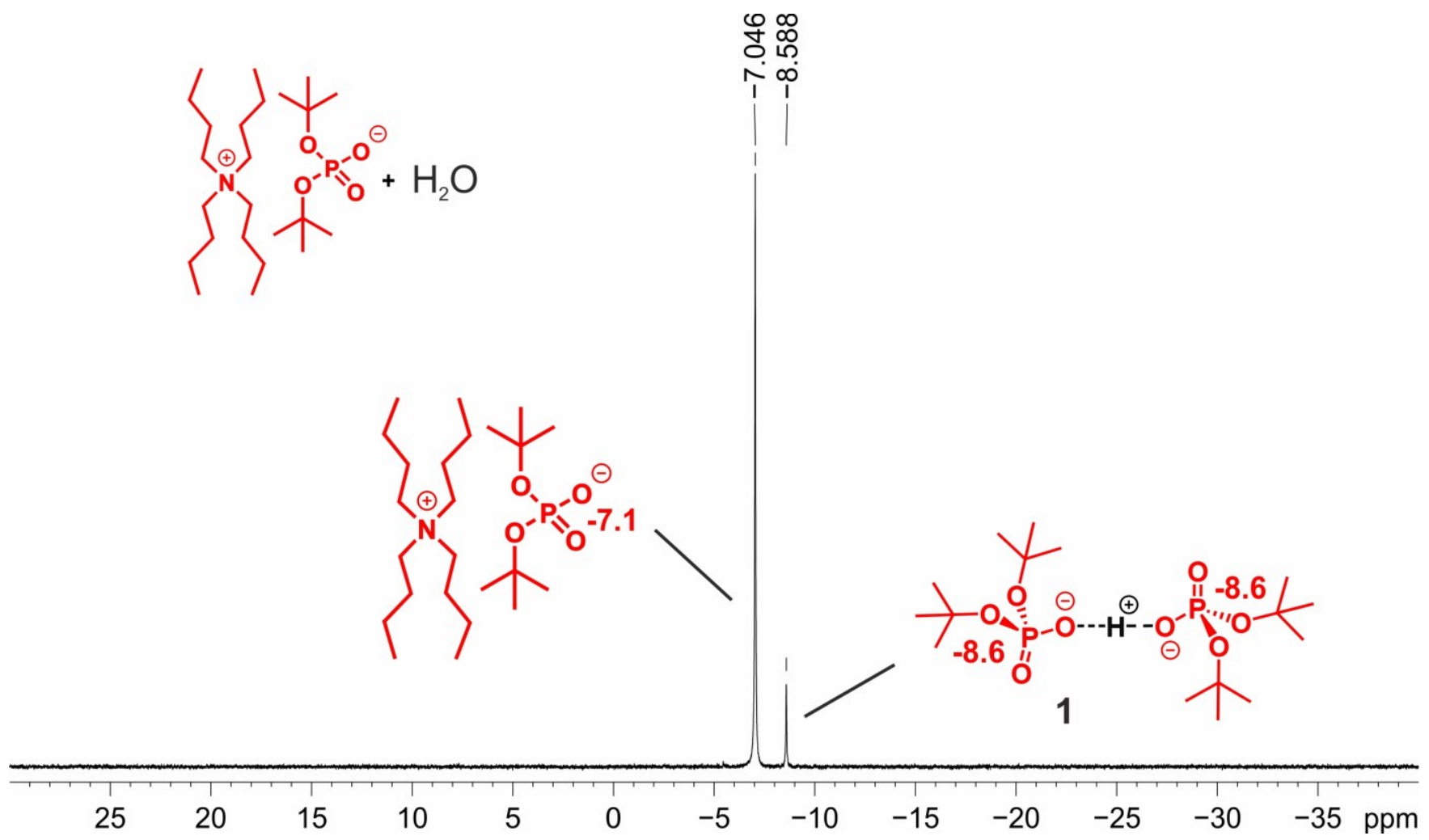

Scheme S46. Full ${ }^{31} \mathrm{P}$ NMR spectrum of tetrabutylammonium di-tert-butylphosphate $(50 \mathrm{mM})$ and $\mathrm{H}_{2} \mathrm{O}\left(45\right.$ equiv.) in $\mathrm{CD}_{2} \mathrm{Cl}_{2}$ at $180 \mathrm{~K}$. The chemical shifts are referenced using the ${ }^{1} \mathrm{H}$ resonance of TMS according to the method of Harris et $a l .{ }^{6}$ 


\subsection{Analysis of the aggregates}

\subsubsection{Identification of the ${ }^{1} \mathrm{H}$ exchange signals}

In order to identify the crucial aggregate being responsible for the effective PCET mediated hydroamidation, the complexation behavior of the reaction system containing amide, base and thiophenol is elucidated in detail in this chapter. The protonation of the phosphate base by thiophenol furnishing the phosphate dimer 1 was already described in chapter 4.1, but its generation as crucial requirement for an efficient photoredox catalytic reaction will be discussed in the following section.

Exchangeable protons inside hydrogen bonds can usually be detected as broad singlets in a ${ }^{1} \mathrm{H}$ spectrum and their chemical shifts are very sensitive to the corresponding surroundings. As these non-covalent interactions are the key to effective PCET, the analysis of these protons helps for the identification of the reactive aggregate.

In Scheme S47, the ${ }^{1} \mathrm{H}$ spectra of the different phosphate containing samples are depicted and the signals referring to exchange protons are highlighted. For complete spectra, see chapter 4.5.1. As already mentioned in section 4.1, the proton inside phosphate dimer 1 (blue), which can also be formed after adding $\mathrm{H}_{2} \mathrm{O}$ to $\mathrm{PhSH}$ (Figure 3a/b, main text; and Scheme S46), corresponds to the signal at 16.43-16.56 ppm. For the pure base containing sample and the amide/base mixture, this complex is already visible in very tiny amounts (compare proton at 16.56 ppm with ${ }^{13} \mathrm{C}$ satellites of $\mathrm{CD}_{2} \mathrm{Cl}_{2}$ in spectrum at the top in Scheme S47). In presence of $\mathrm{PhSH}$ the signal is immensely increased, which argues for the dimer being a central compound in the reaction mixture. In addition, the strong low field position argues for a drastical electron reorganization in the complex having major impact on the reactivity. Importantly, this aggregation motif cannot be generated in presence of $\mathrm{PhOH}$ as hydrogen atom donor (see discussion in the main text). The influence of the chemical environment was also investigated for the chemical shift of residual $\mathrm{H}_{2} \mathrm{O}$ (orange), which is present in all base containing mixtures despite drying the phosphate salt and $\mathrm{CD}_{2} \mathrm{Cl}_{2}$ prior to use. Comparing the orange highlighted signals, $\mathrm{H}_{2} \mathrm{O}$ is shifted to $4.95 \mathrm{ppm}$ at maximum indicating the formation of bulk water inside the samples (the solvent residual signal of $\mathrm{D}_{2} \mathrm{O}$ is $4.79 \mathrm{ppm}^{1}$ ). Even the addition of amide has no further effect on the water chemical shift and thus this demonstrates no significant interaction with phosphate and therefore no influence on the main aggregation. Furthermore, a small amount of $\mathrm{H}_{2} \mathrm{O}$ seems to be attached to phosphate as a signal at 6.62-6.65 ppm is visible (green) for all samples except the pure base. But this signal is small even for the amide/base/PhSH mixture and its chemical shift is only barely changed indicating no influence on the crucial complex. For the $\mathrm{PhSH} / \mathrm{base}$ sample, an additional but small signal at $11.62 \mathrm{ppm}$ is generated (yellow), which is either absent after adding the amide or overlaps with the ${ }^{15} \mathrm{~N}-\mathrm{H}$ doublet. As this signal is low field shifted in comparison to the $\mathrm{H}_{2} \mathrm{O}$ related singlets, we think a hydrogen bond between the generated thiophenolate and the phosphate is generated, which anyways has no influence on the amide-phosphate interaction and it is present in low concentration.

In total, from the chemical shifts and signal intensities, only the formation of phosphate dimer $\mathbf{1}$ has influence on the amide/base/PhSH mixture. 


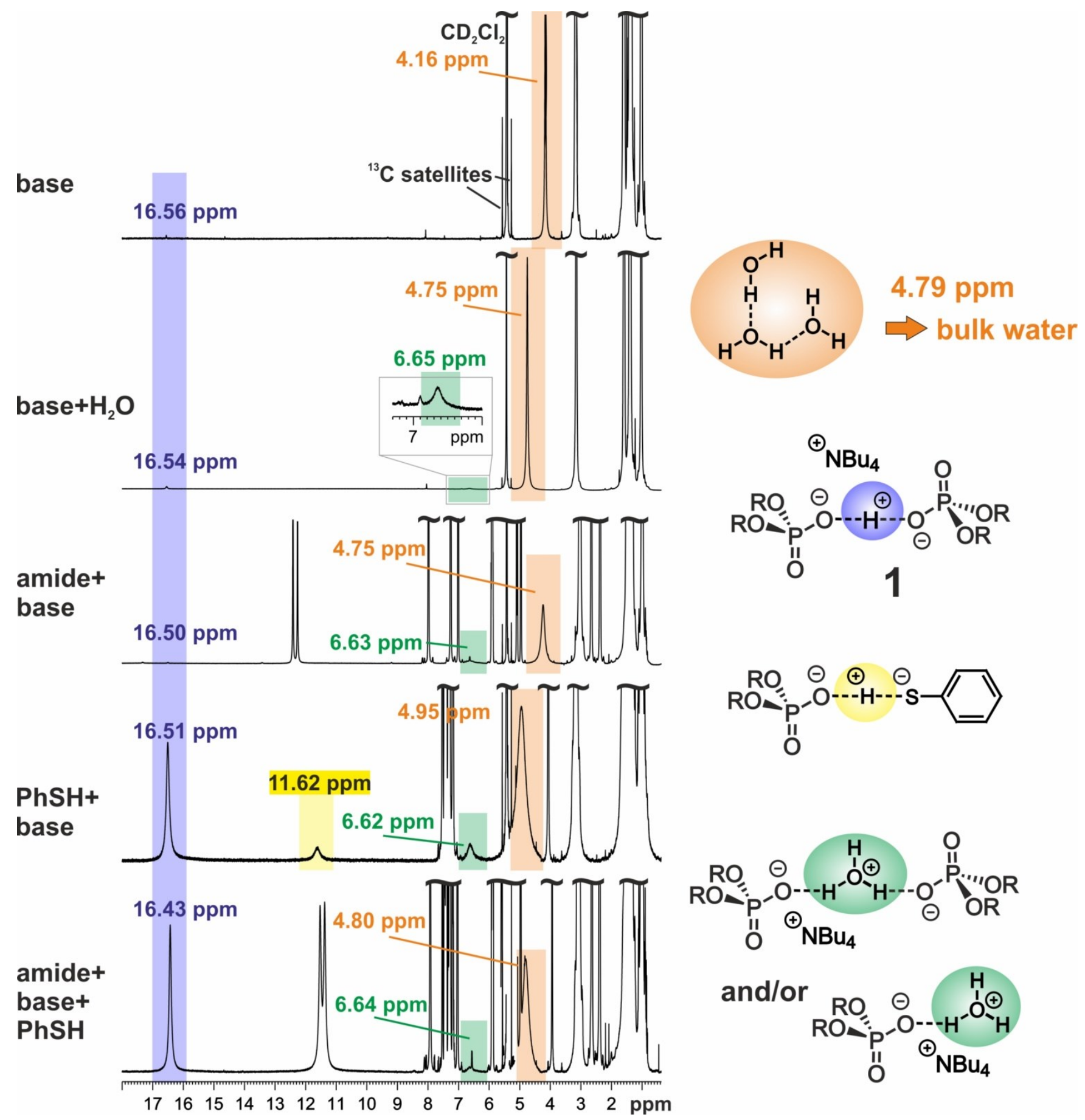

Scheme S47. An excerpt of the ${ }^{1} \mathrm{H}$ spectra of pure base, base $/ \mathrm{H}_{2} \mathrm{O}$, amide/base, $\mathrm{PhSH} / \mathrm{base}$ and amide/base/PhSH samples is depicted and the exchange protons are highlighted and corresponding proposed complex structures are given. 


\subsubsection{Diffusion ordered spectroscopy (DOSY)}

\section{Spectroscopic details:}

The ${ }^{1} \mathrm{H}$-diffusion measurements were performed with the convection suppressing DSTE (double stimulated echo) pulse sequence, developed by Müller and Jerschow in a pseudo 2D mode. ${ }^{13}$ Tetramethylsilane (TMS) was added as reference for the ${ }^{1} \mathrm{H}$ chemical shifts and for temperature and viscosity corrections of the diffusion coefficients of the analytes. ${ }^{1415}$

A set of 0 dummy scans/8 scans and 120 dummy scans/16 scans, respectively, were used with a relaxation delay of $2 \mathrm{~s}$. Sinusoidal shapes were used for the gradient and a linear gradient ramp with 5 or 20 increments between $5 \%$ and $95 \%$ of the maximum gradient strength were applied. For the homospoil gradient strengths values of 100, -13.17, 20 and $-17.13 \%$ were used. An effective diffusion time of $45 \mathrm{~ms}$ was applied. For each compound in the sample, the gradient pulses were adjusted in order to obtain optimized diffusion times $\Delta$ and gradient lengths $\delta$ according to following correlation:

$$
\Delta[m s]=D_{23}+\frac{\delta}{3} ; P_{16}[m s]=\frac{\delta}{2}
$$

The NMR spectra were processed with the Bruker program TopSpin 3.2 and the diffusion coefficients were determined according Müller and Jerschow. ${ }^{13}$

\section{Size Estimation:}

Via DOSY, the experimental translational self-diffusion coefficients $D$ of the molecules in solution were determined according to the Stejskal-Tanner equation. ${ }^{161718}$ From the obtained diffusion coefficients, the hydrodynamic radii of the analytes $\boldsymbol{r}_{\boldsymbol{A}}$ were estimated following the Stokes-Einstein equation (1), with $k=$ Boltzmann constant, $T=$ temperature, $\eta=$ viscosity of the sample, $c=$ correcting factor, $F=$ shape factor. ${ }^{19}$

$$
D\left[m^{2} / s\right]=\frac{k T}{F c \pi \eta r_{A}}
$$

For spherical shape, $F$ is equal to 1 . The correction factor $c$ of the Stokes-Einstein equation was calculated according to the semi-empirical modification according to Chen (2) using literature known values for the solvent $\left(\mathrm{r}_{\text {solv }}=2.46 \AA\right.$ for $\left.\mathrm{CD}_{2} \mathrm{Cl}_{2}{ }^{20}\right)$. ${ }^{21}$

$$
c_{\text {Chen }}=\frac{6 F}{1+0.695\left(\frac{r_{\text {solv }}}{r_{\text {ref }}}\right)^{2.234}} ; F=1 \text { for spheres }
$$

The obtained diffusion coefficients $D$ for the analytes were calibrated by viscosity calculation using the literature known radius of TMS (rref $=2.96 \AA$, calculated from hard-sphere increments ${ }^{22}$ ) and the experimentally determined diffusion coefficient $D_{\text {ref }}$ of TMS for every sample (equation (3)).

$$
\eta[\mathrm{kg} / \mathrm{ms}]=\frac{k T\left(1+0.695\left(\frac{r_{\text {solv }}}{r_{\text {ref }}}\right)^{2.234}\right)}{6 \pi D_{\text {ref }} r_{\text {ref }}}
$$

Including all corrections and calibrations into the Stokes-Einstein equation (4), the hydrodynamic radii $\boldsymbol{r}_{\boldsymbol{A}}$ were calculated according to equation (5). For better imagination, the corresponding volumes $V_{A}$ were calculated assuming a spherical shape.

$$
\begin{gathered}
D=\frac{k T\left(1+0.695\left(\frac{r_{\text {solv }}}{r_{r e f}}\right)^{2.234}\right)}{6 \pi \eta r_{A}}=\frac{k T\left(1+0.695 r_{\text {solv }}^{2.234} r_{r e f}{ }^{-2.234}\right)}{6 \pi \eta r_{A}} \\
0=D 6 \pi \eta r_{A}-k T 0.695 r_{\text {solv }}^{2.234} r_{A}^{-2.234}-k T
\end{gathered}
$$

In Table $\mathrm{S} 1$ the experimental diffusion coefficients $D$, the corresponding calculated radii $r_{A}$, the resulting volumes $V_{A}$ (the calculations were performed assuming spherical molecular shapes) and the estimated monomer volumes $\mathrm{V}_{\mathrm{M}}$ for the corresponding species according to Bondi are depicted. ${ }^{23}$ For each sample, the $D$ values for every species and for TMS as reference are given. If not otherwise mentioned, the average $D$ values of all baseline separated signals referring to the same species were used.

The interpretation of the DOSY derived data and further investigations of the aggregation situation including NOESY experiments from chapter 4.6.3 inside the different samples are given in chapter 4.6.4-4.6.6. The values for the 4-OMe-thiophenol/base mixture were already described in chapter 4.1 . 
Table S1. Information about the aggregation of the compounds in the different samples derived by diffusion ordered spectroscopy (DOSY) in $\mathrm{CD}_{2} \mathrm{Cl}_{2}$. The experiments were performed at $180 \mathrm{~K}$ if not otherwise stated.

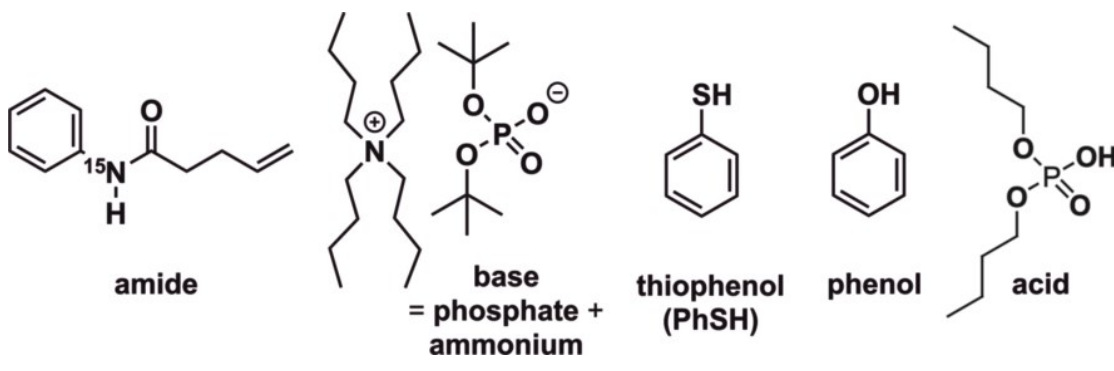

\begin{tabular}{|c|c|c|c|c|c|}
\hline sample & species inside sample & $\begin{array}{c}\text { diffusion coefficient } \\
D^{[a]}\left[\mathbf{m}^{2} / \mathbf{s}\right]\end{array}$ & $\begin{array}{l}\text { hydrodynamic } \\
\operatorname{radius} r_{A}[\AA]\end{array}$ & $\begin{array}{c}\text { volume } V_{A} \\
{\left[\AA^{3}\right]}\end{array}$ & $\begin{array}{c}\text { monomer } \\
\text { volume } \mathbf{V}_{\mathbf{M}^{[\mathrm{c}}} \\
{\left[\AA^{3}\right]} \\
\end{array}$ \\
\hline \multirow[t]{2}{*}{ amide } & amide & $1.05 \times 10^{-10}$ & 5.19 & 587 & 168 \\
\hline & TMS & $2.38 \times 10^{-10}$ & - & - & \\
\hline \multirow[t]{3}{*}{ base } & phosphate $^{[b]}$ & $6.81 \times 10^{-11}$ & 8.65 & 2715 & 210 \\
\hline & ammonium & $7.13 \times 10^{-11}$ & 8.31 & 2399 & 302 \\
\hline & TMS & $2.79 \times 10^{-10}$ & - & - & \\
\hline \multirow[t]{2}{*}{$\mathrm{PhSH}$} & $\mathrm{PhSH}$ & $2.69 \times 10^{-10}$ & 3.06 & 120 & 101 \\
\hline & TMS & $2.85 \times 10^{-10}$ & - & - & \\
\hline \multirow[t]{4}{*}{ amide/base } & amide & $6.48 \times 10^{-11}$ & 7.68 & 1900 & \\
\hline & phosphate & $6.78 \times 10^{-11}$ & 7.38 & 1681 & \\
\hline & ammonium & $7.29 \times 10^{-11}$ & 6.92 & 1387 & \\
\hline & TMS & $2.33 \times 10^{-10}$ & - & - & \\
\hline \multirow[t]{4}{*}{$\mathrm{PhSH} /$ base } & $\mathrm{PhSH}$ & $1.71 \times 10^{-10}$ & 3.16 & 132 & \\
\hline & phosphate $^{[b]}$ & $5.08 \times 10^{-11}$ & 8.01 & 2155 & \\
\hline & ammonium & $6.12 \times 10^{-11}$ & 6.79 & 1310 & \\
\hline & TMS & $1.91 \times 10^{-10}$ & - & - & \\
\hline \multirow[t]{5}{*}{ amide/base/PhSH } & amide & $7.12 \times 10^{-11}$ & 6.79 & 1309 & \\
\hline & phosphate & $6.52 \times 10^{-11}$ & 7.34 & 1655 & \\
\hline & ammonium & $7.95 \times 10^{-11}$ & 6.18 & 986 & \\
\hline & $\mathrm{PhSH}$ & $2.28 \times 10^{-10}$ & 2.92 & 104 & \\
\hline & TMS & $2.22 \times 10^{-10}$ & - & - & \\
\hline amide/base/PhSH & amide & $1.16 \times 10^{-09}$ & 6.14 & 968 & \\
\hline \multirow[t]{4}{*}{ at $300 \mathrm{~K}$} & phosphate & $7.99 \times 10^{-10}$ & 8.54 & 2607 & \\
\hline & ammonium & $8.52 \times 10^{-10}$ & 8.05 & 2185 & \\
\hline & $\mathrm{PhSH}$ & $2.30 \times 10^{-09}$ & 3.66 & 205 & \\
\hline & TMS & $3.22 \times 10^{-09}$ & - & - & \\
\hline \multirow[t]{5}{*}{ amide/base/acid } & amide & $5.12 \times 10^{-11}$ & 8.16 & 2277 & \\
\hline & phosphate & $5.10 \times 10^{-11}$ & 8.19 & 2302 & \\
\hline & ammonium & $5.91 \times 10^{-11}$ & 7.18 & 1552 & \\
\hline & acid & $5.12 \times 10^{-11}$ & 8.17 & 2283 & \\
\hline & TMS & $1.97 \times 10^{-10}$ & - & - & \\
\hline \multirow[t]{2}{*}{ phenol } & phenol & $1.76 \times 10^{-10}$ & 3.70 & 212 & 89 \\
\hline & TMS & $2.50 \times 10^{-10}$ & - & - & \\
\hline \multirow[t]{5}{*}{ amide/base/phenol } & amide & $5.64 \times 10^{-11}$ & 7.94 & 2096 & \\
\hline & phosphate & - & - & - & \\
\hline & ammonium & $6.33 \times 10^{-11}$ & 7.16 & 1537 & \\
\hline & phenol & $5.78 \times 10^{-11}$ & 7.77 & 1966 & \\
\hline & TMS & $2.10 \times 10^{-10}$ & - & - & \\
\hline \multirow[t]{6}{*}{ 4-OMe-thiophenol/base } & 4-OMe-PhSH & $1.53 \times 10^{-10}$ & 3.14 & 129 & 125 \\
\hline & $\begin{array}{l}\text { 4-OMe-PHS } \\
\text { (thiolate 1) }\end{array}$ & $1.24 \times 10^{-10}$ & 3.58 & 192 & \\
\hline & thiolate 2 & $7.73 \times 10^{-11}$ & 5.05 & 539 & \\
\hline & $(4-\mathrm{OMe}-\mathrm{PhS})_{2}$ & $9.29 \times 10^{-11}$ & 4.39 & 355 & \\
\hline & phosphate $^{[b]}$ : & $5.20 \times 10^{-11}$ & 7.03 & 1454 & \\
\hline & ammonium & $6.12 \times 10^{-11}$ & 6.11 & 955 & \\
\hline
\end{tabular}


[a] the diffusion coefficients D are average values of all base line separated signals; ${ }^{[b]}$ the phosphate signal is not base line separated and overlapped with an ammonium signal and the diffusion coefficient refers therefore to an average value of both species; ${ }^{[c]}$ estimated monomer values according to Bondi. ${ }^{23}$

\subsection{3 ${ }^{1} \mathrm{H},{ }^{1} \mathrm{H}$ NOESY}

In order to obtain more information about the nature of the aggregates, $2 \mathrm{D}{ }^{1} \mathrm{H},{ }^{1} \mathrm{H}$ NOESY measurements were performed for the amide/base and amide/base/thiophenol samples at $180 \mathrm{~K}$. Prior to the experiments, the mixing time $(100 \mathrm{~ms})$ was adjusted to achieve the best signal intensity without leaving the linear NOE buildup, which is necessary for the subsequent interproton distance calculation.

The distance calculations were performed by integrating the NOE crosspeaks. ${ }^{24}$ The discrete interproton distances $r$ in $\mathrm{nm}$ were obtained according to equation 6. Importantly, the distance calculated between two integrals (protons) refers to the average value for all involved protons and for all possible conformations in the solution.

$$
r=r_{\text {ref }}\left(a_{\text {ref }} / a\right)^{1 / 6}
$$

For the amide/base sample, $r_{r e f}$ refers to the distance between the amidyl aromatic protons in ortho and meta position, which was obtained using GaussView. The value of $2.5 \mathrm{~nm}$, which is the average value for both ortho-meta distances in the aromatic ring, was applied as reference for the calculation of all intra- and intermolecular distances (Scheme S48a). The integrals of the NOE crosspeaks $a_{r e f}$ and $a$ were adapted according to their number of protons.

As the NOE cross peaks of the aromatic protons were not separated for the amide/base/PhSH sample, $r_{\text {ref }}$ refers to the distance between the trans-configurated olefin protons also obtained by GaussView (3.1 nm; Scheme S49a).

The ${ }^{1} \mathrm{H},{ }^{1} \mathrm{H}$ NOESY spectrum of the amide/base mixture in Scheme S48a shows intermolecular interactions between amide and phosphate (orange) and between amide and the ammonium counterion of the base (yellow). As analyzed in the main text, the amide/phosphate interaction is based on a N-H $\cdots \mathrm{O}-\mathrm{P}$ hydrogen bond. The ammonium-amide interaction, however, is presumably attributed to a cation- $\pi$ interaction. ${ }^{25}$ Distance calculations in Scheme S48b visualize these interactions in more detail. The average distances show that the tertbutyl groups of the phosphate are in average closest to the amidyl N-H proton, which corroborates the amide/base hydrogen bond (top). Moreover, the shorter distances of the central $\mathrm{CH}_{2}$ protons of the tetrabutylammonium towards the aromatic region of the amide verify the cation- $\pi$-interaction (bottom).

a) ${ }^{1} \mathrm{H},{ }^{1} \mathrm{H}$ NOESY of amide/base mixture:

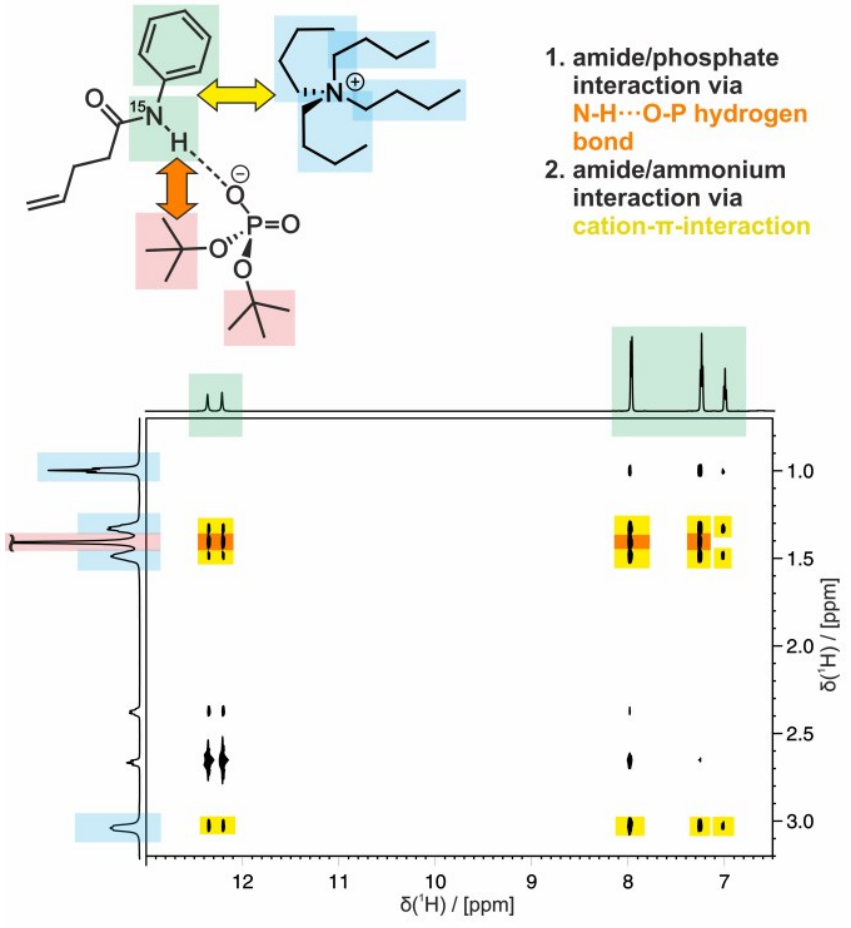

b) distance calculation:

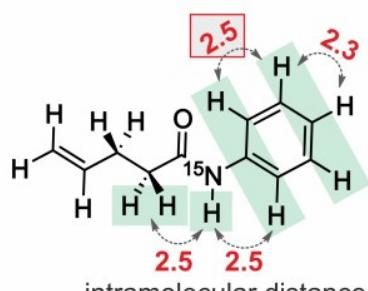

intramolecular distance between ortho- and metaaromatic protons as reference
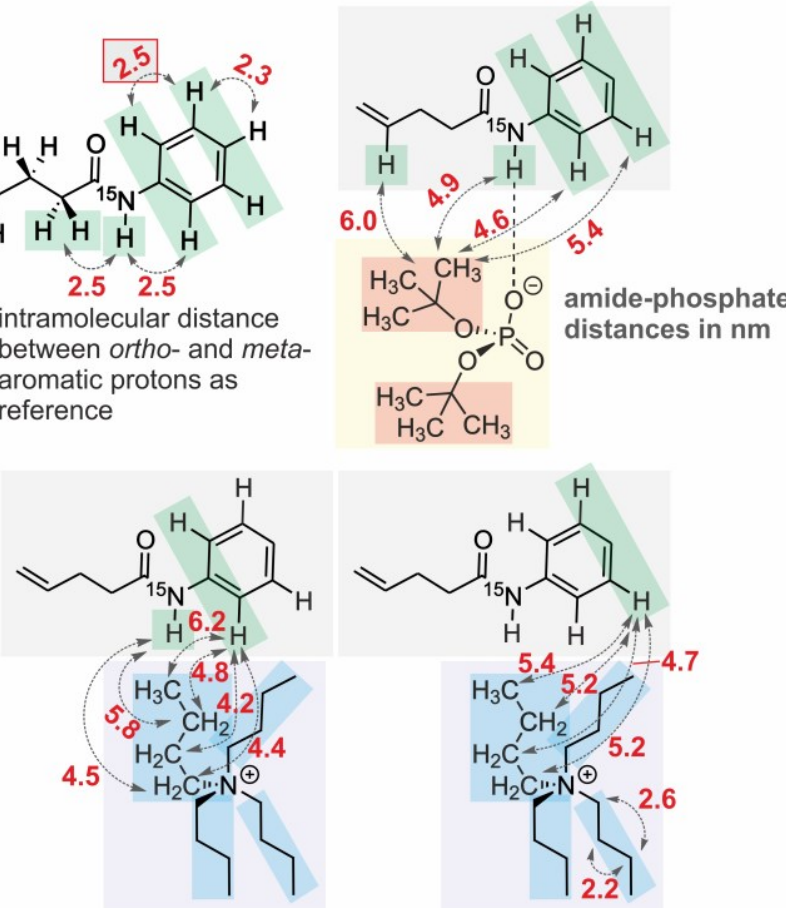

amide-ammonium distances in $\mathrm{nm}$

Scheme S48. a) ${ }^{1} \mathrm{H},{ }^{1} \mathrm{H}$ NOESY experiments of the amide/base mixture corroborate the existence of a hydrogen bond between amide and phosphate and suggest a cation- $\pi$-interaction between tetrabutylammonium and the phenyl group of the amide. $b$ ) These concepts are further supported by the calculation of the average intermolecular distances between the different species. 
In Scheme S49a, the ${ }^{1} \mathrm{H},{ }^{1} \mathrm{H}$ NOESY spectrum of the amide/base/PhSH spectrum is depicted. As was obtained for the amide/base system, the existence of a N-H $\cdots \mathrm{O}-\mathrm{P}$ hydrogen bond is supported by a NOE crosspeak between the tert-butyl groups of the phosphate and the ${ }^{15} \mathrm{~N}-\mathrm{H}$ proton. Furthermore, again, a cation- $\pi$--interaction between ammonium and the aromatic ring of the amide was identified. The distance calculations depicted in Scheme S49b show the shortest average distance between the tert-butyl groups and the N-H proton albeit with increased values compared to the calculations of the amide/base mixture. This hints to a longer amide-phosphate distance, but as the reference distances are different for both samples, the values can only be accurately compared inside the same system. For the amide/base/PhSH sample, the central ammonium $\mathrm{CH}_{2}$ protons are calculated to be closest to the aromatic region of the amide again, supporting the mentioned cation- $\pi$-interaction.

a) ${ }^{1} \mathrm{H},{ }^{1} \mathrm{H}$ NOESY of amide/base/PhSH mixture:

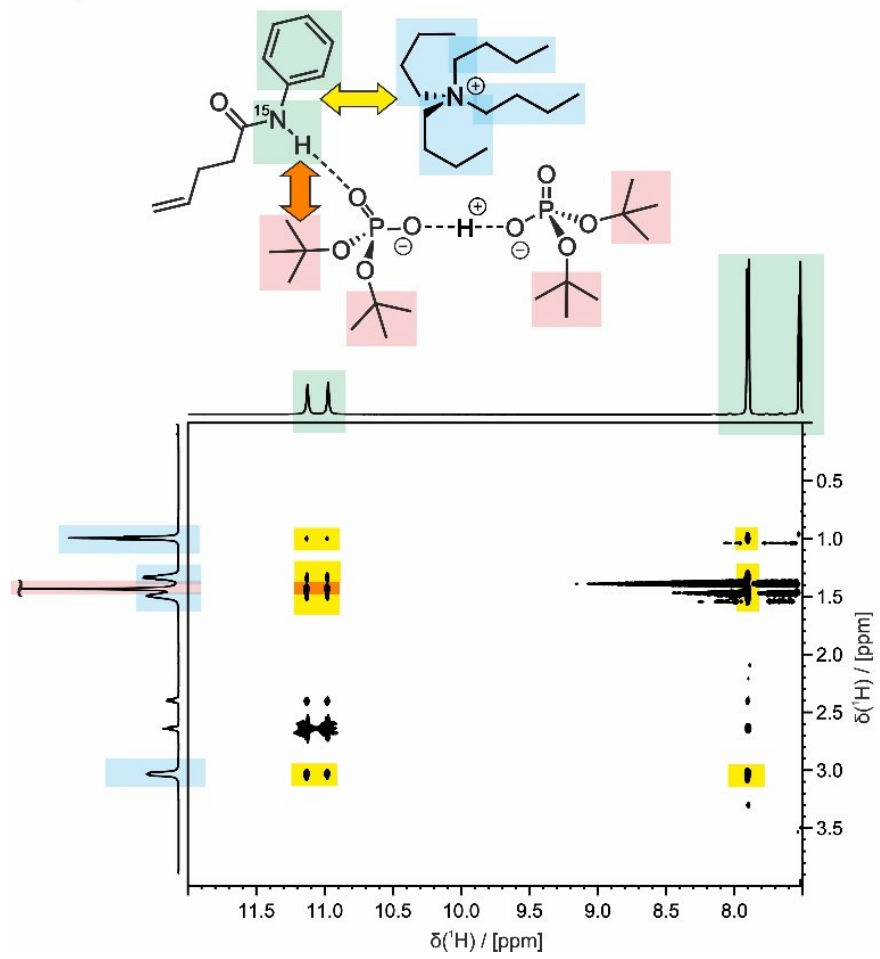

b) distance calculation:

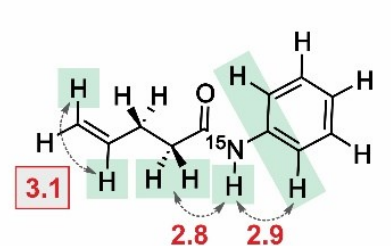

intramolecular distance between trans-alkene protons as reference
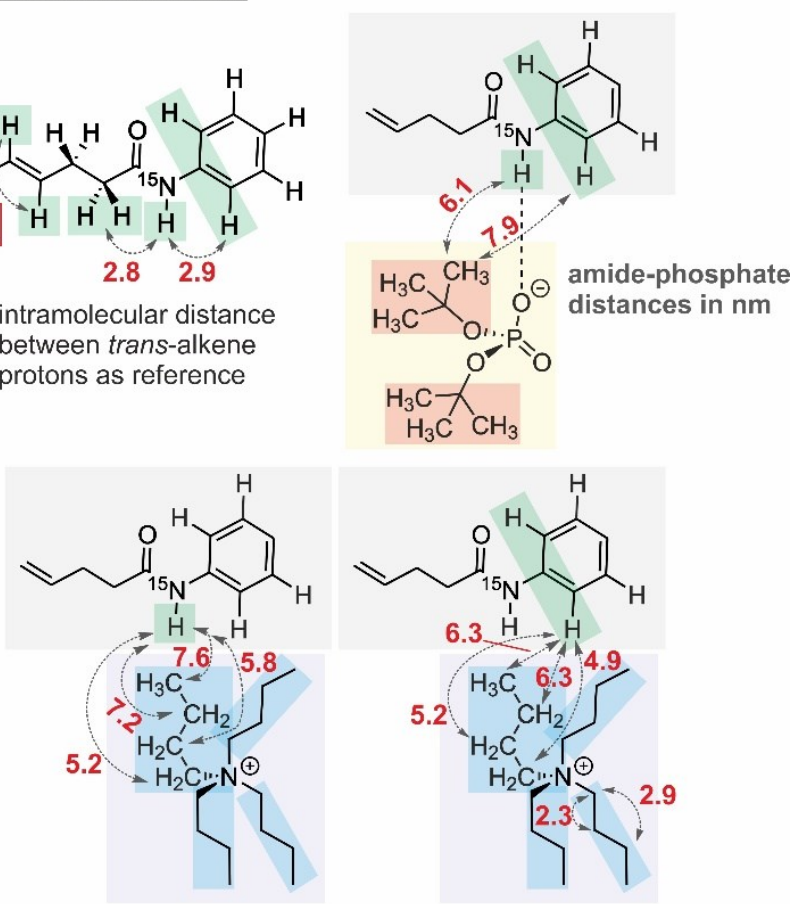

amide-ammonium distances in $\mathrm{nm}$

Scheme S49. a) ${ }^{1} \mathrm{H},{ }^{1} \mathrm{H}$ NOESY experiments of the amide/base/PhSH sample corroborate the existence of a hydrogen bond between amide and base and suggest a cation- $\pi$-interaction between tetrabutylammonium and the phenyl group of the amide as found for the amid/base mixture (Scheme S48). b) These concepts are again further supported by the calculation of the average intermolecular distances between the different species.

\subsubsection{Analysis of the pure compounds in $\mathrm{CD}_{2} \mathrm{Cl}_{2}$}

Taking together the results of the ${ }^{1} \mathrm{H},{ }^{15} \mathrm{~N},{ }^{31} \mathrm{P}$ NMR hydrogen bond analysis, the DOSY and NOESY measurements and the MD simulations (for details about the MD simulations, see chapter 5), the nature of the aggregates inside the different mixtures can be described in detail. In the following sections, the aggregation situation is discussed for the pure compounds in $\mathrm{CD}_{2} \mathrm{Cl}_{2}$, the amide/base, base/thiophenol, amide/base/thiophenol and amide/base/phenol mixtures.

The description of the one- and two-compound systems provide basic and important information which help for the interpretation of the aggregation situation inside the three-compound mixtures being crucial for the overall PCET efficiency for a successful photoredox catalytic hydroamidation reaction.

\section{${ }^{15} \mathrm{~N}$-Phenylpent-4-enamide in $\mathrm{CD}_{2} \mathrm{Cl}_{2}$ at $180 \mathrm{~K}$ :}

Via ${ }^{1} \mathrm{H}$ NMR titration experiments the behavior of the pure amide in $\mathrm{CD}_{2} \mathrm{Cl}_{2}$ was studied.

In Scheme S50a, an excerpt of the ${ }^{1} \mathrm{H}$ NMR spectra of the amide using different concentrations between $50 \mathrm{mM}$ and $0.02 \mathrm{mM}$ is depicted. The continuous shift of the ${ }^{15} \mathrm{~N}-\mathrm{H}$ proton doublet towards low field with higher concentrations indicates an increase of the $\mathrm{N} \cdots \mathrm{O}-\mathrm{C}$ hydrogen 
bond strength by forming dimers or multimers. Scheme S50b shows the graphical correlation between the chemical shift dependence and the concentration including all measured dilutions. The graph illustrates that a molecular finite state is reached at $0.02 \mathrm{mM}$ with a chemical shift of around $7.5 \mathrm{ppm}$, which could refer to the monomer or a dimer state. In general, via $\pi$-bond cooperativity of the amide functionality the hydrogen bond donor and acceptor ability is enhanced and dimer or multimer formation is favored (Scheme S51a). ${ }^{26}$ This solute-solute interaction is also supported by the investigations of Hunter (see chapter 4.4). Including the DOSY derived volume (587 $\AA^{3}$ ) and comparing it to the estimated monomer value according to Bondi ( $168 \AA^{3}$, see Table 1 in chapter 4.6.2), an amide complex consisting of approximately two dimers or four monomers is assumed (Scheme S51b).

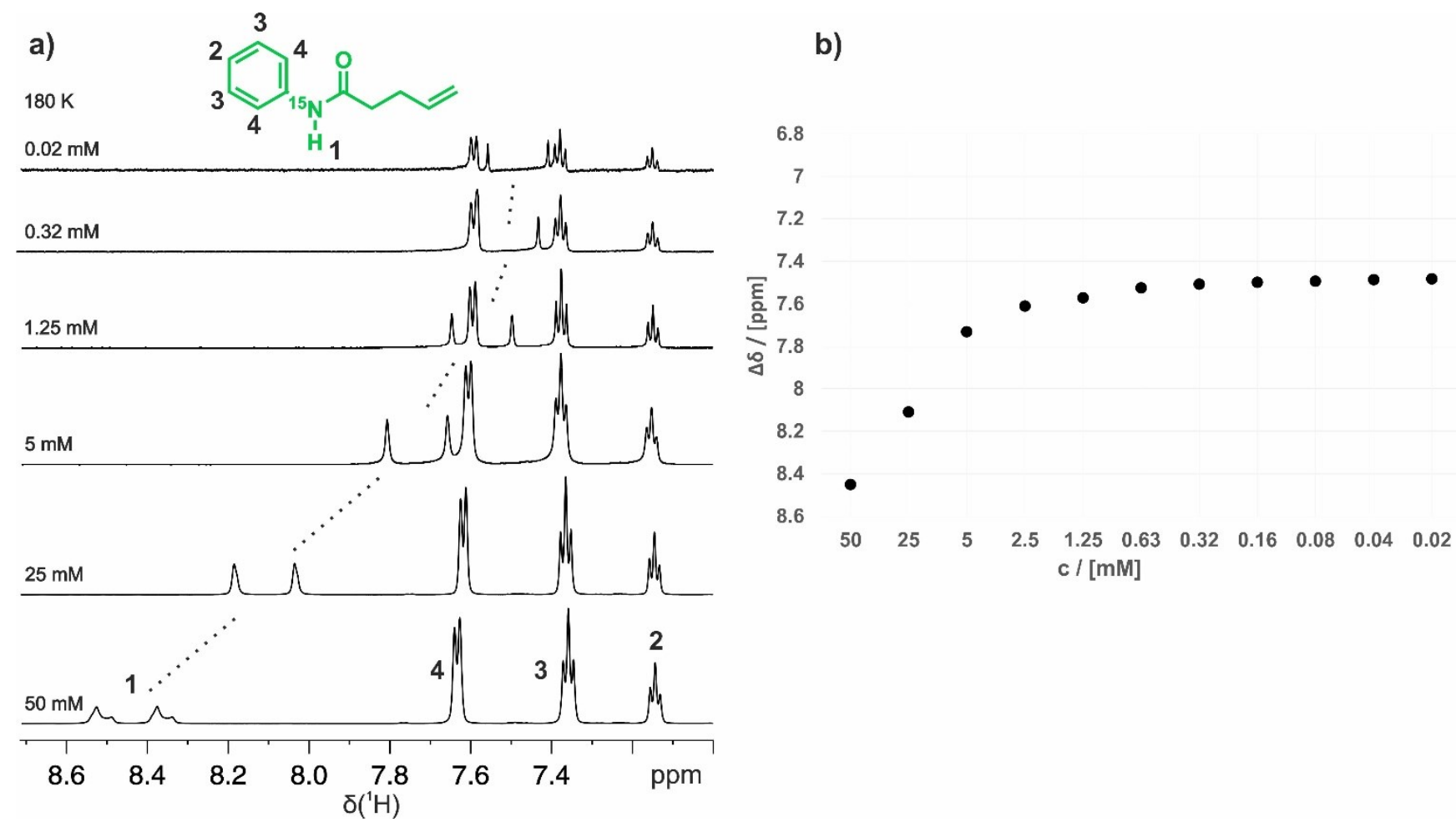

Scheme S50. a) The ${ }^{1} \mathrm{H}$ low field shift of the N-H proton with higher concentrations (from 0.02 to $50 \mathrm{mM}$ ) indicates an increased hydrogen bond mediated amide/amide interaction by the formation of dimers or multimers. b) Graphical representation of the correlation between concentration and shift of the N-H proton.

a) $\pi$-bond cooperativity:<smiles>[R1]NC(=O)CCC([R])N[R]</smiles>

possible dimer formation:<smiles>C=CCCC(=O)Nc1ccccc1</smiles>

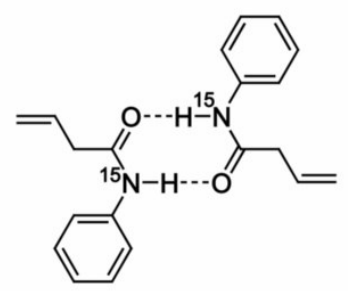

b) aggregation:

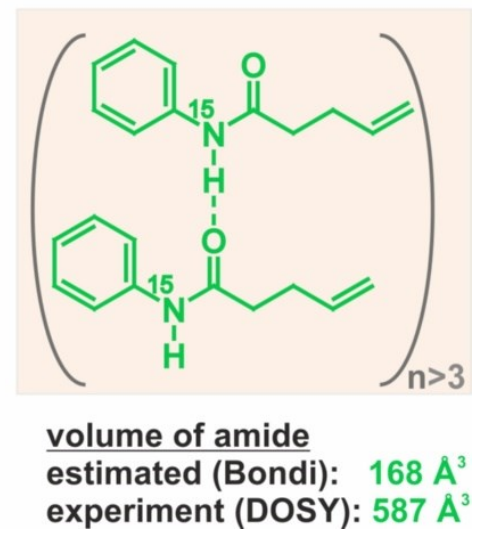

Scheme S51. a) Literature known $\pi$-bond cooperativity leads to the formation of inter-amide dimer or oligomer formation. ${ }^{26} \mathrm{~b}$ ) The DOSY derived volumes for pure amide at $50 \mathrm{mM}$ suggest the formation of an aggregate with in average at minimum 3 amides involved.

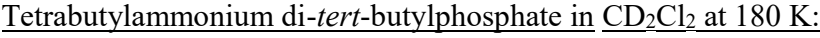

The nature of the phosphate base was investigated via concentration dependent ${ }^{1} \mathrm{H}$ NMR spectroscopy as well. The spectra the phosphate base including its tetrabutylammonium counterion at 50 and $25 \mathrm{mM}$ show no chemical shift deviation of the corresponding signals (Scheme S52a). Comparing the estimated monomer volumes with the values derived by DOSY, the base seems to be highly aggregated (Scheme $\mathrm{S} 52 \mathrm{~b})$. Interestingly, the value for the cation is decreased in comparison to the phosphate indicating a partial dissociation from the anion 
possibly caused by residual water inside the sample. As there is only one set of signals for each species in the spectrum and only one ${ }^{31} \mathrm{P}$ signal for the phosphate (see Scheme S41), the different complexes equilibrate on the NMR time scale.

a)

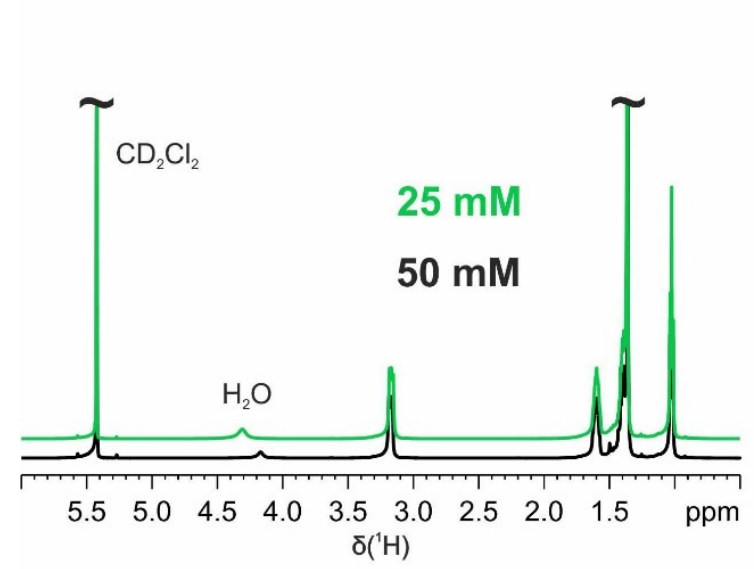

b) aggregation:

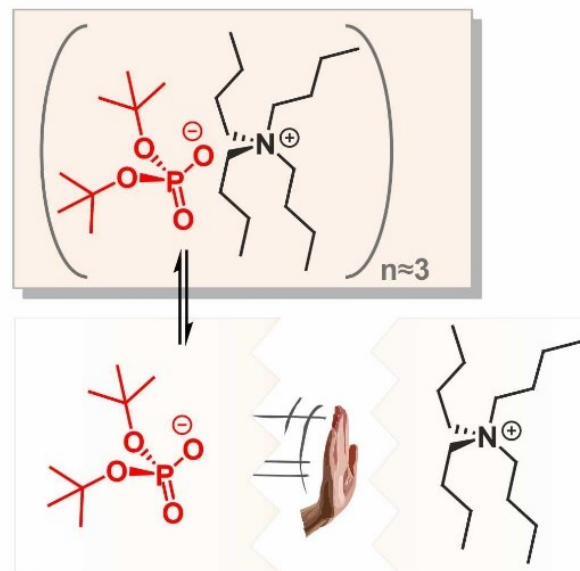

cation partially dissociated

volumes:

estimated (Bondi):

phosphate: $210 \AA^{3}$

experiment (DOSY):

ammonium: $302 \AA^{3}$

Scheme S52. a) The ${ }^{1} \mathrm{H}$ NMR spectra of the base at $180 \mathrm{~K}$ including phosphate anion and tetrabutylammonium cation show no chemical shift changes of the corresponding species using different concentrations ( 25 and $50 \mathrm{mM}$ ). b) The aggregation situation at $50 \mathrm{mM}$ is proposed as phosphate/ammonium ion pair with the cation being partially released.

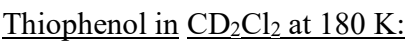

The concentration study and the DOSY derived volumes let suggest that thiophenol is present as a monomer in solution (Scheme S53). According to Hunter, the S-H group is a poor hydrogen bond donor and acceptor (chapter 4.4), which confirm these results.

a)

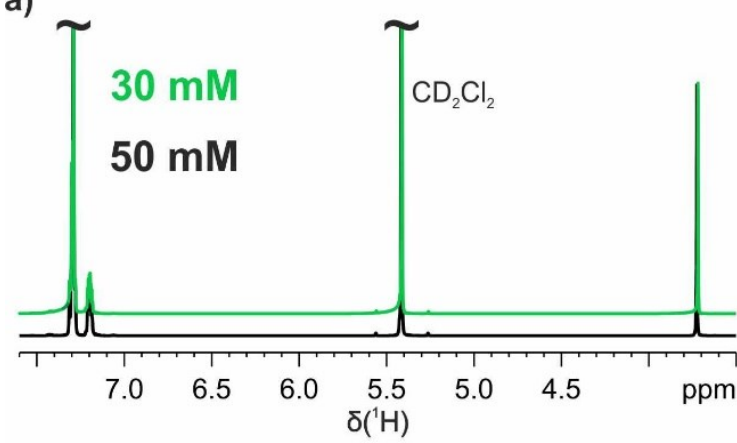

b) aggregation: monomer

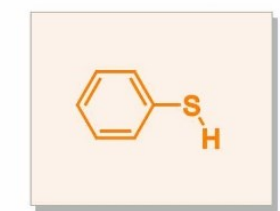

\section{volume of $\mathrm{PhSH}$ \\ estimated (Bondi): $101 \mathrm{~A}^{3}$ experiment (DOSY): $120 \AA^{3}$}

Scheme S53. a) The ${ }^{1} \mathrm{H}$ NMR spectra of thiophenol at $180 \mathrm{~K}$ show no chemical shift changes for 30 and $50 \mathrm{mM}$. b) Including DOSY derived volumes the $\mathrm{PhSH}$ monomer is verified.

\subsubsection{Two-component mixtures}

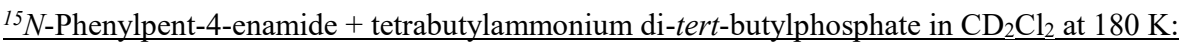

According to Hunter, a hydrogen bond mediated interaction between amide and phosphate is favored because of the high acceptor and donor abilities of the phosphate anion and the amide functionality (see chapter 4.4). The formation of a N-H $\cdots$ O-P hydrogen bond was already identified by low temperature ${ }^{1} \mathrm{H},{ }^{15} \mathrm{~N}$ and ${ }^{31} \mathrm{P}$ hydrogen bond analysis (see main text). The experimentally determined volumes assume an 
overall high complexation in solution (Scheme S54). As only one ${ }^{31} \mathrm{P}$ signal is present for this sample being high field shifted in comparison to the pure phosphate, a large hydrogen bonded amide-phosphate complex is assumed. The reduced volumes for phosphate compared to the amide suggests additional high complexation of amide molecules with each other (vide supra). As for the pure base, comparing the DOSY derived volumes, the ammonium cation is supposed to be partially dissociated from the phosphate, in general.

\section{aggregation:}

volumes:
estimated (Bondi):
amide: $168 \AA^{3}$
phosphate: $210 \AA^{3}$
ammonium: $302 \AA^{3}$

experiment (DOSY):
amide: $1900 \AA^{3}$
phosphate: $1681 \AA^{3}$
ammonium: $1387 \AA^{3}$

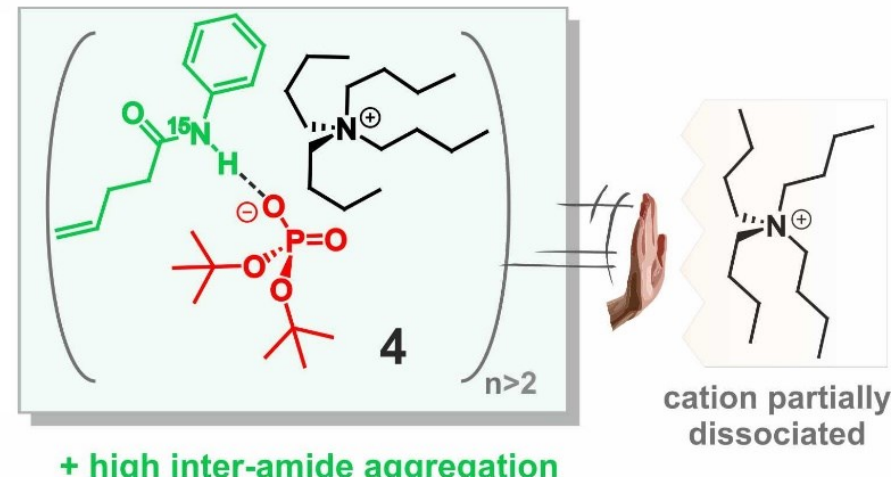

Scheme S54. Including all 1D NMR, NOESY and DOSY investigations a large hydrogen bond mediated complex with partial release of the ammonium counterion is proposed. In addition, high inter-amide complexation is observed via DOSY.

\section{thiophenol + tetrabutylammonium di-tert-butylphosphate in $\mathrm{CD}_{2} \mathrm{Cl}_{2}$ at $180 \mathrm{~K}$ :}

As already investigated in chapter 4.1, an acid-base reaction takes place whenever thiophenol and di-tert-butylphosphate are present. The generated phosphoric acid leads to the formation of phosphate dimer $1\left(\mathrm{see}^{1} \mathrm{H},{ }^{15} \mathrm{~N}\right.$ and ${ }^{31} \mathrm{P}$ NMR studies in the main text and chapter 4.1 of the SI). The further high field shift of the ${ }^{31} \mathrm{P}$ signal in comparison to the amide/base system predicts high electron density being located on the phosphate (see main text and the spectra in chapter 4.5.3 of the SI). In the ${ }^{1} \mathrm{H}$ NMR spectra of all $\mathrm{PhSH}$ and base containing mixtures the signal of the proton inside the strong $\mathrm{P}-\mathrm{O} \cdots \mathrm{H} \cdots \mathrm{O}-\mathrm{P}$ bond is located at $16.49-16.50 \mathrm{ppm}$ (see main text and chapter 4.5.1 in the SI). Regarding the DOSY measurements, the volume for thiophenol verifies to be mainly free in solution with partial formation of thiolate according to the mentioned acid-base reaction (Scheme S55). Furthermore, in comparison with the pure base, the volumes for phosphate and ammonium are in general reduced indicating a partial break of the phosphate-ammonium complex. But the ubiquitous size difference between both species was immensely increased corroborating the release of the cation because of the formation of dimer $\mathbf{1}$. In comparison to the amide/base mixture, ammonium`s volumes remain similar, but the phosphate is drastically enlarged in presence of $\mathrm{PhSH}$, which is attributed to the dimerization of the base.

aggregation:

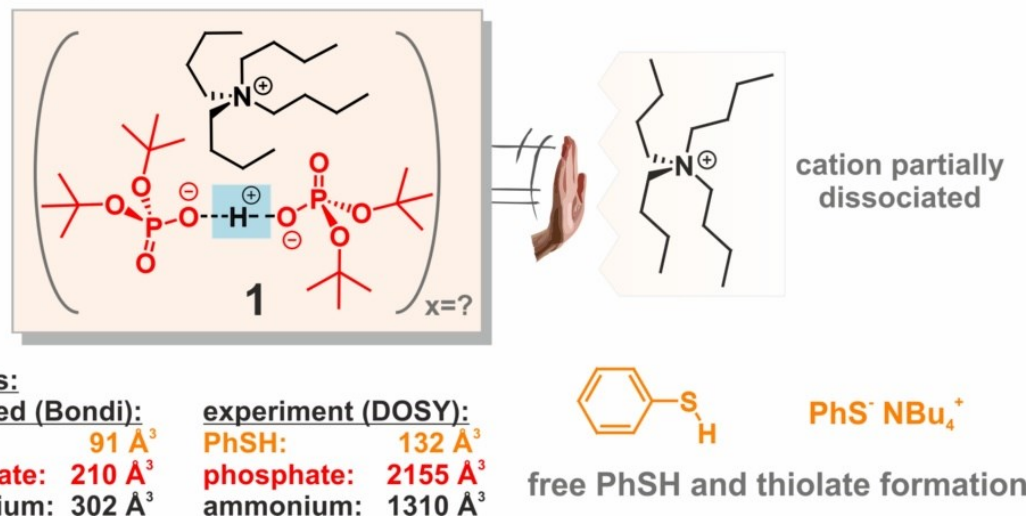

Scheme S55. Including all 1D NMR, NOESY and DOSY investigations a strong hydrogen bond mediated phosphate dimer 1 was identified with partial release of the ammonium counterion as found for other mixtures. In addition, DOSY corroborates a large phosphate complex and free thiophenol. 


\subsubsection{Three-component mixture}

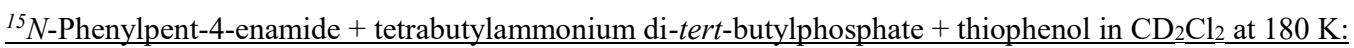

The partial protonation of the phosphate base by thiophenol as identified for the thiophenol/base mixture was also verified in presence of the amide. This was already shown in chapter 4.1. Taking together all 1D NMR, NOESY, DOSY investigations and MD simulations, the existence of dimer 1 and an amide containing aggregate 2 were identified (Scheme S56).

Comparing the DOSY results for the amide, which is activated inside the photocatalytic mixture, of the amide/base and amide/base/PhSH sample, interestingly, a tremendous deaggregation of the substrate was obtained. This suggests very reduced self-aggregation and a dynamic nature in the whole system, which offers an extended amount of hydrogen bond acceptor sites due to dimer $\mathbf{1}$. Moreover, the volume of the ammonium counterion is lowest for this mixture indicating its release from the phosphate because of the dimer formation as was found for the base/PhSH sample. But these small values imply that the formed thiophenolate is only barely attached to ammonium. The thiophenol value being similar to the monomer value again verifies its monomeric behavior.

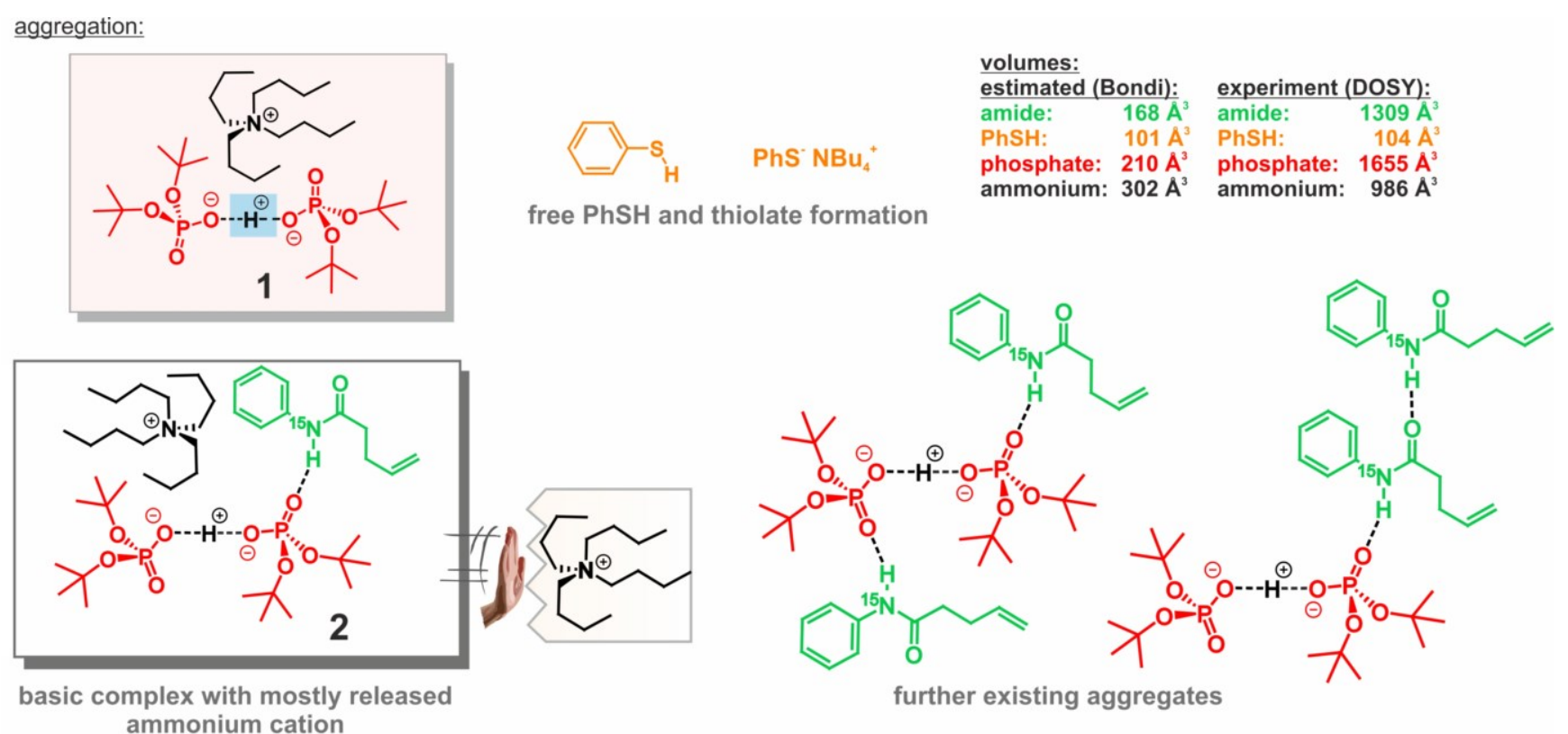

Scheme S56. Including all results from 1D NMR, NOESY, DOSY investigations and MD simulations phosphate dimer 1 and the crucial amide containing complex 2 were identified with partial release of the ammonium counterion as found for other mixtures. Further aggregates including more than one amide corroborate an extended H-bond network. In addition, DOSY corroborates free thiophenol in solution.

The formed phosphate- $\mathrm{H}^{+}$-phosphate dimers provide an extended $\mathrm{H}$-bond network with amides allowing a productive regeneration of the photocatalyst (see discussion in the main text) Thus, complex 2, with high electron density located on the phosphates is assumed to be the crucial aggregate for an effective PCET event.

Altogether, thiophenol acts not only as HAT reagent but helps to generate the phosphate dimer. Furthermore, its low hydrogen bond donor ability is necessary as it is not incorporated into the reactive complex. We hope, this study reveals the importance of analyzing the aggregation of the reaction mixture and helps for the development of new PCET mediated photoredox catalytic protocols.

\section{${ }^{15} \mathrm{~N}$-Phenylpent-4-enamide + tetrabutylammonium di-tert-butylphosphate + phenol in $\mathrm{CD}_{2} \mathrm{Cl}_{2}$ at $180 \mathrm{~K}$ :}

In Scheme S57, the DOSY derived volumes indicate high aggregation of amide, phenol and ammonium. Taking together all results from 1D NMR and DOSY analysis, phenol seems to be fully incorporated into the amide/base complex (see discussion in the main text). And, very importantly, no phosphate dimer is formed. Thus, the hydrogen bond donor ability and its incapability of modulating the electron density of the phosphate in an effective manner by generating the dimer is assumed to be one reason for being inefficient for photoredox catalytic hydroamidation, besides its different radical and HAT properties compared to $\mathrm{PhSH}$. 


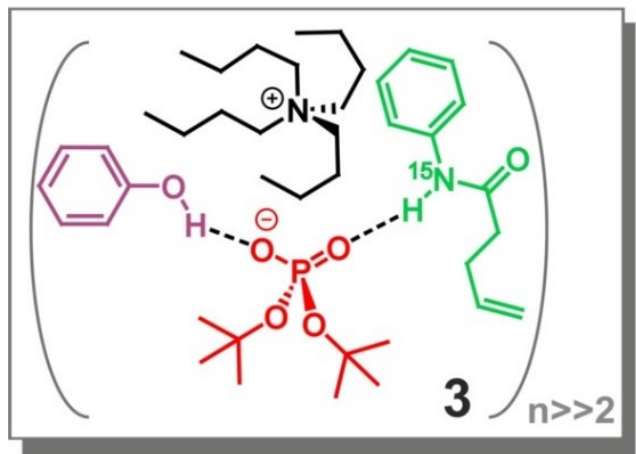

volumes:

estimated (Bondi):

amide: $\quad 168 \AA^{3}$

PhOH: $\quad 89 \AA^{3}$

phosphate: $210 \AA^{3}$

ammonium: $302 \AA^{3}$

experiment (DOSY):

amide: $2096 \AA^{3}$

PhOH: $\quad 1966 \AA$

phosphate: -

ammonium: $1537 \AA^{3}$

large aggregate with incorporated $\mathrm{PhOH}$

Scheme S57. Including all 1D NMR and DOSY investigations the formation of complex 3 with phenol being incorporated into the amide/base complex is identified. The lack of phosphate dimer $\mathbf{1}$ and the hydrogen bond donor ability of phenol seem to be one reason for an ineffective PCET.

\section{Molecular Dynamics Simulations}

\section{Methods:}

All simulations were performed using Gromacs version 2018. ${ }^{27}$ All molecular topologies were prepared with acpype ${ }^{28}$ based on the General Amber Force Field (GAFF) ${ }^{29}$. Partial atomic charges were determined from HF/6-31G* wave functions with $\mathrm{CHelpG}^{30}$ using the Orca 4.1 .2 quantum chemical program ${ }^{31}$. The Lennard-Jones parameters for the $\mathrm{Cl}$ atom in the dichloromethane solvent were slightly adjusted ( $\mathrm{s}=0.33$ $\mathrm{nm}, \mathrm{e}=1.2 \mathrm{~kJ} / \mathrm{mol}$ ) for reproducing the correct solvent density at $300 \mathrm{~K}$. Van der Waals interactions were cut off above $1 \mathrm{~nm}$ and electrostatic interactions were determined with the smooth particle-mesh Ewald summation method. Simulations with different content of phenole, thiophenole, thiophenolate, tert-butyl phosphoric acid, hydronium, hydroxide, and water were performed. The phosphoric acid is presumably formed in an acid-base reaction between thiophenol and phosphate base. Table S2 gives a summary of the studied system compositions. All simulations were performed at $200 \mathrm{~K}$ temperature and 1 bar pressure using stochastic velocity rescaling ${ }^{32}$ and a Parrinello-Rahman barostat ${ }^{33}$. All simulation times were $1 \mathrm{~ms}$, configurations were saved every $50 \mathrm{ps}$. The first $200 \mathrm{~ns}$ were discarded for equilibration and the remaining 800 ns were used for analysis.

Table S2: System compositions (number of molecules) of the seven studied reaction mixtures $(\mathrm{Sim}=1-7) . \mathrm{H}_{3} \mathrm{O}^{+}=\mathrm{H}_{3} \mathrm{O}, \mathrm{OH}^{-}=\mathrm{OH}$, phenol $=\mathrm{PH}$, thiophenol $=\mathrm{SPH}, \mathrm{H}_{2} \mathrm{O}=\mathrm{WAT}$, amide $=\mathrm{AMD}, \mathrm{NBu}_{4}{ }^{+}=\mathrm{NB} 4$, phosphoric acid $=\mathrm{PHA}$, phosphate $=\mathrm{PHO}$, thiophenolate $=\mathrm{SPM}$, $\mathrm{CH}_{2} \mathrm{Cl}_{2}=\mathrm{DCM}$.

\begin{tabular}{cccccccccccc} 
Sim & H3O & OH & PH & SPM & WAT & $\begin{array}{c}\text { AM } \\
\text { D }\end{array}$ & NB4 & PHO & SPH & PHA & DCM \\
\hline 1 & 0 & 0 & 27 & 0 & 0 & 27 & 27 & 27 & 0 & 0 & 6581 \\
2 & 0 & 0 & 0 & 0 & 0 & 27 & 27 & 27 & 27 & 0 & 6581 \\
3 & 0 & 0 & 0 & 0 & 27 & 27 & 27 & 27 & 27 & 0 & 6581 \\
4 & 5 & 5 & 0 & 0 & 27 & 27 & 27 & 27 & 27 & 0 & 6581 \\
5 & 5 & 0 & 0 & 5 & 27 & 27 & 27 & 27 & 22 & 0 & 6581 \\
6 & 27 & 0 & 0 & 27 & 27 & 27 & 27 & 27 & 0 & 0 & 6581 \\
7 & 13 & 0 & 0 & 27 & 27 & 27 & 27 & 13 & 0 & 14 & 6581
\end{tabular}

All diffusion constants were determined from the center of mass trajectories using the Einstein relation, $\left\langle r^{2}\right\rangle=6 D t$, with averaging over all present molecules of the given type and restarting the analysis every $10 \mathrm{ps}$. The slopes of the $\left\langle r^{2}\right\rangle(t)$ data were determined for lag times up to $50 \mathrm{~ns}$ by linear regression. The diffusion constants were normalized by the $\mathrm{CH}_{2} \mathrm{Cl}_{2}$ diffusion constant obtained for the respective 
simulation, which is between $1.3143 * 10^{-9} \mathrm{~m}^{2} / \mathrm{s}$ and $1.3615^{*} 10^{-9} \mathrm{~m}^{2} / \mathrm{s}$ (which is approximately a factor of 2 to large compared to the experimental diffusion constant ${ }^{34}$ ).

Hydrogen bonds were determined following the Luzar-Chandler criterion for water-water hydrogen bonds ${ }^{35}$ : donor-acceptor distance lower than $3.5 \AA$ and donor-H-acceptor angle lower than $30^{\circ}$.

\section{Results:}

Aggregate structures in the reaction media comprise a huge variety of hydrogen-bonded (and furthermore also otherwise connected) pairs, triples, and larger aggregates. The chosen sampling approach is able to provide a look into the manifold of aggregate compositions in the solution.

The complete analysis of the aggregation in the seven different simulation systems is far too complex for a full analysis, and in the following we focus on observations that relate to the scope of this work - the existence of the aggregates observed by NMR and the weakening or strengthening of the amide-phosphate hydrogen bonds. Here, the simulations give an independent view that also allows to have a look at $\mathrm{H}-$ bonds involving thiophenolate as acceptor, which cannot be directly detected on the acceptor side by NMR (see chapter 4.1). Scheme S58 shows the average number of hydrogen bonds between amides and phosphates for the simulations 1-7. The most remarkable effect is seen when significant amounts of thiophenolate are present (simulation 6 and 7). In accordance with the disaggregation effect observed in the DOSY studies upon addition of thiophenol (see Figure 4, main text), the average number of amide-phosphate hydrogen bonds decreases when 27 thiophenolates are present (15.3 to 22.6 in the absence of thiophenolate compared to 8.8 in its presence for simulation 6 ).

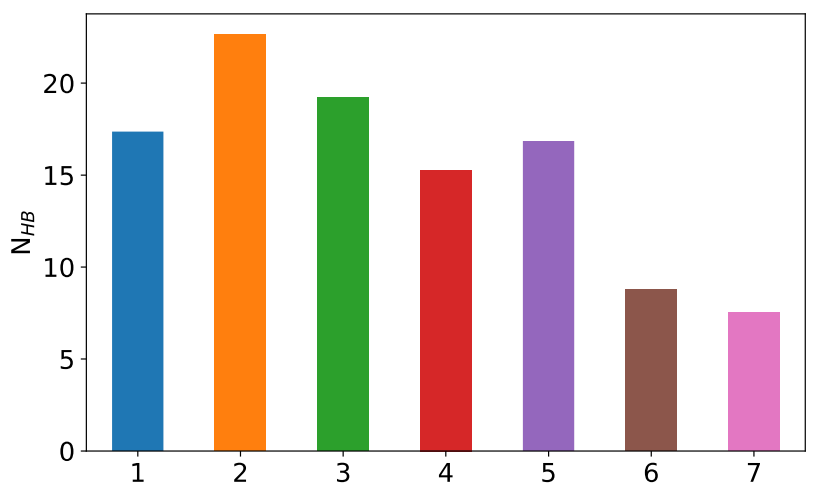

Scheme S58. Average number of amide-phosphate hydrogen bonds $\left(\mathrm{N}_{\mathrm{HB}}\right)$ in simulations 1-7. Note that in simulation 7 there are only 13 phosphate ions present compared to 27 in simulations 1-6.

Scheme S59 shows a selection of PCET relevant aggregates observed for the mixture containing 14 tert-butyl phosphoric acid molecules. In general, phosphate dimer 1 could frequently be found in different frames of the snapshots derived by MD simulation. Scheme S59a shows two randomly picked snapshots of our proposed crucial complex 2 containing the phosphate dimer and one amide attached. Those structures directly confirm our results obtained by NMR in a descriptive way. Moreover, aggregates including the dimer and two amides hydrogen bonded in a row were found and are depicted in Scheme S59b. Furthermore, not only one amide can be attached to the phosphate dimer $\mathbf{1}$. As there are multiple hydrogen bond acceptor positions, an extended network can be created. One possibility, which could be directly found by the MD simulations (Scheme S59c), is the sterically demanding attachment of two amides on both sides of the dimer. We propose such network to be partially responsible for the overall reduction of the $\mathrm{H}$-bond strength identified by ${ }^{1} \mathrm{H}$ and ${ }^{15} \mathrm{~N}$ NMR (see discussion in the main text) as its geometrical nature leads to a lengthening of the $\mathrm{N}-\mathrm{H} \cdots \mathrm{O}-\mathrm{P}$ hydrogen bond.

Furthermore, structures like depicted in Scheme S60 were found for a system including $\mathrm{H}_{3} \mathrm{O}^{+}$. The attached amide points outward of the complex regarding the $\mathrm{N}-\mathrm{H}$ group. As residual water is present in the mixture these structures corroborate the reduction of the $\mathrm{N}-\mathrm{H}$ chemical shift in the ${ }^{1} \mathrm{H}$ and ${ }^{15} \mathrm{~N}$ spectra (see main text). But on the other hand, the amide cannot be activated via PCET and therefore these structural motifs do not account for enhanced reactivity. Moreover, as shown in chapter 4.6.1, the small signal of the postulated $\mathrm{H}_{3} \mathrm{O}^{+}$involved structure is not affected in presence of $\mathrm{PhSH}$. 
a)
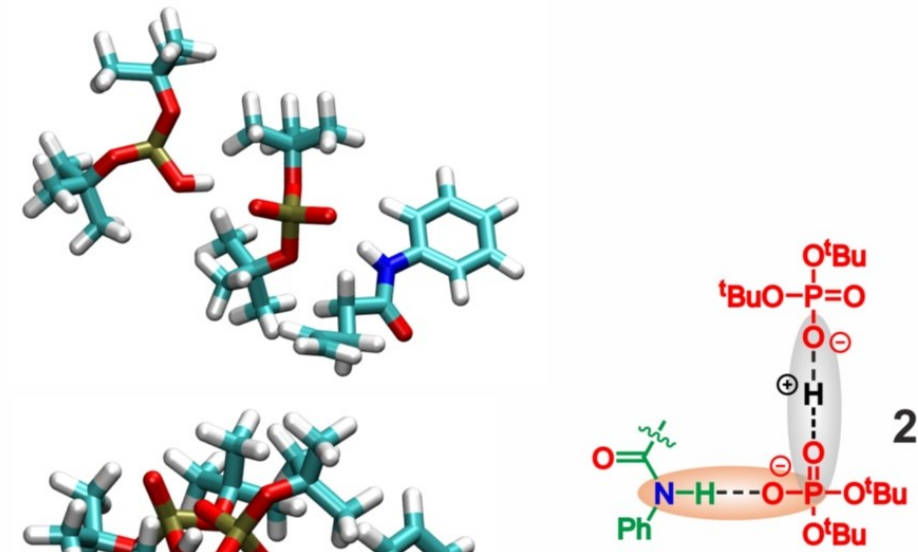

b)

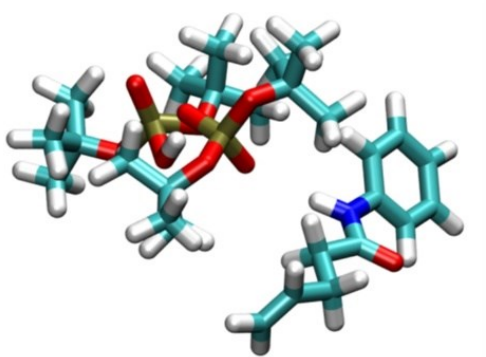

2

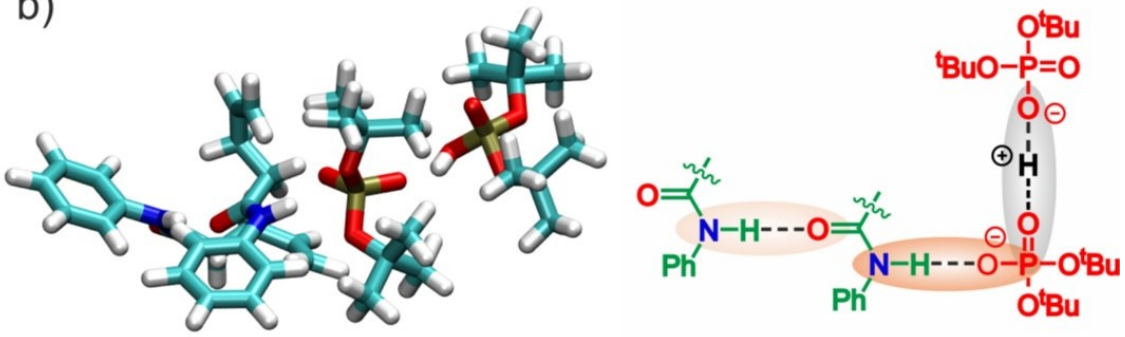

c)
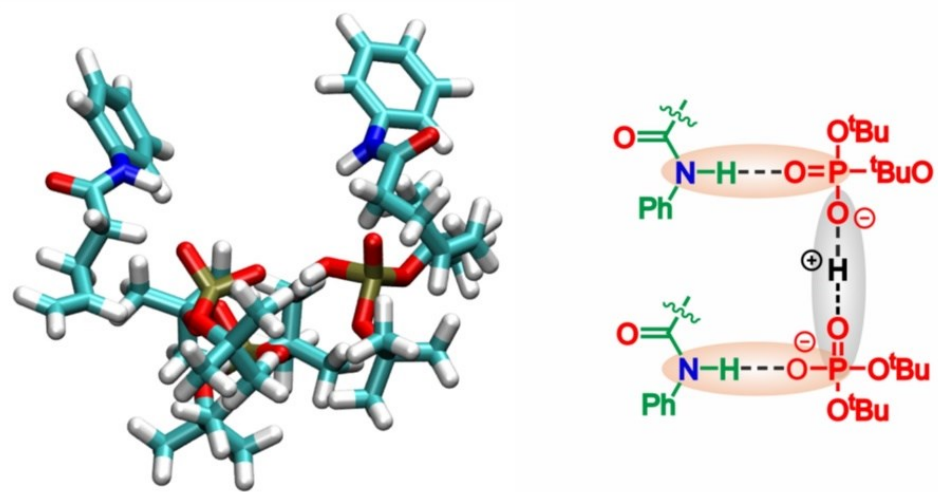

Scheme S59. Selected PCET relevant aggregates including phosphoric acid (PHA), amide (AMD) and phosphate (PHO) observed in the simulations. Shown are results from simulation 7. 

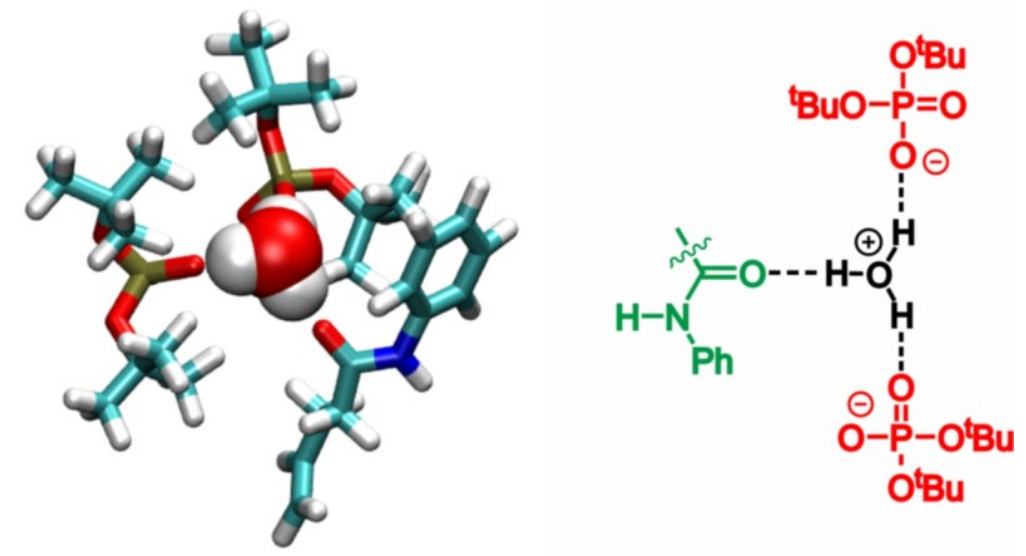

Scheme S60. Aggregate including $\mathrm{H}_{3} \mathrm{O}^{+}(\mathrm{H} 3 \mathrm{O})$, amide (AMD) and phosphate (PHO) observed in simulation 6 .

In order to obtain more information about the role of thiophenolate inside the reaction mixture, the MD derived diffusion coefficients are opposed for the simulations 1-7 in Scheme S61. The observed diffusion constants of thiophenolate are drastically smaller than the ones of thiophenol, which indicates its incorporation into a large complex because of its charged character.

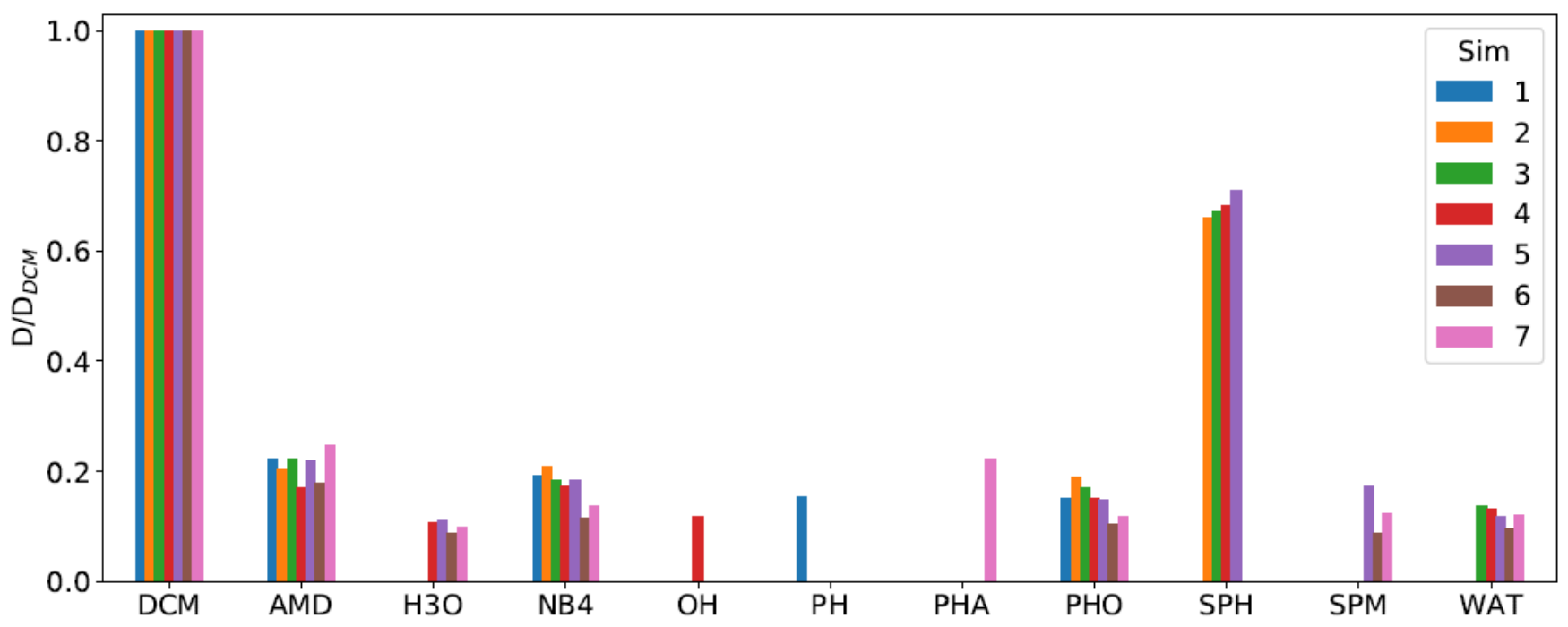

Scheme S61. Diffusion constants normalized by the dichloromethane diffusion constants obtained from the respective simulation.

\section{Emission Spectroscopy}

\section{Method:}

A Fluorolog 3-22 spectrometer (Horiba Jobin Yvon) in combination with a multichannel scaler PCI card from FAST ComTec (time resolution $250 \mathrm{ps}$ ) and a pulsed diode laser (Picobrite PB-375L) with an excitation wavelength of $\lambda_{\mathrm{exc}}=378 \mathrm{~nm}$ (pulse width $<100 \mathrm{ps}$ ) was used to determine the emission decays. Because of the high optical densities of the sample, the experiments were performed in reflectance geometry, i.e. the detected emission direction was parallel to the cuvette window normal, whereas the excitation laser beam hit the same cuvette window under an angle of roughly $45^{\circ}$ with regard to the window normal and thus the propagation direction of the emission detected

A solution of 3,3-dimethyl- $N$-phenylpent-4-enamide (1 equiv.; $100 \mathrm{mM}$ ), diphenyldisulfide (1 equiv.; $100 \mathrm{mM}$ ), tetrabutylammonium ditert-butylphosphate (1 equiv.; $100 \mathrm{mM})$ and $\operatorname{Ir}\left(\mathrm{dF}_{\left(\mathrm{CF}_{3}\right) \text { ppy) }}\right.$ (bpy) $\mathrm{PF}_{6}(0.02$ equiv., $2 \mathrm{mM})$ in $\mathrm{CH}_{2} \mathrm{Cl}_{2}$ was degassed in a cuvette using the freeze-pump-thaw technique. After measuring the emission decay the cuvette was opened to add 0.3 equiv. of phosphoric acid dibutylester for the second decay curve and additional 0.6 equiv. for the third curve (Figure S62). The solution was again degassed for each emission decay curve. 


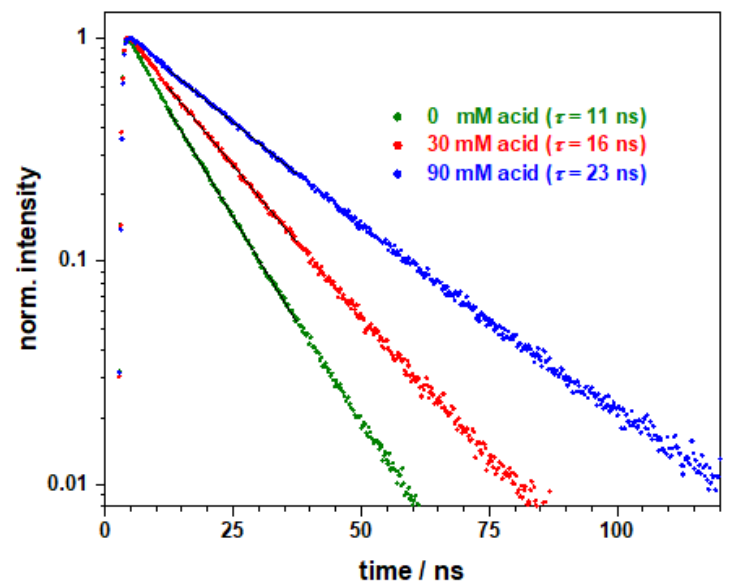

Scheme S62. Emission decay curves and decay times of the iridium photocatalyst $(c=2 \mathrm{mM})$ at a detection wavelength of $500 \mathrm{~nm}$ in a degassed $\mathrm{CH}_{2} \mathrm{Cl}_{2}$ solution of substrate (1 equiv.; $c=100 \mathrm{mM}$ ), base (1 equiv.), diphenyldisulfide (1 equiv.) and the different amounts of acid as given in the figure legend.

\section{References}

(1) Fulmer, G. R.; Miller, A. J. M.; Sherden, N. H.; Gottlieb, H. E.; Nudelman, A.; Stoltz, B. M.; Bercaw, J. E.; Goldberg, K. I. NMR Chemical Shifts of Trace Impurities: Common Laboratory Solvents, Organics, and Gases in Deuterated Solvents Relevant to the Organometallic Chemist. Organometallics 2010, 29 (9), 2176-2179.

(2) Miller, D. C.; Choi, G. J.; Orbe, H. S.; Knowles, R. R. Catalytic Olefin Hydroamidation Enabled by Proton-Coupled Electron Transfer. J. Am. Chem. Soc. 2015, 137 (42), 13492-13495.

(3) Manzoni, M. R.; Zabawa, T. P.; Kasi, D.; Chemler, S. R. Palladium(II)-Catalyzed Intramolecular Aminobromination and Aminochlorination of Olefins. Organometallics 2004, 23 (23), 5618-5621.

(4) Wang, G.; Zou, Y.; Li, Z.; Wang, Q.; Goeke, A. Unexpected Cycloisomerizations of Nonclassical Carbocation. J. Org. Chem. 2011, 76 (I), 58255831.

(5) Feldmeier, C.; Bartling, H.; Riedle, E.; Gschwind, R. M. LED Based NMR Illumination Device for Mechanistic Studies on Photochemical Reactions - Versatile and Simple, yet Surprisingly Powerful. J. Magn. Reson. 2013, 232, 39-44.

(6) Harris, R. K.; Becker, E. D.; Cabral de Menezes, S. M.; Goodfellow, R.; Granger, P. NMR Nomenclature. Nuclear Spin Properties and Conventions for Chemical Shifts(IUPAC Recommendations 2001). Pure Appl. Chem. 2001, 73 (11), 1795-1818.

(7) Sorgenfrei, N.; Hioe, J.; Greindl, J.; Rothermel, K.; Morana, F.; Lokesh, N.; Gschwind, R. M. NMR Spectroscopic Characterization of Charge Assisted Strong Hydrogen Bonds in Brønsted Acid Catalysis. J. Am. Chem. Soc. 2016, 138 (50), 16345-16354.

(8) Jansen, D.; Gramüller, J.; Zhu, H.; Niemeyer, F.; Schaller, T.; Letzel, M. C.; Grimme, S.; Gschwind, R. M.; Niemeyer, J. What Is the Role of Acid-Acid Interactions in Asymmetric Phosphoric Acid Organocatalysis? A Detailed Mechanistic Study Using Interlocked and Non-Interlocked Catalysts. Chemical Science 2020, 11, 4381-4390.

(9) Joshi, A. V.; Bhusare, S.; Baidossi, M.; Qafisheh, N.; Sasson, Y. Oxidative Coupling of Thiols to Disulfides Using a Solid Anhydrous Potassium Phosphate Catalyst. Tetrahedron Lett. 2005, 46 (20), 3583-3585.

(10) Qiu, X.; Yang, X.; Zhang, Y.; Song, S.; Jiao, N. Efficient and Practical Synthesis of Unsymmetrical Disulfides via Base-Catalyzed Aerobic Oxidative Dehydrogenative Coupling of Thiols. Org. Chem. Front. 2019, 1-5.

(11) Joshi, A. V.; Bhusare, S.; Baidossi, M.; Qafisheh, N.; Sasson, Y. Oxidative Coupling of Thiols to Disulfides Using a Solid Anhydrous Potassium Phosphate Catalyst. Tetrahedron Lett. 2005, 46 (20), 3583-3585.

(12) Hunter, C. A. Quantifying Intermolecular Interactions: Guidelines for the Molecular Recognition Toolbox. Angew. Chem. Int. Ed. 2004, 43 (40), $5310-5324$.

(13) Jerschow, A.; Müller, N. Suppressioin of Convection Artifacts in Stimulated-Echo Diffusion Experiments. Double-Stimulated-Echo Experiments. J. Magn. Reson. 1997, 375 (125), 372-375.

(14) Cabrita, E. J.; Berger, S. DOSY Studies of Hydrogen Bond Association: Tetramethylsilane as a Reference Compound for Diffusion Studies. Magn. Reson. Chem. 2002, 39, S142-S148. 
(15) Claridge, T. D. W. High-Resolution NMR Techniques in Organic Chemistry. In High-Resolution NMR Techniques in Organic Chemistry; 2009; pp 303-334.

(16) Johnson Jr., C. S. Diffusion Ordered Nuclear Magnetic Resonance Spectroscopy: Principles and Applications. Prog. Nucl. Magn. Reson. Spectrosc. 1999, 34, 203-256.

(17) Price, W. S. Pulsed-Field Gradient Nuclear Magnetic Resonance as a Tool for Studying Translational Diffusion: Part II. Experimental Aspects. Concepts Magn. Reson. 1998, 10 (4), 197-237.

(18) Stejskal, E. O.; Tanner, J. E. Spin Diffusion Measurements: Spin Echoes in the Presence of a Time-Dependent Field Gradient. J. Chem. Phys. 1965, 42 (1), 288-292.

(19) Macchioni, A.; Ciancaleoni, G.; Zuccaccia, C.; Zuccaccia, D. Determining Accurate Molecular Sizes in Solution through NMR Diffusion Spectroscopy. Chem. Soc. Rev. 2008, 37 (3), 479-489.

(20) Zuccaccia, D.; Macchioni, A. An Accurate Methodology to Identify the Level of Aggregation in Solution by PGSE NMR Measurements: The Case of Half-Sandwich Diamino Ruthenium(II) Salts. Organometallics 2005, 24 (14), 3476-3486.

(21) Chen, H. C.; Chen, S. H. Diffusion of Crown Ethers in Alcohols. J. Phys. Chem. 1984, 88 (21), 5118-5121.

(22) Ben-Amotz, D.; Willis, K. G. Molecular Hard-Sphere Volume Increments. J. Phys. Chem. 1993, 97 (29), 7736-7742.

(23) Bondi, A. Van Der Waals Volumes and Radii. J. Phys. Chem. 1964, 68 (3), 441-451.

(24) Butts, C. P.; Jones, C. R.; Towers, E. C.; Flynn, J. L.; Appleby, L.; Barron, N. J. Interproton Distance Determinations by NOE - Surprising Accuracy and Precision in a Rigid Organic Molecule. Org. Biomol. Chem. 2011, 9 (1), 177-184.

(25) Meyer, E. A.; Castellano, R. K.; Diederich, F. Interactions with Aromatic Rings in Chemical and Biological Recognition. Angew. Chemie Int. Ed. 2003, 42 (11), 1210-1250.

(26) Steiner, T. The Hydrogen Bond in the Solid State. Angew. Chem. Int. Ed. 2002, 41 (1), 48-76.

(27) Abraham, M. J.; Murtola, T.; Schulz, R.; Páll, S.; Smith, J. C.; Hess, B.; Lindah, E. Gromacs: High Performance Molecular Simulations through Multi-Level Parallelism from Laptops to Supercomputers. SoftwareX 2015, 1-2, 19-25.

(28) Sousa da Silva, A. W.; Vranken, W. F. ACPYPE - AnteChamber PYthon Parser InterfacE. BMC Res. Notes 2012, 5, 1-8.

(29) Wang, J.; Wolf, R. M.; Caldwell, J. W.; Kollman, P. A.; Case, D. A. Development and Testing of a General Amber Force Field. J. Comput. Chem. 2004, 25 (9), 1157-1174.

(30) Breneman, C. M.; Wiberg, K. B. Determining Atom - centered Monopoles from Molecular Electrostatic Potentials. The Need for High Sampling Density in Formamide Conformational Analysis. J. Comput. Chem. 1990, 11 (3), 361-373.

(31) Neese, F. The ORCA Program System. WIREs Comput. Mol. Sci. 2012, 2 (1), 73-78.

(32) Bussi, G.; Donadio, D.; Parrinello, M. Canonical Sampling through Velocity Rescaling. J. Chem. Phys. 2007, 126 (1), 1-7.

(33) Parrinello, M.; Rahman, A. Polymorphic Transitions in Single Crystals: A New Molecular Dynamics Method. J. Appl. Phys. 1981, 52 (12), $7182-$ 7190.

(34) Prielmeier, F. X.; Ludemann, H. D. Self Diffusion in Compressed Liquid Chloromethane, Dichloromethane and Trichloromethane. Mol. Phys. 1986, 58 (3), 593-604.

(35) Luzar, A.; Chandler, D. Effect of Environment on Hydrogen Bond Dynamics in Liquid Water. Phys. Rev. Lett. 1996, 76 (6), 928-931. 